\title{
The Microstructure of Polar Ice. Part II: State of the $\operatorname{Art}^{\text {th }}$
}

\author{
Sérgio H. Faria ${ }^{\mathrm{a}, \mathrm{b}, *}$, Ilka Weikusat ${ }^{\mathrm{c}}$, Nobuhiko Azuma ${ }^{\mathrm{d}}$ \\ ${ }^{a}$ Basque Centre for Climate Change (BC3), Alameda Urquijo 4-4, 48008 Bilbao, Spain \\ ${ }^{b}$ IKERBASQUE, Basque Foundation for Science, Alameda Urquijo 36-5, 48011 Bilbao, Spain \\ ${ }^{c}$ Alfred Wegener Institute for Polar and Marine Research, Columbusstrasse, 27568 Bremerhaven, \\ Germany \\ ${ }^{d}$ Department of Mechanical Engineering, Nagaoka University of Technology, \\ 1603-1 Kamitomioka, Nagaoka 940-2188, Niigata, Japan
}

\begin{abstract}
Besides the obvious relevance of glaciers and ice sheets for climate-related issues, another important feature of natural ice is its ability to creep on geological time scales and low deviatoric stresses at temperatures very close to its melting point, without losing its polycrystalline character. This fact, together with its strong mechanical anisotropy and other notable properties, makes natural ice an interesting model material for studying the high-temperature creep and recrystallization of rocks in Earth's interior. After having reviewed the major contributions of deep ice coring to the research on natural ice microstructures in Part I of this work (Faria et al., this issue), here in Part II we present an up-to-date view of the modern understanding of natural ice microstructures and the deformation processes that may produce them. In particular, we analyse a large body of evidence that reveals fundamental flaws in the widely accepted tripartite paradigm of polar ice
\end{abstract}

\footnotetext{
${ }^{2}$ Dedicated to Sepp Kipfstuhl on occasion of his 60th birthday.

*Corresponding author. Tel.: +34-94-4014690.

Email addresses: sergio.faria@bc3research.org (Sérgio H. Faria), ilka.weikusat@awi.de (Ilka Weikusat), azuma@mech.nagaokaut.ac.jp (Nobuhiko Azuma) 
microstructure (also known as the "three-stage model," cf. Part I). These results prove that grain growth in ice sheets is dynamic, in the sense that it occurs during deformation and is seriously affected by the stored strain energy, as well as by air inclusions and other impurities. The strong plastic anisotropy of the ice lattice gives rise to high internal stresses and concentrated strain heterogeneities in the polycrystal, which demand large amounts of strain accommodation. From the microstructural analyses of ice cores, we conclude that the formation of many and diverse subgrain boundaries and the splitting of grains by rotation recrystallization are the most fundamental mechanisms of dynamic recovery and strain accommodation in polar ice. Additionally, in fine-grained, high-impurity ice layers (e.g. cloudy bands), strain may sometimes be accommodated by diffusional flow (at low temperatures and stresses) or microscopic grain boundary sliding via microshear (in anisotropic ice sheared at high temperatures). Grain boundaries bulged by migration recrystallization and subgrain boundaries are endemic and very frequent at almost all depths in ice sheets. Evidence of the nucleation of new grains is also observed at various depths, provided that the local concentration of strain energy is high enough (which is not seldom the case). As a substitute for the tripartite paradigm, we propose a novel dynamic recrystallization diagram in the three-dimensional state space of strain rate, temperature, and mean grain size, which summarizes the various competing recrystallization processes that contribute to the evolution of the polar ice microstructure.

Keywords: ice, glacier, ice sheet, mechanics, creep, recrystallization, grain growth, microstructure, fabric, texture 


\section{Introduction}

An essential feature of Earth's dynamics is the hot deformation of large rock masses in a slow and continuous flow regime called creep. The study of creeping rocks is complicated by various factors; among them diversity and inaccessibility. The former means that rocks are seldom monomineral; rather, they are usually made of complex and variable compositions of minerals with distinct properties. The latter expresses the fact that field observations of creeping rocks are often very difficult or even impossible to perform, because most high-temperature deformation processes occur in Earth's interior.

For these reasons (not to mention other well-known reasons stemming from climatology; Lemke et al., 2007), the creep of ice turns out to be very interesting for geologists and geoscientists (Hudleston, 1977; Wilson, 1979, 1982; Burg et al., 1986; Kirby et al., 1991; Zhang and Wilson, 1997; for a deeper discussion see Wilson et al., this issue). The abundance, purity, and low melting point of natural ice make the field study of creeping glaciers and ice sheets a feasible task. Polar ice sheets over Greenland and Antarctica are particularly appealing in these respects, because of their immense mass $\left(2.7\right.$ and $22.6 \times 10^{18} \mathrm{~kg}$, respectively; Lemke et al., 2007) and purity (polar ice typically has an impurity content in the ppb range; Legrand and Mayewski, 1997), as well as their relatively simple and steady flow, when compared to smaller ice bodies like glaciers and ice caps (Paterson, 1994).

Evidently, the investigation of creep and recrystallization of polar ice sheets has also its shortcomings, mainly related to the complex logistics and drilling technology necessary for retrieving old ice samples from several kilometres of depth. A brief review of the difficulties and advances in deep ice core drilling in Antarc- 
tica and Greenland has been presented in the first part of this work (Faria et al., this issue) - from now on called Part I - together with the major contributions of deep ice coring to the research on natural ice microstructures. Through that historical synopsis we could appreciate how the current paradigm of natural ice microstructures has emerged, and also how it started being challenged in recent times.

Here in Part II we discuss in detail these recent challenges and show how they may reveal to us a new perspective of the mechanics and microstructure of natural ice. To achieve this aim, we carefully reconsider several aspects of our current understanding about natural ice microstructures and the deformation processes that may have produced them, including strain-induced anisotropy, grain growth, and dynamic recrystallization, among others. The whole review ends with a new paradigm for the microstructure evolution of natural ice. For convenience, the key concepts invoked in this work are summarized in a glossary in Appendix A.

As it will become evident in the next pages, in spite of many insightful studies of natural ice microstructures and deformation mechanisms, our knowledge about this subject is still imperfect and incomplete. On the other hand, we do have enough information to propose novel plausible models, which together with modern technologies are helping to make this field of research more promising and exciting than ever.

\section{Crystalline structure and dislocations}

Under natural conditions on Earth's surface, ice occurs in the ordinary hexagonal form of ice $I h$. This should not be confused with its closely related cubic variant, ice $I c$, which presents a similar tetrahedral coordination of oxygen atoms, but 
is metastable at all temperatures (Bartels-Rausch et al., 2012). Ordinary ice Ih has a rather open lattice, with an atomic packing factor of less than $34 \%$, which accounts not only for its abnormally low density compared to liquid water, but also for the pressure-induced reduction of its melting point at high temperatures (Schulson and Duval, 2009).

Oxygen ions build the essence of the ice lattice (from now on the term "ice" refers to ordinary hexagonal ice Ih, except when explicitly mentioned otherwise). They are arranged in a structure which resembles that of wurtzite or high-tridymite (Hobbs, 1974; Evans, 1976; Poirier, 1985), viz. layers of puckered hexagonal rings piled in an alternate sequence of mirror images normal to the $c$-axis (Fig. C.1). Hydrogen nuclei (protons) remain statistically distributed in the oxygen lattice, building covalent and hydrogen bonds along the lines joining pairs of oxygens (Pauling, 1935). This proton disorder is however not completely arbitrary: it must conform with the Bernal-Fowler rules (also called "ice rules"), which require that two protons should be close to any oxygen, with only one proton per bond (Bernal and Fowler, 1933). Hence, each oxygen is involved in two covalent and two hydrogen bonds.

The violation of the ice rules, either by an excess or a deficiency or protons, gives rise to particular point defects in the crystalline structure, known as ionization and Bjerrum defects. These point defects, together with more conventional molecular defects (vacancies and interstitials) play a fundamental role in the mechanics of ice, as they influence the motion of the main agents of deformation in ice: dislocations (Glen, 1968; Goodman et al., 1981; Okada et al., 1999; Petrenko and Whitworth, 1999; Louchet, 2004). 


\subsection{Slip systems and plastic anisotropy}

According to the fundamentals of dislocation theory (Hirth and Lothe, 1992; Weertman and Weertman, 1992), possible slip systems in ice can in principle be found on the basal, prismatic, and pyramidal planes, as described in Table D.1 and Fig. C.2.

Experience shows, however, that the plasticity of monocrystalline ice is strongly anisotropic (Duval et al., 1983): single crystals of ice deform very readily when the shear stress acts on the basal plane, as epitomized more than a century ago by McConnel's (1890) "deck of cards" metaphor. This phenomenon was later beautifully illustrated in Nakaya's (1958) experiments, through the use of shadow photography for revealing slip bands (Appendix A) in deformed monocrystalline ice bars. Not long after, Bryant and Mason (1960) found grouped etch pits and channels along slip bands in formvar replicas of deformed ice monocrystals, corroborating the hypothesis that slip bands consist of a high density of dislocations. In polar ice, the optical observation of slip bands turns out to be much more difficult, because of the very low strain rates characteristic of ice sheet flow. Nevertheless, advanced digital methods of optical microscopy could show (Fig. C.3) that slip bands are also a common feature of polar ice (Wang et al., 2003; Faria and Kipfstuhl, 2004; Kipfstuhl et al., 2006).

The modern explanation for the strong plastic anisotropy of hexagonal ice is that the energy of a stacking fault on the basal plane is so low that perfect basal dislocations may dissociate into Shockley partial dislocations separated by a stacking fault (Fukuda et al., 1987; Hondoh, 2000). Thus, recalling that the self-energy of a dislocation is proportional to the square of its Burgers vector, it follows that a perfect basal dislocation in ice with Burgers vector $\boldsymbol{b}$ is expected 
to stabilize into a ribbon-like structure (Fig. C.4) consisting of a stacking fault delimited by two partial dislocations with Burgers vectors $\boldsymbol{b}_{1}$ and $\boldsymbol{b}_{2}=\boldsymbol{b}-\boldsymbol{b}_{1}$, provided that

$$
b^{2}>b_{1}^{2}+b_{2}^{2}, \quad \text { with } \quad b_{i}^{2}:=\boldsymbol{b}_{i} \cdot \boldsymbol{b}_{i} \quad(i=1,2, \varnothing),
$$

and the energy of the stacking fault created by this dissociation is sufficiently low to preserve the inequality (1).

The reason for the low stacking fault energy of ordinary ice is the small energy difference between hexagonal ice Ih and cubic ice Ic (Bartels-Rausch et al., 2012). This leads to the conclusion that the stacking fault between the two partial dislocations should possess cubic structure (Hondoh, 2000). Actually, the width of the resulting stacking fault is expected to be rather large, ranging from one to two orders of magnitude larger than the lattice spacing (Fukuda et al., 1987). As a result, cross-slip and climb of such widely extended dislocations should be strongly suppressed, seeing that the stress required to constrict extended dislocations, allowing them to move on non-basal planes, is considerably large (Gilra, 1974; the need of full constriction for cross-slip has been objected by Duesbery, 1998, provided that the driving stress on the cross-slip plane is large enough). Another consequence of the dissociation of basal dislocations is that a dislocation with an initially arbitrary shape soon evolves into a combination of long basal and short non-basal segments (Fig. C.4a), owing to the strong tendency of basal segments to elongate (Hondoh, 2000). In fact, theory and experiments suggest that non-basal segments should be one to two orders of magnitude shorter than basal segments (Fukuda et al., 1987; Ahmad and Whitworth, 1988; Hondoh, 2000). Therefore, non-basal dislocation segments are generally too short to significantly contribute to macroscopic deformation (Petrenko and Whitworth, 1999). 
To sum up, the dissociation of basal dislocations into partials and its many consequences are essential for explaining the extreme plastic anisotropy of ice.

\subsection{Heterogeneous strain and non-basal slip}

Non-basal slip in high-quality ice single crystals has often been observed by Xray topography (Fukuda et al., 1987; Ahmad and Whitworth, 1988; Higashi et al., 1988; Hondoh et al., 1990; Shearwood and Whitworth, 1991). These studies revealed an interesting feature of ice plasticity, namely the rapid motion of short edge dislocation segments on non-basal planes. While such fast-moving short segments are not expected to significantly contribute to macroscopic deformation, they provide mechanisms for the multiplication of basal dislocations (e.g. as moving Frank-Read sources; Petrenko and Whitworth, 1999) and for accommodation of heterogeneous strain.

Although the study of individual dislocations in carefully prepared ice single crystals, deformed under precisely controlled conditions, yields invaluable information about the fundamental properties of dislocations in ice, it is evident that the deformation processes naturally occurring in polycrystalline ice are much more complex. Hondoh and Higashi (1983) and Liu et al. (1993, 1995) used X-ray topography to study the interactions between dislocations and grain boundaries in ice bicrystals and polycrystalline ice, respectively. They could demonstrate that the regions surrounding grain boundaries (viz. the "mantle" of the grain, after Gifkins, 1976) generally deform before the grain interiors (viz. the "core" of the grain). Dislocations are emitted from stress concentrations at grain boundaries, caused by strain misfits and/or grain boundary sliding, and this process completely overwhelms any lattice dislocation generation mechanism. Depending on the relative configuration of grain boundaries and applied stress, not only basal disloca- 
tions but also fast non-basal edge segments can be emitted by grain boundaries, trailing screw segments behind them.

These findings are in close agreement with the results from microscopic observations of natural ice microstructures in fresh ice core samples (Wang et al., 2003; Faria and Kipfstuhl, 2004, 2005; Kipfstuhl et al., 2006, 2009; Weikusat et al., 2009a,b), where abundant evidences of heterogeneous strain and internal stresses can be found in form of multiple subgrain boundaries and dislocation walls, bent slip bands, pinned and bulged grain boundaries (cf. Sect. 4). In particular, the large amount of subgrain boundaries and dislocation walls in regions surrounding grain boundaries clearly indicates the tendency of polar ice grains to develop intracrystalline strain gradients and high internal stresses in their "mantle" region, while preserving their "cores." Additionally, it is not uncommon to observe the manifestation of internal stress concentrations through bulged or cuspidate grain boundaries with radiating subgrain boundaries and dislocation walls (examples can be found in almost all micrographs shown here, e.g. Fig. C.5; see also Kipfstuhl et al., 2006; Faria et al., 2009, 2010; Weikusat et al., 2009b). In fact, according to recent statistical studies on subgrain boundaries in polar ice (Weikusat et al., 2010, 2011; see Sect. 4.1), internal stresses are high enough to produce a considerable amount of non-basal dislocations, as revealed by the significant fraction of tilt boundaries on basal planes, which are formed by geometrically necessary non-basal edge dislocations.

Recalling the fact that the strong plastic anisotropy of ice has been known for more than a century (McConnel and Kidd, 1888; McConnel, 1890), the findings described above should seem unsurprising: large internal stresses and heterogeneous strains that vary in space with a wavelength comparable to the grain size are 
actually expected in a polycrstalline material made of such remarkably anisotropic grains (Remark 1).

Remark 1. The homogeneous deformation by dislocation glide of an incompressible polycrystal into an arbitrary shape requires the activity of at least five independent slip systems, in order to avoid geometric incompatibilities between the grains (Taylor, 1938). If the condition of homogeneous strain is waived, then only four independent systems are necessary, provided that the strain gradients resulting from geometric incompatibilities are balanced by internal stresses (Hutchinson, 1976). In the case of ice, the basal plane provides only two independent slip systems: further two systems must be active by slip or climb on prismatic and/or pyramidal planes. Notwithstanding, non-basal deformation of ice requires stresses at least 60 times larger than those for basal slip at the same strain rate, so that large internal stresses are expected in ice undergoing dislocation creep (Duval et al., 1983; Wilson and Zhang, 1996).

Despite their fundamental importance for the mechanics of glaciers and ice sheets, internal stresses and heterogeneous strain phenomena have been largely ignored (or treated as a secondary issue) in models of the microstructure evolution of natural ice. For instance, recrystallization models based on an average dislocation density (e.g. De la Chapelle et al., 1998; Montagnat and Duval, 2000) are often invoked in support of the tripartite paradigm of polar ice microstructure (also called "three-stage model"; see Sect. 3.3 of Part I). From the results discussed here, and extended in Sects. 4 and 5, it turns out that such models are not appropriate for describing the microstructure evolution of polar ice, because they seriously underestimate recrystallization processes, which are very sensitive 
to internal stress concentrations and localized values of dislocation density close to grain boundaries.

Recently, the small-scale modelling of the effects of internal stresses and heterogeneous strains on the evolution of ice microstructures has become a very active research topic, as reviewed in this Issue (Montagnat et al., 2013). On the other hand, on the much larger scale of ice sheet dynamics, this problem becomes particularly difficult, because a multiscale continuum model is needed. To our knowledge, there is only one theory currently capable of dealing simultaneously with large scale ice sheet flow and dynamic recrystallization, taking into account the effects of strain heterogeneities and internal stresses (Faria, 2006a,b; Faria et al., 2006b). It models the polycrystal as a heterogeneous structured medium within the framework of the general theory of Mixtures with Continuous Diversity (MCD; Faria, 2001; Faria et al., 2003). As pointed out by Placidi et al. (2004) and Faria and Kipfstuhl (2004), internal stresses are modeled by the orientational couple-stress tensor $\varpi^{*}$ (sometimes also called "polygonization tensor"), which describes the action of localized bending stresses acting on the ice lattice. Heterogeneous strain is modelled by a set of $N$ scalar-, vector-, or tensor-valued dislocation parameters $\boldsymbol{B}_{\varkappa}^{*}$ (with $\varkappa=1,2, \ldots, N$ ), which characterize the spatial arrangement of dislocations in the polycrystal (Faria et al., 2006b).

At this point it should be clear that, in order to improve large-scale glacier and ice sheet models, we have first to find out realistic, explicit expressions for abstract concepts like the "orientational couple-stress tensor" and the set of "dislocation arrangement parameters," which require information from detailed investigations of the type described in this section, as well as results from models on the small polycrystalline scale, as those reviewed elsewhere in this Issue (Montagnat et al., 
2013).

\section{Creep of glacier ice}

Section 2 of Part I warned about the potential injustice of naming milestones for defining decisive moments in scientific research. In the case of ice mechanics, however, the period 1947-1952 is widely acknowledged for establishing a paradigm shift that irreversibly changed the glaciologists' attitude to the mechanics of glaciers and ice sheets (Sharp, 1954; Waddington, 2010). Its milestone is Glen's (1952) article on mechanical tests showing that the secondary creep of ice could be described by a power law (of the type proposed by Norton, 1929, in metallurgy), therefore confirming a conjecture about the non-Newtonian creep behavior of ice (Perutz, 1949, 1950; cf. Sect. 2.1 of Part I). Glen's (1952) preliminary study was soon complemented by Glen and Perutz (1954), Steinemann (1954), Glen (1955) and others, including the corroboration of the suitability of such a power law for modeling glacier flow (Nye, 1953, 1957).

\subsection{The creep curve}

Isotropic polycrystalline ice (viz. homogeneous polycrystalline ice with no lattice preferred orientation; cf. Appendix A) exhibits a creep curve typical of many polycrystalline materials undergoing high-temperature creep (Fig. C.6). It is characterized by a preliminary "instantaneous" Hookean elastic strain (cf. Remark 2), followed by three creep stages. Natural ice in glaciers and ice sheets is expected to undergo all these creep stages in situ, even when subjected to polar conditions (viz. stresses lower than $0.1 \mathrm{MPa}$, temperatures down to $-50^{\circ} \mathrm{C}$, strain rates about $10^{-12} \mathrm{~s}^{-1}$, and total shear strains exceeding $\left.1000 \%\right)$. 
Remark 2. Budd and Jacka (1989) report that the Hookean elastic strain of isotropic polycrystalline ice reaches $0.024 \%$ at $0.2 \mathrm{MPa}$ octahedral stress, and has little dependence on temperature. Indeed, according to Gammon et al. (1983), the variation in the elastic properties of isotropic polycrystalline ice in the temperature range between $-50^{\circ} \mathrm{C}$ and close to the melting point should lie below $10 \%$, although they may vary considerably with the impurity content of ice.

The achievement of all three creep stages in laboratory tests simulating polar conditions is clearly impossible, since this would require thousands of years of uninterrupted straining under carefully controlled conditions. Therefore, the creep behavior of natural ice is usually extrapolated from mechanical tests performed at higher temperatures or stresses (e.g. Steinemann, 1954; Glen, 1955; Lile, 1978; Jacka, 1984; Jacka and Li, 2000), and then compared with field measurements of glacier flow or the deformation of glacial tunnels and deep boreholes (e.g. Nye, 1953; Paterson, 1977; Fischer and Koerner, 1986; Talalay and Hooke, 2007).

During the first creep stage, usually called transient or primary creep, the strain rate decreases rapidly. This deceleration is due to work hardening mainly produced by the load transfer from easy-glide to hard-glide systems and the increasing strain incompatibilities between the grains, which build up internal stresses and localized heterogeneous strains (Wilson, 1986; Petrenko and Whitworth, 1999; Schulson and Duval, 2009; cf. Sect. 2.2), both clearly identified by the formation of the first dislocation walls and subgrain boundaries (Hamann et al., 2007; Sect. 4.1). Primary creep in ice extends to about $1 \%$ of strain, irrespective of temperature or stress (Budd and Jacka, 1989), and a considerable fraction of it consists of a recoverable "delayed-elastic" strain (sometimes also called "anelastic" strain), implying that part of the deformation is recovered after the load is 
removed, in a relaxation process that can take several hours (Duval, 1978). Budd and Jacka (1989) report primary recoverable strains of $0.15 \%$ and $0.30 \%$ for isotropic polycrystalline ice at $-10^{\circ} \mathrm{C}$ compressed at $0.2 \mathrm{MPa}$ and $1.0 \mathrm{MPa}$ octahedral stress, respectively. It is believed that the delayed elasticity of ice is mainly caused by the relaxation of internal stresses by dislocation back-gliding (Glen, 1975; Cole, 2004; Schulson and Duval, 2009).

The primary creep of ice ends with the inception of secondary creep. In contrast to other materials, a steady-state regime has not been observed in the secondary creep of ice at any temperature down to $-50^{\circ} \mathrm{C}$, or at stresses as low as 22 kPa octahedral (Budd and Jacka, 1989; Remark 3).

Remark 3. We emphasized above the conjunction "or" in order to make clear that the minimum strain rate could not be achieved so far in any single test combining the lowest temperature and stress just mentioned. Jacka and Li (2000) report minimum strain rates attained in some extreme compression tests, including one ran during more than five years at $-45^{\circ} \mathrm{C}$ and $550 \mathrm{kPa}$ octahedral stress, as well as another one executed at $-19^{\circ} \mathrm{C}$ and $100 \mathrm{kPa}$ octahedral. Russell-Head and Budd (1979) describe a sequence of strain rate minima attained in a shear test performed at $22 \mathrm{kPa}$ octahedral stress and an initial temperature of $-2^{\circ} \mathrm{C}$, with subsequent temperature drops to $-5^{\circ} \mathrm{C}$ and $-10^{\circ} \mathrm{C}$ after each strain rate minimum.

Instead of reaching a steady state, the secondary creep of ice seems to be essentially a transition zone between $0.5 \%$ and $2 \%$ strain that connects the decelerating primary creep to the accelerating tertiary creep. Its main characteristic is the inflection point in the creep curve, which occurs at about $1 \%$ strain, irrespective of temperature or stress, and defines the minimum strain rate for the whole creep 
process. As demonstrated by Jacka (1984), this minimum is best visualized in a $\log -\log$ plot of strain rate versus strain (Fig. C.6), which has since then become a standard in the ice mechanics literature.

In spite of not being identified as a true steady state, the secondary creep of ice has a fundamental physical meaning: its minimum strain rate defines the point where hardening caused by evolving internal stresses is counterbalanced by the softening produced by dynamic recovery and recrystallization, e.g. through the re-arrangement of geometrically necessary dislocations into low-energy structures (subgrain boundaries, dislocation walls, etc.) and the obliteration of localized internal stresses by strain-induced grain boundary migration (SIBM), among other processes (Remark 4 and Sects. 4 and 5).

Remark 4. The above explanation of the physical meaning of the secondary creep of ice holds for the ductile regime only, which is the focus of this review. At high stresses and/or low temperatures, ice becomes brittle and the characteristic softening of secondary and tertiary creep regimes (if they can be achieved prior to material failure) is mainly caused by crack formation, which eventually leads to the fracture of the ice specimen (Petrenko and Whitworth, 1999; Schulson and Duval, 2009).

The creep response of ice following the minimum strain rate is somewhat more complicate. In most mechanical tests, performed at temperatures above $-15^{\circ} \mathrm{C}$ and stresses higher than $0.3 \mathrm{MPa}$ (corresponding to minimum strain rates about $10^{-8} \mathrm{~s}^{-1}$ ), the secondary creep gives way to accelerating tertiary creep after $1-$ $2 \%$ of strain, which eventually reaches a stable, steady-state regime after ca. $10 \%$ strain (Budd and Jacka, 1989). The accelerating part of tertiary creep is accompanied by the development of lattice preferred orientations (LPOs) and an increase 
in the mean grain size. The latter eventually reaches a tertiary steady-state size, which can be roughly predicted by the relation (Jacka and Li, 1994)

$$
D_{\mathrm{ss}}^{2}=\frac{\varphi}{\sigma^{3}},
$$

where $D_{\mathrm{ss}}$ is the linear dimension of the mean grain size in the tertiary steadystate stage, $\sigma$ is the applied stress, and $\varphi$ is a dimensional factor with negligible temperature dependence. It should be noticed that the rapid LPO formation in such "fast" experiments is not caused by slip-driven lattice rotation, since strains of only a few percent are not sufficient to produce noticeable LPOs by lattice rotation alone (Azuma and Higashi, 1985; Jacka and Li, 2000). Rather, this early LPO formation must be related to the nucleation of new grains (SIBM-N; Appendix A). Steinemann (1958) was the first to suggest that, for a given temperature and stress regime, the ratio between the tertiary maximum and the secondary minimum strain rates (nowadays called strain-rate enhancement) could be expressed as a function of the minimum strain rate, that is

$$
\frac{\dot{\varepsilon}_{\text {max }}}{\dot{\varepsilon}_{\text {min }}}=f\left(\dot{\varepsilon}_{\text {min }}\right), \quad(T=\text { const. })
$$

where $\dot{\varepsilon}_{\max }$ and $\dot{\varepsilon}_{\text {min }}$ denote the tertiary maximum and the secondary minimum strain rates, respectively, while $f$ is an increasing function of the minimum strain rate. Indeed, at lower temperatures and stresses (corresponding to minimum strain rates of about $10^{-9} \mathrm{~s}^{-1}$ ), the strain-rate enhancement abates and the LPO development slows down. As remarked by Steinemann (1958), this reflects the fact that nucleation recrystallization (SIBM-N) is no longer effective, being gradually replaced by migration recrystallization (SIBM-O) and rotation recrystallization (RRX; cf. Sects. 4, 5, and Appendix A). 
At even lower temperatures and stresses (e.g. $0.1 \mathrm{MPa}$ at $-20^{\circ} \mathrm{C}$, or any equivalent stress-temperature combination resulting in minimum strain rates about $10^{-10} \mathrm{~s}^{-1}$ ), observations are inconclusive. Secondary minimum strain rates could be achieved at $1 \%$ strain in a few tests after several years of continual deformation (e.g. Jacka and $\mathrm{Li}, 2000$ ), but many more years would be necessary in order to investigate tertiary creep under such slow conditions.

\subsection{Creep laws}

Glen (1955) and Barnes et al. (1971) have shown that the creep of ice up to the minimum strain rate (that is, including the primary and early stages of secondary creep, prior to acceleration), is reasonably well fitted with Andrade's Law (Andrade, 1910) in the form (from now on, the creep regimes in which a given equation is valid will be expressed by the acronyms PC, SC and TC within square brackets, denoting primary, secondary and tertiary creep, respectively)

$$
\begin{aligned}
\varepsilon & =\varepsilon_{0}+\ln \left(1+\beta t^{1 / m}\right)+\kappa t \\
& \approx \varepsilon_{0}+\beta t^{1 / m}+\kappa t,
\end{aligned}
$$

with $m=3$, where the approximation is valid for small strains, such that $\beta t^{1 / m} \ll 1$ and $\varepsilon \lesssim 1 \%$. In (4), $\varepsilon$ and $\varepsilon_{0}$ are the true (logarithmic) and instantaneous elastic strains, respectively, $t$ denotes time, while $\beta$ and $\kappa$ are parameters depending on the applied stress and temperature. It is not difficult to recognize that $\beta$ describes the material response at the onset of primary creep, while $\kappa$ represents the secondary asymptotic "steady-state" strain rate, which would be reached if the accelerating tertiary creep had not occurred. Consequently, $\beta t^{1 / m}$ is sometimes called the transient creep term, while $k t$ is the secondary "steady-state" creep term.

For temperatures and stresses usually considered in ice creep tests, experience 
shows that the early stage of transient creep $(\varepsilon \lesssim 0.01 \%$; Budd and Jacka, 1989) is characterized by a roughly linear relation between stress $\sigma$ and strain $\varepsilon$ within a fixed time interval, therefore implying that $\beta \propto \sigma$. On the other hand, Glen (1955) attempted to use (4) for deriving the stress dependence of the asymptotic secondary minimum strain rate $\kappa$ from creep tests, but the accuracy of the method was impaired by the onset of recrystallization and the difficulty to identify the end of the transient creep. From tests performed at $-0.02^{\circ} \mathrm{C}$ between $0.15-0.90 \mathrm{MPa}$, he found $\kappa \propto \sigma^{n}$ with $n=4.2$.

An independent determination of the secondary minimum strain rate was pursued by Glen $(1952,1955)$, by determining a power-law relation between the minimum strain rate actually observed in experiments and the stress required to produce it. In its most popular version (due to Nye, 1953), the power law that would soon be known as Glen's Flow Law takes the form

$$
\dot{\varepsilon}=A \sigma^{n}
$$

(cf. Remark 5), or in tensorial formulation (cf. Hutter, 1983; Paterson, 1994; Hooke, 2005)

$$
\dot{\varepsilon}=A \sigma^{n-1} \sigma
$$

with

$$
\begin{gathered}
\sigma=\sigma^{\top}, \quad \dot{\varepsilon}=\dot{\varepsilon}^{\top}, \quad \operatorname{tr}(\sigma)=\operatorname{tr}(\dot{\varepsilon})=0, \\
\dot{\varepsilon}:=\sqrt{\frac{1}{2} \operatorname{tr}\left(\dot{\varepsilon}^{2}\right)} \quad \text { and } \quad \sigma:=\sqrt{\frac{1}{2} \operatorname{tr}\left(\sigma^{2}\right)} .
\end{gathered}
$$

Remark 5. Power-law relations similar to (5) were introduced in fluid dynamics in 1923 by de Weale and Ostwald (cf. Ostwald, 1929) and some years later in metallurgy by Norton (1929). 
In the above equations, $(\cdot)^{\top}$ denotes the transpose and $\operatorname{tr}(\cdot)$ the trace of the respective tensor. The tensors $\sigma$ and $\dot{\varepsilon}$ describe the deviatoric (traceless) Cauchy stress and the strain rate, respectively. The non-negative scalars $\sigma$ and $\dot{\varepsilon}$ are the square roots of the deviatoric second invariants of $\sigma$ and $\dot{\varepsilon}$, and consequently correspond to $\sqrt{3 / 2}$ times the octahedral shear stress and strain rate. At temperatures below circa $-10^{\circ} \mathrm{C}$, the flow parameter $A$ is assumed to depend on temperature $T$ and hydrostatic pressure $p$ according to an Arrhenius-like equation (Remark 6)

$$
A=\alpha e^{-(Q+p V) / k_{\mathrm{B}} T} \approx \alpha e^{-Q / k_{\mathrm{B}} \vartheta} \approx \alpha e^{-Q / k_{\mathrm{B}} T},
$$

where $Q$ and $V$ are the activation energy and volume for creep, $k_{\mathrm{B}}$ is the Boltzmann constant, and the parameter $\alpha$ is usually regarded as a constant, although it may also depend on such factors as grain size, impurity and/or water content (Alley, 1992; Paterson, 1994).

Remark 6. Above $-10^{\circ} \mathrm{C}$ the increase of the minimum strain rate with temperature is enhanced and the Arrhenius law breaks down (Glen, 1955, 1975; Hooke, 1981; Budd and Jacka, 1989). It is believed that grain boundary sliding and the presence of water within the grain boundaries may be the main causes of this creep enhancement (Barnes et al., 1971). Due to the lack of a more realistic alternative, an empirical Arrhenius-like equation similar to (9) is frequently used to model the temperature dependence of ice creep above $-10^{\circ} \mathrm{C}$, including an apparent (and in fact temperature-dependent) activation energy with no physical meaning (Mellor and Testa, 1969b; Budd and Jacka, 1989; Paterson, 1994).

Rigsby (1958a) asserted that the effect of the activation volume of ice is in most cases negligibly small $\left(-55 \lesssim V \lesssim 32 \mathrm{~cm}^{3} / \mathrm{mol}\right.$, according to Jones and 
Chew, 1983) and can be accounted for in (9) by using the pressure-dependent temperature relative to the melting point

$$
\vartheta:=T+B p,
$$

with $B=98 \mathrm{~K} / \mathrm{GPa}$ (Lliboutry, 1976; Remark 7).

Remark 7. It should be noticed that the value of the constant $B$, which is appropriate for natural ice, does not coincide with the theoretical value of the relation between pressure and melting temperature of pure ice (Clausius-Clapeyron relation) $-\mathrm{d} T_{\mathrm{m}} / \mathrm{d} p=74 \mathrm{~K} / \mathrm{GPa}$. As explained by Glen (1974) and Lliboutry (1976), this discrepancy is mainly due to the natural saturation of air in water.

Values of the exponent $n$ in (5) and (6) derived from experiments and field measurements range from 1 to 4 , with a general consensus for using $n=3$ (Hobbs, 1974; Hooke, 1981; Weertman, 1983; Budd and Jacka, 1989; Alley, 1992; Paterson, 1994; Petrenko and Whitworth, 1999; Schulson and Duval, 2009). In his pioneering work, Glen (1952) found $n=4$. After extending his preliminary results, he came to $n=3.2$ (Glen, 1955). in a later review, Glen (1975) eventually suggested $n=3.5$ for stresses above about $0.1 \mathrm{MPa}$, with its value falling off with decreasing stress towards (but not necessarily reaching) unity. A similar fall-off of the exponent $n$ at sufficiently low stresses has been observed and/or suggested by a number of authors, based on field and laboratory results (e.g. Mellor and Testa, 1969a; Hooke, 1973; Goodman et al., 1981; Doake and Wolff, 1985; Pimienta and Duval, 1987; Goldsby and Kohlstedt, 1997; Azuma et al., 2000; Peltier et al., 2000; Cole and Durell, 2001; Durham et al., 2001; Goldsby and Kohlstedt, 2001, 2002; Marshall et al., 2002; Song, 2008). The case $n \approx 2$ is usually associated 
to grain boundary sliding, while $n \rightarrow 1$ is believed to be caused by diffusional flow or Harper-Dorn creep (Goodman et al., 1981; Duval et al., 1983; Weertman, 1983; Alley, 1992; Goldsby and Kohlstedt, 2001).

From the mathematical point of view, a power-law exponent $n \rightarrow 1$ at vanishing stresses would also be welcomed by modelers (see e.g. Thompson, 1979; Hutter, 1982, 1983; Fowler, 2001). The case $n>1$ when $\sigma \rightarrow 0$ leads to an infinite effective viscosity $\mathrm{d} \sigma / \mathrm{d} \dot{\varepsilon}$, and consequently to some pathological singularities in the modeling of ice-sheet flow (e.g. an infinite surface curvature on the ice divide and infinite slope at the ice-sheet margin). Owing to this, simple generalizations of (5) have been proposed, like

$$
\dot{\varepsilon}=A_{\mathrm{I}} \sigma+A_{\mathrm{II}} \sigma^{n}
$$

with $n$ non-integer, or alternatively the polynomial form

$$
\dot{\varepsilon}=\sum_{i=1}^{N} A_{i} \sigma^{i}
$$

with $i$ integer (e.g. Meier, 1958, 1960; Lliboutry, 1969; Colbeck and Evans, 1973; Thompson, 1979; Hutter, 1980, 1981; Hutter et al., 1981; Smith and Morland, 1981; Pettit and Waddington, 2003). The parameters $A_{\mathrm{I}}, A_{\mathrm{II}}$ and $A_{i}$ are usually assumed to be functions of temperature, and possibly also of other factors, like grain size, water/impurity content, etc. (Remark 8). More sophisticated generalizations of (5), based e.g. on the Garofalo or the Prandtl-Eyring models, are discussed by Barnes et al. (1971) and Hutter (1983).

Remark 8. Flow law generalizations like (11) or (12) are not necessarily mathematical artifices to overcome numerical singularities: they may in fact represent 
the competition of several deformation mechanisms. For instance, Azuma et al. $(1999,2000)$ proposed a combination of dislocation creep $(n=3)$ and diffusional flow $(n=1)$ to explain the weaker $c$-axis clustering observed in fine-grained, high-impurity ice layers (viz. cloudy bands) at low temperatures and stresses in the Dome Fuji deep ice core.

Compared to secondary creep, the tertiary creep of ice has been much less studied, in spite of its widespread occurrence in nature. The reason is, as already mentioned in Sect. 3.1, the extremely long period necessary to reach tertiary creep in deformation tests under the low temperatures and stresses typically found in glaciers and ice sheets.

From a series of tests at $-11.5^{\circ} \mathrm{C},-4.8^{\circ} \mathrm{C}$ and $-1.9^{\circ} \mathrm{C}$, with stresses ranging from 0.3 to $1.6 \mathrm{MPa}$ (corresponding to strain rates between $10^{-8}$ and $10^{-5} \mathrm{~s}^{-1}$ ), Steinemann (1958) derived the following power law, valid for the secondary and tertiary regimes

$$
\dot{\varepsilon}=A \sigma^{n}, \quad n=n_{0}+P(\sigma, T),
$$

where $A(T)$ is still given by (9), $n_{0}=$ const., and $P$ is a polynomial function of $\sigma$ and $T$, such that $n=n_{0}$ during secondary creep. During tertiary creep, $n$ may reach quite large values, depending on the applied stress and temperature, e.g. $n \geq 10$ for $\sigma=1.6 \mathrm{MPa}$ and $T=-1.9^{\circ} \mathrm{C}$.

More recently, it became customary in glaciology to follow an alternative approach, in which the power-law exponent is kept constant, e.g. $n=n_{0}=3$ in (13), and all microstructural changes characteristic of tertiary creep are subsumed into the flow parameter $A$. The usual procedure is to introduce a dimensionless 
enhancement factor $E$, such that

$$
\dot{\varepsilon}=E A \sigma^{n}, \quad n=n_{0},
$$

where $A(T)$ is still given by (9), $n_{0}=$ const., and the enhancement factor $E$ satisfies the compatibility condition

$$
\left.E\right|_{\dot{\varepsilon}_{\min }}=1
$$

which ensures that (14) is equivalent to (5) during the secondary creep of isotropic ice. By extending Steinemann's (1958) results summarized in (3), Jacka and Li (2000) could show that, for a given stress regime,

$$
\max (E)=\frac{\dot{\varepsilon}_{\max }}{\dot{\varepsilon}_{\min }}=E_{\max }\left(\dot{\varepsilon}_{\min }, T\right),
$$

where $E_{\max }$ is an increasing function of temperature and secondary minimum strain rate. In particular, for uniaxial compression at high stresses and temperatures, they found the upper bound $E_{\max }=3$. Likewise, for simple shear at high temperatures and stresses Budd and Jacka (1989) report the upper bound $E_{\max }=8$. These upper-bound values are believed to be the result of the symmetry superposition of the applied stress on fully developed Lattice Preferred Orientations (LPOs) through Curie's principle (Rosen, 1995, 2005).

In the case of natural ice, the enhancement factor $E$ is either derived from direct observation (Shoji and Langway, Jr., 1984; Dahl-Jensen, 1985; Wang et al., 2002) or modeled as a function (or functional) of a suitable set of variables that satisfactorily describe the microstructural evolution of ice during tertiary creep (Lile, 1978; Azuma, 1995; Placidi et al., 2010). It is believed that the main cause of enhancement is the strain-induced anisotropy due to LPOs, but other factors 
may play also an important role, like impurities or grain stereology (i.e. grain sizes, shapes, and arrangement, see Appendix A).

Remark 9. It is important to have in mind that only those effects emerging in the tertiary creep should enter in the definition of the enhancement factor $E$. For instance, the effect of hardening provoked by the interaction of dislocations with dispersed fine particles (Ashby, 1966) is already active during secondary creep and consequently should not be included in $E$, but rather in the factor $\alpha$ of (9).

Unfortunately, it is a formidable task to study the enhancement of tertiary creep by impurities and/or grain stereology in deformation tests at the low temperatures, stresses, and impurity concentrations typical of glaciers and ice sheets. On the other hand, such an enhancement is frequently observed in the field through ice-core and borehole studies (Gundestrup and Hansen, 1984; Fischer and Koerner, 1986; Dahl-Jensen and Gundestrup, 1987; Etheridge, 1989; Paterson, 1991; Cuffey et al., 2000a,b), but in such cases it is very difficult to identify the real agent of the effect because, as explained in detail in Part I, anisotropy, grain size and shape, soluble and insoluble impurity concentrations all correlate generally well with climate signals. Be that as it may, a clear example of tertiary creep enhancement by impurities and/or grain size and shape is offered by the study of a "soft ice" layer discovered at the EDML drilling site in Antarctica (Faria et al., 2006a, 2009, in preparation; see also Part I): microstructural analyses revealed the occurrence of strain accommodation by microscopic grain boundary sliding via microshear (cf. Drury and Humphreys, 1988; Bons and Jessell, 1999). Evidences suggest that this phenomenon is triggered by a combination of high impurity content and temperature with small grain sizes and a suitable LPO, which facilitates 
the sliding of grain boundaries and leads the microstructure to recrystallize into a characteristic "brick wall" pattern that promotes further microshear.

Sophisticated tensorial models that explore the anisotropy of natural ice LPOs have also been proposed (Azuma, 1994; Gödert and Hutter, 1998; Morland and Staroszczyk, 1998; Gillet-Chaulet et al., 2005; Faria, 2006b; Placidi and Hutter, 2006), although their use in large scale computer models has been greatly hampered by their intrinsic mathematical complexities (Montagnat et al., 2013). They are generally characterized by a fourth-rank tensor-valued fluidity $\boldsymbol{F}$ (or its reciprocal, the viscosity $\boldsymbol{\mu}=\boldsymbol{F}^{-1}$ ) such that

$$
\dot{\varepsilon}=F \sigma \text {. }
$$

The fluidity tensor $\boldsymbol{F}$ is usually a function or functional of the stress, temperature, and a set of time-dependent vector- and/or tensor-valued variables used to describe the LPO symmetry. In some models the fluidity tensor may also depend on additional factors already mentioned, like grain size, impurity concentration or water content (Faria, 2006b).

\subsection{Flow-structure interplay and the tripartite paradigm}

From the discussions in Sects. 3.1 and 3.2 it turns out that the regimes of strain, stress, strain rate and temperature typically found in polar ice sheets cannot be simultaneously achieved in laboratory. Extrapolations of the results of extreme creep tests (e.g. Russell-Head and Budd, 1979; Pimienta and Duval, 1987; Jacka and Li, 2000; Goldsby and Kohlstedt, 2001) do not converge to a unified conclusion, leaving open the possibility that several mechanisms of deformation, recrystallization and recovery may be coincidently active in polar ice. Therefore, 
in order to acquire a better understanding of the interplay between flow and microstructure in ice sheets, we must resort to indirect approaches. The most effective of them is undoubtedly the microstructural analysis of ice core samples, which is reviewed in the ensuing sections. Before embarking on such a review, however, it may be interesting to approach the interplay issue from the standpoint of large-scale ice-sheet mechanics.

For several decades, the tripartite paradigm (also called "three-stage model"; cf. Sect. 3.3 of Part I) has defined the status quo in regard to our general understanding of polar ice microstructures. It has set the framework for interpreting the evolution of grain sizes (Stephenson, 1967; Gow, 1969; Alley et al., 1986a,b; Durand et al., 2006) and lattice preferred orientations (Alley, 1992; Alley et al., 1995; Thorsteinsson et al., 1997), as well as the onset of dynamic recrystallization (Duval and Castelnau, 1995). It has also established the basis for polycrystalline ice models (De la Chapelle et al., 1998; Montagnat and Duval, 2000; Faria et al., 2002; Ktitarev et al., 2002) and provided arguments in disputes about deformation mechanisms in polar ice (Pimienta and Duval, 1987; Duval and Montagnat, 2002).

The cornerstone of the tripartite paradigm is the assumption that Normal Grain Growth (NGG) dominates the evolution of the polar ice microstructure in the upper hundreds of meters of the ice sheet, including the firn layer, according to the parabolic law

$$
D^{2}-D_{0}^{2}=K t
$$

where $D^{2}$ is the mean grain cross-sectional area at time $t, D_{0}^{2}$ is its extrapolated initial value, and $K$ is the grain growth rate (Stephenson, 1967; Gow, 1969; Alley et al., 1986a; Paterson, 1994; De la Chapelle et al., 1998). This assumption has 
recently been challenged by Kipfstuhl et al. $(2006,2009)$ through a detailed microstructure study of Antarctic ice and firn from the EDC and EDML sites. These authors found clear evidence of migration and rotation recrystallization (RRX) already at very shallow depths (a few tens of meters at EDML) and identified them as one of the dominant mechanisms of microstructure evolution in deep firn and bubbly ice (Figs. C.7 and C.8). Laboratory experiments and computer simulations of normal grain growth (Roessiger et al., 2011, 2013; Azuma et al., 2012) have also cast doubts on the tripartite paradigm, by showing that the microstructure of shallow polar ice seems to be affected by processes other than NGG.

Based on these recent results and the information discussed in the previous sections, we can now investigate the reasons for the failure of the tripartite paradigm. In the pioneering work of Gow (1969), which established the notion of NGG in polar ice, mean grain size was derived from the cross-sectional areas of the 50 largest grains in a sample. Clearly, this method is fast and practical, but it ignores (i.e. it cuts off) most of the grain size distribution and is therefore inappropriate (Remark 10).

Remark 10. Gow (1969) justified this approach by his observation of a certain uniformity in the size of grains disaggregated from specific snow layers. Such uniformity is however questionable and has not been observed in modern studies. It has possibly been caused by a bias towards larger grains, which is introduced during the process of disaggregation of the fragile snow and firn.

As discussed in Part I, despite its shortcomings the 50-largest-grains method has been used for determining the mean grain sizes of several firn and ice cores, including GISP2. More elaborated methods, like the linear intercept (Dye 3, GRIP, 
GISP2), the counting of grains within a given area (Camp Century, Byrd, Vostok) or the modern Automatic Fabric Analysis, AFA (NGRIP, EDC, Dome F) share a common limitation: they are all based on thickness-integrated images of the ice sample, so that the resolution of the method is limited by the thickness of the thin section under analysis (usually around $0.3-0.5 \mathrm{~mm}$ ). Grains or grainboundary features smaller than the section thickness cannot be identified, and very inclined boundaries give rise to large experimental errors. This limitation imposes a serious cut-off in the grain size distribution, which handicaps interpretations of microstructure evolution in natural ice.

To date, the best solution for improving the resolution of ice microstructure analyses is actually based on the old, pioneering work of Seligman (1949), illustrated in Fig. C.9: we simply record the the grain-boundary grooves on the ice surface, which are naturally produced by thermal etching. Today it is no longer necessary to cover the ice sample with a sheet of paper and rub it with a pencil, in order to record its microstructure. We can simply photograph the thermally etched ice surface with a high-resolution digital camera. This is the physical principle of the Microstructure Mapping method ( $\mu \mathrm{SM})$, proposed by Kipfstuhl et al. (2006). If the thermal etching is well done, the resolution of the $\mu \mathrm{SM}$ method is limited mainly by the resolution of the optical equipment and the digital image analysis software. Current set-ups work with resolutions in the range 3-65 $\mu \mathrm{m}$ (Kipfstuhl et al., 2006, 2009). Another promising option, with even higher resolution than $\mu \mathrm{SM}$, is Electron Backscatter Diffraction (EBSD; Iliescu et al., 2004; Piazolo et al., 2008; Weikusat et al., 2010; Prior et al., 2012). The use of EBSD on ice is technically very difficult and is still in its infancy, but rapid technological and methodological developments suggest that it may become a powerful tool for 
future studies of ice microstructure.

In the sequel, we investigate the validity of the tripartite paradigm in the EDML site. The reason for selecting this site is twofold: first, it provides the most detailed and up-to-date information about polar firn and ice microstructures; second, it offers one of the best examples of "typical" Antarctic ice, because the EDML drilling site is representative of the Antarctic plateau without being located at such an unusual place like an ice dome (e.g. EDC, Dome F) or above a large subglacial lake (viz. Vostok).

The increase of grain size with depth in EDML polar firn was studied by Kipfstuhl et al. (2009) at three distinct "resolutions," viz. average grain area of the 100 largest grains, of the 500 largest grains, and of all grains in each firn section. These three "resolutions" were chosen in order to investigate how the afore-mentioned cut-off of the grain size distribution affects our perception of grain growth. From the results of that study, we can now calculate the grain growth rate $K$ appearing in (18) for each of the three cut-offs. We find $K_{100}=3.3 \times 10^{-3} \mathrm{~mm}^{2} / \mathrm{a}$ for the 100 largest grains, $K_{500}=2.0 \times 10^{-3} \mathrm{~mm}^{2} / \mathrm{a}$ for the 500 largest grains, and $K_{\text {all }}=1.5 \times 10^{-4} \mathrm{~mm}^{2} / \mathrm{a}$ when all grains in the sample are taken into account. These values can be compared with Paterson's empirical curve relating growth rate and temperature, derived from a compilation of field measurements of grain growth rates in firn from various polar locations (Fig. 2.5 of Paterson, 1994). For the EDML site, where the mean temperature in firn and shallow ice is ca. $-45^{\circ} \mathrm{C}$ (Table B.1 of Part I), Paterson's curve predicts a grain growth rate in the range $2( \pm 1) \times 10^{-3} \mathrm{~mm}^{2} / \mathrm{a}$. Clearly, the EDML values of $K_{100}$ and $K_{500}$ are compatible with Paterson's empirical prediction, while the most reliable of them, $K_{\text {all }}$, is too low by one order of magnitude. 
The cause of this serious discrepancy is related to the different cut-offs of the grain size distributions. The flawed rates $K_{100}$ and $K_{500}$ describe solely the kinetics of the larger grains, that is, of truncated grain size distributions. In this manner, they systematically ignore the formation, existence, and kinetics of smaller grains. It is evident that it makes no sense to use such inaccurate growth rates as basis for a theory of NGG in polar ice. Unfortunately, the limited resolution of most methods of polar ice microstructure analysis imply that the great majority of grain growth rates reported in the literature of polar firn and shallow ice may be impaired by such shortcomings.

Furthermore, the sheer fact that grain size data can be fitted with a parabolic growth law is by no means a corroboration of the occurrence of NGG (especially if the growth rates are flawed): Strain-Induced Grain Boundary Migration (SIBM) does not preclude a linear increase of the mean grain cross-sectional area with time, in a regime that may be called Dynamic Grain Growth (DGG, cf. Appendix A). SIBM-driven grain growth data can sometimes be fitted with a NGG law, but in this case the law parameters (activation energy, growth rate, etc.) have no real physical meaning. This explains the low value found for the most reliable grain growth rate, $K_{\text {all }}$ : it does not describe the real velocity of grain boundaries in the NGG regime, simply because NGG cannot control the microstructure evolution of a material undergoing deformation, like polar firn.

As pointed out by Azuma et al. (2012) and Roessiger et al. (2011, 2013), the motion of grain boundaries in firn and bubbly ice is strongly affected by a number of influences, including some extraneous to NGG, like stored strain energy and a non-steady-state configuration of the grain-boundary network. Indeed, according to Azuma et al. (2012), the grain boundary migration rate of pure, bubble-free 
ice undergoing true $\mathrm{NGG}$ at $-45^{\circ} \mathrm{C}$ should be $K_{\text {free }}=1.6 \times 10^{-1} \mathrm{~mm}^{2} / \mathrm{a}$, which is several orders of magnitude larger than the rates predicted by Paterson (1994) or measured by Kipfstuhl et al. (2009). The reason for the much slower growth rate observed in polar firn cannot be attributed just to pinning by bubbles and other impurities: complex strain-induced boundary motions (SIBM-O) and the formation of new grains by dynamic recrystallization (RRX and SIBM-N) spoil NGG and disguise the real migration rate of the boundaries.

An important corollary of the tripartite paradigm is the assumption that grain boundary migration during NGG (i.e. migration driven by the free energy of the grain boundaries) is an efficient softening mechanism that accommodates basal slip deformation. As explained by Pimienta and Duval (1987):

In conclusion, grainboundary migration associated with [normal] grain growth is an efficient accommodation process for dislocation glide in fine-grained ices. In consequence the usual transient creep cannot occur and strain energy is always small compared with the driving force for [normal] grain growth.

The fact that grain boundary migration is an important recovery mechanism in natural ice is obvious and beyond doubt. On the other hand, considering the fact that grain boundary migration is not a deformation mechanism, its role in the accommodation of deformation is per se controversial (Kocks, 1970; Means and Jessell, 1986; Goldsby and Kohlstedt, 2002; Cahn and Taylor, 2004) and becomes highly questionable in the case of NGG, seeing that migrating boundaries in the NGG regime should, by definition, move free from the influence of internal stresses and strain heterogeneities.

In the case of EDML firn, it is not difficult to show that NGG does not dictate 
the microstructure evolution and that grain boundary migration, if it can be an accommodation mechanism in the first place, is not sufficient to suppress dynamic recrystallization. From Ruth et al. (2007) we calculate two bound estimates for the vertical strain rate ("layer thinning") of EDML firn at $50 \mathrm{~m}$ depth: $\dot{\varepsilon}_{\text {total }} \approx$ $3.2 \times 10^{-11} \mathrm{~s}^{-1}$ and $\dot{\varepsilon}_{\text {i.eq. }} \approx 7.4 \times 10^{-12} \mathrm{~s}^{-1}$, see Appendix B. The former $\left(\dot{\varepsilon}_{\text {total }}\right)$ describes the total thinning of the firn layers, including pore-space compression. In contrast, $\dot{\varepsilon}_{\text {i.eq. }}$ is based on the ice-equivalent depth and consequently excludes any contribution of the pore space. As discussed in Appendix B, the average real strain rate locally experienced by the ice grains in firn, $\dot{\varepsilon}_{\text {real }}$, is very difficult to determine with precision, since it depends on the highly variable contribution of the pore space to the strain accommodation. In any case, it should lie between these two extreme strain-rate averages, viz. $\dot{\varepsilon}_{\text {total }} \geq \dot{\varepsilon}_{\text {real }} \geq \dot{\varepsilon}_{\text {i.eq. }}$.

In addition to strain rates, in Appendix B we also compute the total vertical strain and the water-equivalent strain at $50 \mathrm{~m}$ depth, respectively, $\varepsilon_{\text {total }} \approx-30 \%$ and $\varepsilon_{\text {i.eq. }} \approx-7 \%$. Thus, from these estimates we conclude that EDML firn at ca. $50 \mathrm{~m}$ depth is already deforming in the tertiary creep regime (cf. Sect. 3.1) and should be undergoing dynamic recrystallization (Fig. C.7). These conclusions are in accordance with the experimental observation of dynamic recrystallization in EDML firn by Kipfstuhl et al. (2009).

\section{Grain and subgrain boundaries}

As any other polycrystalline material, polar ice consists of connected regions of uninterrupted crystalline lattice known as grains, which are bounded together by grain boundaries. Such crystalline regions are not perfect, though. Localized distortions of the lattice are caused by defects, especially dislocations (Sect. 2), which 
can sometimes arrange themselves in stable structures called subgrain boundaries. By gradually increasing the lattice misorientation across a subgrain boundary, the latter may evolve to a new grain boundary. For this reason, grain and subgrain boundaries are also named high-angle and low-angle boundaries, respectively. These names make evident that the grain-/subgrain-boundary dichotomy is a conceptual simplification, since the transition from low to high misorientation is in fact continuous. As such, the critical misorientation angle that distinguishes between grain and subgrain boundaries is to some extent a matter of convention, which depends on the boundary properties under consideration. In this work we follow Weikusat et al. (2011) by assuming that the lattice misorientation across subgrain boundaries in polar ice is not larger than ca. $5^{\circ}$, a result consistent with observations in other minerals (Drury and Urai, 1990; Passchier and Trouw, 2005).

\subsection{Subgrain boundaries}

Subgrain boundaries are essential features of the ice microstructure, as they are indisputable evidences of heterogeneous strains, intercrystalline incompatibilities, internal stresses and high concentration of geometrically necessary dislocations. They have been observed in ice for at least a century (Tarr and Rich, 1912). By analysing thin sections of bent ice samples, Matsuyama (1920) reported "faint but distinct straight lines" developed within some grains with zigzag boundaries, and the straight lines were observed to sometimes "start from the angular points of these zigzag boundaries."

Nakaya (1958) later recognized that such straight lines were actually subgrain boundaries made up of geometrically necessary dislocations. He performed bending experiments in single crystals with $c$-axes parallel to the bending load and ob- 
served the formation of slip bands (cf. Appendix A), which would initially bend with the crystal. This bending of slip bands is the precursor of a particular type of subgrain boundary, by accumulating edge dislocations along several basal-gliding layers in a dislocation wall perpendicular to the slip bands. At already $\ll 1^{\circ}$ of crystal bending, subgrain boundaries can be seen, typically emerging from the high curvature part of slip bands, transforming them into a kink structure, if misorientation further increases with ongoing deformation. In the glaciological literature, this process is often called "polygonization" (Alley et al., 1995).

The particular type of subgrain boundary described above is known as a basal tilt boundary. In the ideal case it bisects the angle formed by the tilted basal plane and is made up exclusively of basal edge dislocations with Burgers vector $\boldsymbol{b}=\boldsymbol{a}$ (Table D.2). In ice, tilted basal planes or c-axes can be measured using an Automatic Fabric Analyzer (AFA; Wilson et al., 2007) or the formvar etch-pit method (Matsuda, 1979; Barrette and Sinha, 1994; Hamann et al., 2007). Actually, most studies of subgrain boundaries in ice are performed on experimentally deformed specimens (Wilson et al., 1986, this issue; Barrette and Sinha, 1994; Hamann et al., 2007). In the case of naturally deformed ice, as in polar ice sheets or glaciers, the occurrence of subgrain boundaries has often been determined indirectly from neighbouring grain misorientation statistics (Alley et al., 1995; Wang et al., 2003; Durand et al., 2008). Only recently, new microscopy methods have allowed the direct and extensive (statistically relevant) observation of subgrain boundaries in naturally deformed ice, e.g. through Microstructure Mapping ( $\mu$ SM; Kipfstuhl et al., 2006). These studies have revealed that, in addition to the classical tilt boundaries characteristic of "polygonization," other subgrain boundary configurations are also very common in both, naturally and artificially deformed 
ice (Hamann et al., 2007; Weikusat et al., 2009a,b). These configurations (arrangements) include boundaries parallel and normal to the basal planes, as well as zigzag combinations of them (Fig. C.10).

The observation of such detailed subgrain boundary configurations is only possible because thermal etching (sublimation) is highly sensitive to boundaries with very low-misorientation $\left(\ll 0.5^{\circ}\right)$, as proven directly by high-resolution crystal orientation measurements, such as X-ray Laue diffraction (Miyamoto et al., 2011; Weikusat et al., 2011) and Electron Backscatter Diffraction (EBSD; Weikusat et al., 2010). These two methods enable complete determination of the crystalline lattice misorientation across the boundary, including both $c$ - and $a$-axes. A detailed knowledge of subgrain boundary misorientation and configuration allows to identify the possible slip systems of its constituent dislocations (Trepied et al., 1980; Prior et al., 1999, 2002; Piazolo et al., 2008). Following this approach, Weikusat et al. (2011) combined $\mu \mathrm{SM}$ with X-ray Laue diffraction to obtain first statistical data about subgrain boundaries and their constituent dislocations in polar ice (Table D.2).

By recalling the consequences of the low stacking fault energy on the basal plane of hexagonal ice (Sect. 2.1), it may seem paradoxical at first to see in Table D. 2 that almost $30 \%$ of all subgrain boundaries in polar ice are composed of non-basal dislocations. The solution of this apparent paradox lies in the high temperatures and low strain rates typical of natural ice deformation, which turn dynamic recovery effective enough to allow the rearrangement of basal and nonbasal geometrically necessary dislocations in complex dislocation walls and subgrain boundaries. Indeed, from the microstructural features observed in polar ice, we conclude that dynamic recovery through the formation of a variety of sub- 
grain boundaries by grain subdivision (cf. Appendix A), as well as the splitting of grains by rotation recrystallization (Sect. 5.1), are fundamental mechanisms of strain accommodation in natural ice. Thus, it follows that geometrically necessary dislocations play a decisive role in the accommodation of deformation in polar ice.

\subsection{Grain boundaries}

The structure of grain boundaries plays an essential role in the mechanics, recrystallization, and molecular diffusion of ice, since it determines the energetics, mobility, cohesion, and permeability of grain boundaries. While the structure of low-angle grain boundaries (i.e. subgrain boundaries) in ice is well described by the theory of dislocation arrays (Read and Shockley, 1950; Higashi and Sakai, 1961; Suzuki and Kuroiwa, 1972), little is actually known about the structure of high-angle grain boundaries (Higashi, 1978; Hondoh and Higashi, 1978; Petrenko and Whitworth, 1999). For this reason, classical views from metallurgy (Sutton and Balluffi, 1995) are commonly adopted for ice (Goodman et al., 1981; Frost and Ashby, 1982), in particular that the excess volume of grain boundaries render them favourable diffusion paths for interstitials and solutes, in such a manner that the activation energy for diffusion of self-interstitials is expected to be lower within grain boundaries (grain-boundary self-diffusion) than through the ice lattice (lattice self-diffusion).

Notwithstanding, the density anomaly of water poses an interesting prospect for the structure of grain boundaries in ice: in contrast to metals, water molecules in the grain boundaries of polycrystalline ice could be packed more closely than in the ice lattice (i.e. a negative excess volume), in a sort of amorphous or quasiliquid state (Clifford, 1967; Kondo et al., 2007). This conjecture is consistent with 
the high molecular disorganization expected within grain boundaries and near free surfaces due to proton disorder (Petrenko and Whitworth, 1999; cf. Sect. 2), as well as with the observation of liquid water veins at the corners and edges of grain boundaries in polycrystalline ice at temperatures close to the melting point (Steinemann, 1958; Barnes et al., 1971; Nye and Frank, 1973; Mader, 1992). An important corollary of such a "dense grain boundary" conjecture is that the behaviour of grain boundaries in ice could be very sensitive to temperature and impurity content, causing grain boundaries to possess either a more "liquid" or more "glassy" structure.

Unfortunately, direct observation of the molecular structure of ice grain boundaries has not been possible so far, and grain-boundary diffusion experiments in ice are also very difficult to accomplish. Consequently, grain-boundary migration experiments are still regarded as the simplest means of obtaining valuable insights into the structure of ice grain boundaries, seeing that, like the phenomenon of self-diffusion, the migration of grain boundaries involves the jumping of water molecules between lattice and grain-boundary sites, as well as their movement inside the grain boundary.

As reviewed in Sect. 3.3 (see also Sect. 3.3 of Part I) the tripartite paradigm states that grain-boundary migration in the upper hundreds of meters of polar ice sheets should occur via Normal Grain Growth (NGG) according to the parabolic law (18). Thus, if the tripartite paradigm were true, the temperature dependence of the grain growth rate $K$ of polar ice could be estimated from grain size versus age data of ice cores extracted from different polar sites. The activation energy of grain growth derived from such analyses $(40-50 \mathrm{~kJ} / \mathrm{mol})$ has been accepted and widely applied in glaciology. It happens, however, that polar ice is under con- 
tinual deformation and contains many air bubbles. In the past, it was assumed that air bubbles and pores should not significantly affect the migration of grain boundaries (Duval, 1985; Alley et al., 1986b), but recent computer simulations (Roessiger et al., 2013), field observations (Kipfstuhl et al., 2006, 2009) and laboratory experiments (Azuma et al., 2012) have proven the contrary. Furthermore, it has been shown that the stored strain energy in polar ice sheets is sufficient not only to keep the ice microstructure out of the quasi-stationary state required for NGG (Faria and Kipfstuhl, 2005; Roessiger et al., 2011), but also to trigger rotation and migration recrystallization in firn and shallow ice (Kipfstuhl et al., 2006, 2009; Faria et al., 2009; Weikusat et al., 2009a,b). Therefore, the tripartite paradigm is generally not valid and the activation energy derived from ice-core grain-size data cannot be the true activation energy of NGG in ice.

By using a new technique for producing pure, bubble-free ice, derived from a method introduced by Stern et al. (1997), Azuma et al. (2012) could study the temperature dependence of the true NGG rate $K$ of ice. They found that $K$ in bubblefree ice is approximately three orders of magnitude larger than that estimated from ice-core data (Paterson, 1994; cf. Sect. 3.3). Furthermore, an activation energy for NGG of about 110-120 kJ/mol was observed in bubble-free ice at temperatures between $-40^{\circ} \mathrm{C}$ and $-5^{\circ} \mathrm{C}$. In contrast, the activation energy for NGG of bubbly ice under the same conditions is circa $40-70 \mathrm{~kJ} / \mathrm{mol}$. The similarity between the values of activation energy for grain growth derived from ice-core data and experimentally measured in bubbly ice is evident. This fact compared with the apparent activation energy of $50 \mathrm{~kJ} / \mathrm{mol}$ calculated by Azuma et al. (2012) for the migration of air bubbles in ice, suggest that the slow grain growth observed in polar ice cores is significantly affected by the migration velocity of air bubbles. 
It must be noticed that the true activation energy for NGG in pure, bubble-free ice is approximately twice the activation energy for lattice self-diffusion (Ramseier, 1967). In the absence of reliable measurements of grain-boundary selfdiffusion in ice, and recalling that grain-boundary migration and diffusion involve akin molecular processes (for a deeper discussion see Azuma et al., 2012), we come to the conclusion that the activation energy for grain-boundary diffusion may also be considerably larger than that for lattice diffusion. This result adds support to the dense-grain-boundary conjecture, as suggested by Azuma et al. (2012): when grains grow, the total grain-boundary area must decrease. This leads to fluxes of water molecules across and along the grain boundaries. If the grain boundaries have some sort of "semi-glassy" structure, the activation energies for grain-boundary migration and diffusion must be high, because the water molecules are jammed inside the grain boundaries. On the other hand, if the grain boundaries have a kind of "quasi-liquid" structure, the activation energies for grain-boundary migration and diffusion may be high if the water molecules are aggregated in clusters that must be either thermally activated as a group or broken down to allow self-diffusion (Mott, 1948; Merkle and Thompson, 1973).

As a closing remark, it should be noticed that even if the activation energies for grain-boundary migration and diffusion are larger than previously expected, so is also the growth rate $K$, and consequently the grain boundary mobility, within the temperature range typical of ice sheets (between $-80^{\circ} \mathrm{C}$ and $0^{\circ} \mathrm{C}$ ). Consequently, grain boundaries in polar ice are very mobile and the grain size evolution turns out to be controlled by second-phase dragging and dynamic recrystallization in a process called Dynamic Grain Growth (DGG; Appendix A). These effects give rise to the well-known apparent correlation of grain size with climate proxies (see 
Part I).

\section{Dynamic recrystallization}

In the old glaciological literature, the word "recrystallization" was loosely used in reference to nucleation and growth of new grains favourably oriented for deformation; a definition that still can be found in more recent works (Paterson, 1994). Here we adopt a more precise and comprehensive definition of recrystallization as "any reorientation of the lattice caused by grain boundary migration and/or formation of new grain boundaries" (cf. Appendix A), which is consistent with its modern meaning in geology (Urai et al., 1986; Drury and Urai, 1990; Passchier and Trouw, 2005).

It is worth noticing that metallurgists use a concept of recrystallization similar to the one adopted here, although they often exclude processes driven by the grain boundary energy (Doherty et al., 1997; Humphreys and Hatherly, 2004). This minor difference in terminology reflects the slightly distinct focuses of these two research fields. Metallurgists are frequently concerned with static annealing phenomena, in which recrystallization processes driven by grain boundary energy (usually called "grain growth/coarsening" in metallurgy) occur after the stored strain energy has been consumed by previous static recovery and recrystallization. In contrast, geologists are mostly concerned with dynamic recrystallization processes, in which strain energy is continually produced during deformation (cf. Remark 11). In particular, in the case of natural ice, the increase in mean grain size with age observed in ice cores (see Part I) is clearly influenced by the stored strain energy in a process of Dynamic Grain Growth (DGG; cf. Sect. 4.2 and Appendix A). 
Remark 11. The common etymology of the metallurgical and geological terminologies mentioned above may help us to understand their subtle (but consequential) distinction. In the primordial times of research in recrystallization, Alterthum (1922a,b) coined the terms "Bearbeitungsrekristallisation" and "Oberflächen-Rekristallisation," meaning respectively "work-recrystallization" (namely, driven by the stored strain energy) and "surface-recrystallization" (i.e. driven by the grain boundary energy). It is interesting to perceive how the modern metallurgical terminology evolved giving emphasis on the distinguishing prefixes "work-" and "surface-," whereas the current geological terminology emphasizes the common suffix "-recrystallization." It seems that Alterthum himself had a preference for emphasizing the common suffix, seeing that he considered also the situation when both driving forces (viz. stored strain and grain boundary energies) act together, in a process he named "gemischte Rekristallisation," that is "mixed recrystallization."

\subsection{Rotation recrystallization $(R R X)$}

By definition, the formation of a subgrain boundary is related to a slight rotation of the crystalline lattice of a certain portion of the grain, called the subgrain. Such a locallized rotation is usually driven by local distortions of the lattice caused by internal stresses and intercrystalline misfits (cf. Sect. 2.2), which are accommodated by the subgrain rotation and the resulting concentration of the lattice distortion (i.e. geometrically necessary dislocations) along the subgrain boundary (Sect. 4.1). If the driving force for rotation persists, the lattice misorientation across the subgrain boundary increases until the subgrain divides from the parent grain to become a grain in its own. Alternatively, the misorientation across the subgrain boundary may increase by subgrain growth and consumption of neighbouring subgrain boundaries in a region with monotonic lattice misorientation 
gradient. In any case, it is the last step of the process, namely the splitting of the parent grain into two or more grains, that we name here rotation recrystallization (RRX; Appendix A).

Not all subgrain boundaries evolve to grain boundaries, though. In order to accomplish the creation of a new grain boundary via RRX, the internal stresses causing the subgrain rotation and growth must persist unchanged for a period long enough, and this is often not the case. Instead of developing a single high-angle boundary, the stressed grain often accommodates the internal stresses through the creation of several subgrain boundaries, which offer smoother but more complex geometrical possibilities of strain accommodation than a single large-angle boundary could provide (e.g. Figs. C.3, C.7b, C.8b-f and C.10).

It is actually not trivial to identify the transformation of a subgrain boundary into a grain boundary via RRX in naturally deformed ice, since natural ice samples provide just a static snapshot of the microstructure evolution. Experience and good sense help in the direct identification of the most conspicuous examples, but direct inspection of grain boundary shapes is not a reliable method for quantifying RRX. In the past, RRX has been estimated indirectly from the stabilization of mean grain size (cf. ice-core reviews in Sects. 3.3, 4.2, 4.3, and 5.2 of Part I). This was relatively simple under the assumption of the tripartite paradigm (Sect. 3.3 of Part I; see also Sect. 3.3), since in this case RRX could be inferred from the deviation of the observed grain growth data from the theoretical predictions of normal grain growth (NGG) theory (Montagnat and Duval, 2000; Faria et al., 2002; Mathiesen et al., 2004; Placidi et al., 2004). However, if the tripartite paradigm is not valid, as proposed here, then the indirect quantification of RRX from grain size data becomes more difficult, due to the more complex motion of grain boundaries 
during strain-induced boundary migration (SIBM-O), compared to NGG.

Alley et al. (1995) have proposed the most reliable method to date for quantifying RRX in natural ice. It involves an ingenious analysis of grain boundary misorientations, based on the assumption that a grain newly formed by RRX should have a lattice orientation closely related to that of its neighbouring sibling grain. Considering the fact that only $c$-axes can currently be measured extensively (using an Automatic Fabric Analyzer, AFA; Wilson et al., 2007; see also Sect. 4.3 of Part I), this method tends to underestimate RRX. Nevertheless, this underestimation may be tolerable, seeing that the fraction of grains formed by RRX about the $c$-axis is expected to be less than 10\%, according to Weikusat et al. (2011), cf. Table D.2.

It should be remarked that RRX in ice can start already at very early stages of deformation. As explained in Sect. 3.1, during primary creep $(\varepsilon \lesssim 1 \%)$ there occurs the load transfer from easy-glide to hard-glide systems, together with the build up of internal stresses and strain incompatibilities between the grains. All these processes promote the generation of the geometrically necessary dislocations needed for subgrain boundary formation and evolution.

\subsection{Nucleation and migration recrystallization}

An important contribution of glaciology to geology has been the study of deformation and/or recrystallization of thin polycrystalline sections via transmitted light microscopy. The use of this technique in glaciology can be traced back to the first decades of 20th century (Tammann and Dreyer, 1929; Steinemann, 1958; Rigsby, 1960; Wakahama, 1964), and later it found widespread application in structural geology through the use of a number of mineral-analogue materials, including magnesium, camphor, sodium chlorate, and octachloropropane (Burrows et al., 
1979; Urai et al., 1980; Jessell, 1986; Means, 1989; den Brok et al., 1998).

By using this kind of technique, Tammann and Dreyer (1929) managed to monitor the real-time static recrystallization of polycrystalline ice cold-rolled from snow, therefore providing first estimates of two-dimensional grain-boundary migration rates in the temperature range between $-2^{\circ} \mathrm{C}$ and $-6^{\circ} \mathrm{C}$. Additionally, they observed grain coalescence and nucleation, and even embarked on an unsuccessful attempt of explaining the growth of ice grains during static recrystallization.

As mentioned in Sect. 2.1 of Part I, Seligman (1941) accredited to Perutz the interpretation of grain growth in ice during recrystallization as a consequence of grains well-oriented for basal slip having a lower free energy than badly-oriented grains, so that the former should grow at the expenses of those grains that cannot yield to the imposed stresses. This thermodynamic interpretation was subsequently extended to the nucleation of new grains and tested in experiments and field investigations of recrystallization in temperate and polar (frozen) ice (e.g. Bader, 1951; Rigsby, 1951; Steinemann, 1958; Shoumsky, 1958; Rigsby, 1958b; Kamb, 1959; Rigsby, 1960; Gow, 1963; Kamb, 1964; Wakahama, 1964; Rigsby, 1968; Kizaki, 1969; Budd, 1972; Kamb, 1972; Matsuda and Wakahama, 1978). These studies provided a wealth of data, but results were not always fully accordant (Remark 12). It became a general consensus that recrystallized ice grains tend to develop irregular shapes (as previously observed by Perutz and Seligman, 1939; cf. Sect. 2.1 of Faria et al., this issue) combined with lattice preferred orientations (LPOs) that maximize the resolved shear stress on the basal planes. While the LPOs produced by recrystallization in uniaxial compression and extension seemed compatible with Perutz' thermodynamic interpretation (viz. large/small girdles centred around the axis of extension/compression; Kamb, 1972), those 
produced by simple shear appeared much less intuitive and defied simple explanation. Therefore, owing to the importance of simple shear for the flow of glaciers and ice sheets, during the 1950-1980's much attention was dedicated to the understanding of dynamic recrystallization of ice under simple shear.

Remark 12. The reader revising the literature from the second half of 20 th century should keep in mind that many glaciologists used to employ the term "recrystallization" in a loose manner, often in reference to recrystallization with nucleation only. Less frequently, the term also included ordinary migration recrystallization without nucleation (SIBM-O, cf. Appendix A). Rotation recrystallization (RRX) was often ignored in pre-1980 studies.

Rigsby (1958b, 1960) observed much slower recrystallization rates in ice rich in small air bubbles, and no evidence of mechanical twinning. He reported different LPOs in polar (frozen) and temperate ice: in the case of simple shear the former exhibited a single maximum perpendicular to the shear plane, while the latter showed multiple maxima. He interpreted the multiple maxima as the result of migration recrystallization in a "nearly stress-free environment." Steinemann (1958) also found no evidence of mechanical twinning and emphasized the distinction between the LPOs produced by dynamic and static recrystallization. In his torsion-simple-shear experiments $\left(420\right.$ and $660 \mathrm{kPa}$ at $\left.-1.9^{\circ} \mathrm{C}\right)$ he reported that dynamic recrystallization generated multiple maxima, while subsequent static recrystallization transformed them into a single maximum perpendicular to the shear plane (these observations were subsequently criticized and re-analysed by Kamb, 1959).

By compiling results from other researchers and from his own investigations, Kamb $(1959,1964,1972)$ concluded that the typical LPOs produced in simple- 
shear tests at high temperatures (ca. $-5^{\circ} \mathrm{C}$ and above) had a single maximum perpendicular to the shear plane, sometimes accompanied by a secondary, transient maximum rotated away from the first in the reverse shear direction. In contrast, LPOs found in glacier ice, which was supposedly deforming under simpleshear conditions similar to those applied to the simple-shear tests, where characterized by four maxima about the normal to the shear plane, ideally forming a cross/diamond pattern with monoclinic symmetry. Kamb attributed the discrepancy between laboratory and natural deformation to the vast difference in time scales, so that some sort of lattice-orientation controlling mechanism should become operative at very large strains $(\varepsilon \lesssim 100 \%)$. In contrast to Rigsby's observations, Kamb (1972) found in his experiments and observations no detectable influence of air bubbles on recrystallization.

Kizaki (1969) and Budd (1972) proposed that LPOs with multiple maxima could be produced by ordinary migration recrystallization (SIBM-O, cf. Appendix A) during dynamic grain growth, so that $c$-axis distributions with multiple maxima should be characteristic of ice with coarse irregular grains, while the $c$-axes of fine-grained ice should be either weakly-oriented or clustered in a single maximum. Finally, by analysing $c$ - and $a$-axis orientations in recrystallized ice with multiple maxima, Matsuda and Wakahama (1978) discovered a common coincidentlattice relationship between neighbouring grains and speculated that the multiple maxima could be the result of nucleation via mechanical twinning under a high shear stress. Such a conjecture was later challenged by Parameswaran (1982) on the basis of a dislocation model, and by Wilson (1986) through the fact that twinning as a deformation mechanism has never been observed in ice: rather, coincident-lattice relationships could be the result of boundary migration during 
the impingement of growing grains.

Even if mechanical twinning is ruled out as a mechanism of nucleation recrystallization in ice, at least two other nucleation hypotheses are generally considered by glaciologists. They are named here classical (or spontaneous) nucleation and pseudo-nucleation (cf. the entry "nucleation" in Appendix A). During classical nucleation a cluster of water molecules spontaneously form a new embryo, which evolves to a nucleus that grows as a new strain-free grain. In contrast, during pseudo-nucleation a microscopic portion of the parent grain undergoes a combination of elementary recovery and recrystallization processes (e.g. boundary migration, subgrain rotation and growth, etc.; cf. SIBM-N in Appendix A), which lead to the formation of a little strain-free new grain, called pseudo-nucleus (the prefix "pseudo-" is used here to emphasize that this nucleus may be larger than a classical nucleus, but still small enough to undergo complete recovery and become strain-free). Despite recurrent considerations of classical nucleation in the glaciological literature, it has long been recognized that spontaneous nucleation as a recrystallization mechanism in single-phase polycrystals is energetically unfavourable (Cahn, 1970; Urai et al., 1986; Drury and Urai, 1990; Humphreys and Hatherly, 2004) and there is no evidence that this should be different for ice (Glen, 1974; Wilson, 1986; Kipfstuhl et al., 2009).

During the 1970's and 1980's it became increasingly clear that the unsteady flow of glaciers most likely affected their LPO evolution, making the analysis of recrystallization structures rather difficult. Therefore, attention slowly turned to the microstructures of polar ice sheets, which seemed simpler to interpret and were produced under much more stable flow conditions. A decisive step in this regard was made by Azuma and Higashi (1985), who empirically discovered that, under 
common natural conditions, the strain in an ice grain is generally proportional to the resolved shear stress on its basal plane. Based on this result, they derived the first successful theoretical model of LPO evolution by lattice rotation in polar ice (subsequently extended by Frujita et al., 1987; Alley, 1988; Lipenkov et al., 1989). Later, this model would serve as basis for Azuma's ice flow model (Azuma, 1994, 1995; Azuma and Goto-Azuma, 1996), which is still today one of the most popular approaches for describing the anisotropic flow of glaciers and ice sheets.

Finally, by combining Azuma and Higashi's (1985) lattice rotation model and Kamb's (1972) extension of Perutz' thermodynamic interpretation of recrystallization, Alley $(1988,1992)$ managed to merge several ideas about polar ice microstructure evolution, which were emerging in the ice-core community during the 1970's and 1980's, into the simple and self-consistent version of the tripartite paradigm (cf. Sect. 3.3 of Part I) that many glaciologists still adopt today (when consulting the works by Alley, 1988, 1992, the reader should have in mind that he used the terms "recrystallization" and "polygonization" as loose synonyms for "nucleation" and "rotation recrystallization," respectively). The establishment of this paradigm brought order to what was a rather chaotic topic, providing the framework for the development of models of microstructure evolution and anisotropic flow of ice sheets (Van der Veen and Whillans, 1994; Azuma and Goto-Azuma, 1996; Gödert and Hutter, 1998; Montagnat and Duval, 2000; Staroszczyk and Morland, 2001; Faria et al., 2002; Thorsteinsson, 2002).

In spite of being as welcome and needed as it was, today we know that the tripartite paradigm is fundamentally wrong. Besides the arguments put forward in Sect. 3.3, recent observations have shown that rotation recrystallization (RRX) and migration recrystallization with and without nucleation (SIBM-N and SIBM- 
O, respectively, cf. Appendix A) are widespread phenomena in polar ice sheets and take place already in firn (e.g. Figs. C.5, C.7, C.8 and C.11; Kipfstuhl et al., 2006, 2009; Faria et al., 2009, 2010; Weikusat et al., 2009a,b, 2011). Nucleation is not predominant in polar ice, but newly nucleated grains can be found regularly in ice-core samples from any depth, and are specially frequent in samples from the lower firn. Nucleation occurs via SIBM-N through the formation of pseudo-nuclei (cf. Appendix A) at localized sites characterized by high internal stresses and large misorientation gradients, like e.g. at grain boundaries, triple junctions, and similar regions characterized by high concentrations of dislocation walls and subgrain boundaries. Most frequently the newly nucleated grain seems to grow from the boundary towards the inside of the parent grain, but nuclei formed at grain boundary bulges or corners that grow over the neighbouring grains are also common (e.g. Figs. C.3, C.5, and C.8a,b). Much more rare are nucleated islands, which are new grains or subgrains formed inside a very distorted parent grain, characterized by an entangled network of dislocation walls and subgrain boundaries, which combine to form the boundaries of the new nucleus (Figs. C.5 and C.11).

Ordinary migration recrystallization (SIBM-O; i.e. strain-induced boundary migration without nucleation of new grains, cf. Appendix A) and grain boundary pinning are ubiquitous in polar ice. In micrographs, the migration direction of a moving grain boundary can often be easily identified by the curved shape of the boundary and the presence of subgrain boundaries and dislocation walls, which are predominantly found at the convex side of the moving boundary (Figs. C.5, C.8, and C.11). Polar ice grains are generally irregular in shape, evidencing the essential role of stored strain energy on the microstructure evolution at all depths. Pinning is most frequently caused by subgrain boundaries, air hydrates, air bub- 
bles and firn pores. Particularly interesting is the pinning by microinclusions: in the upper ice, where the temperature is below ca. $-10^{\circ} \mathrm{C}$, it is difficult to find evidence of pinning by individual microinclusions, except occasionally in some grain boundaries in the strongest cloudy bands. Consequently, the explanation for the typical fine-grained structure of cloudy bands (cf. Fig. A.4 of Part I) remains uncertain. In contrast, as the temperature rises above $-10^{\circ} \mathrm{C}$ in deep ice, most microinclusions can be found at grain boundaries and at the interfaces between ice and air hydrates (Fig. C.12). Possible causes of these intriguing phenomena are analysed in detail by Faria et al. (2010).

\subsection{The dynamic recrystallization diagram}

As a substitute for the old tripartite paradigm, we propose the dynamic recrystallization diagram in Fig. C.13, which summarizes the various recrystallization processes that contribute to the microstructure evolution of polar ice, as regions in the three-dimensional state space $\mathcal{S}=\{\dot{\varepsilon}, T, D\}$ of strain rate $\dot{\varepsilon}$, temperature $T$, and mean grain size $D$.

The main feature of this diagram is the attractor surface $D=D_{\mathrm{ss}}(\dot{\varepsilon}, T)$, which describes the grain size at steady state, $D_{\mathrm{ss}}$, as a function of $T$ and $\dot{\varepsilon}$. This attractor surface works as follows: in a general situation, the mean grain size $D$ of a piece of ice evolves according to the kinetic function $D=\chi(\dot{\varepsilon}, T, t)$. Thus, for fixed conditions of temperature and strain rate, the mean grain size may evolve in time by recrystallization, provided that

$$
\frac{\partial D}{\partial t}=\frac{\partial}{\partial t} \chi(\dot{\varepsilon}, T, t) \neq 0
$$

The explicit form of the kinetic function $\chi$ depends on the active recrystallization processes and cannot be easily determined. However, one thing we know about 
1150

(19), namely

$$
\frac{\partial D}{\partial t} \begin{cases}>0 \text { (grain growth) } & \text { if } D<D_{\mathrm{ss}} \\ <0 \text { (grain reduction) } & \text { if } D>D_{\mathrm{ss}} \\ =0(\text { steady state) } & \text { if } D=D_{\mathrm{ss}}\end{cases}
$$

Thus, $D_{\text {ss }}$ defines an attractor surface in the state space $\mathcal{S}$ which reduces the kinetic function $D=\chi(\dot{\varepsilon}, T, t)$ to the steady state relation $D=D_{\mathrm{ss}}(\dot{\varepsilon}, T)$ when the mean grain size achieves its steady-state value.

The derivation of the explicit form of $D_{\mathrm{ss}}(\dot{\varepsilon}, T)$ is really straightforward. First we recall that $D_{\text {ss }}$ should obey the empirical relation (2). Second, we combine this relation with Glen's flow law (5), setting $n=3$ as usual. Finally, using the Arrhenius-like equation (9) we obtain

$$
D_{\mathrm{ss}}(\dot{\varepsilon}, T)=\left(\frac{\alpha \varphi}{\dot{\varepsilon}}\right)^{\frac{1}{2}} e^{-Q / 2 k_{\mathrm{B}} T} .
$$

For the sake of illustration, let us consider the case of a hypothetical ice core, whose mean grain size evolves with depth as depicted by the green-and-red curves in Fig. C.13. If the conditions of temperature and strain rate were constant throughout the core, the mean-grain-size path in $\mathcal{S}$ would be a straight, vertical line hitting the attractor surface $D_{\text {ss }}$ and stopping there. This would correspond to grain growth until the steady-state grain size $D_{\text {ss }}$ is achieved. However, in this hypothetical core we assume that the temperature increases with depth (which is the expected physical behaviour within an ice sheet) whereas, for simplicity, the strain rate remains nearly constant. As a consequence, the mean-grain-size path in $\mathcal{S}$ follows not only upwards, but also sidewards, in the direction of higher temperatures (green part of the curve). Once it hits the attractor surface $D_{\mathrm{ss}}$, it continues its trajectory towards higher temperatures, without moving away from 
the surface (red part of the curve). Thus, after the mean grain size achieves its steady-state value, further grain growth with depth is caused by the increase of $D_{\text {ss }}$ with temperature, as described by (21).

Finally, one could imagine a situation where the attractor surface $D_{\text {ss }}$ is shifted by a sudden change in strain rate or temperature (or impurity content, if we allow $\alpha$ to depend on it). This situation is not illustrated in the example, but it is not difficult to realize that in this case the microstructure would turn into a non-steady state and would start once again to pursue the attractor surface $D_{\text {ss }}$, through a suitable growth or reduction of grain size.

The zones of influence in $\mathcal{S}$ of the different recrystallization mechanisms are illustrated in Fig. C.14. Owing to the difficulty in visualizing and portraying such zones in three dimensions, we present here only three cross sections of $\mathcal{S}$. Depicted are the regions in the state space where a particular process dominates. It is important to notice, however, that these zones have no sharp boundaries and they do overlap in most part of $\mathcal{S}$. In fact, the typical situation is that various processes occur simultaneously and compete with or complement each other. The only exception is Normal Grain Growth (NGG), which is possible only on the plane $\mathcal{S}_{\mathrm{NGG}}=\{\dot{\varepsilon}=0, T, D\}$.

\section{Conclusion}

Compared to glaciers and other natural ice bodies, polar ice sheets offer many advantages for the study of natural ice microstructure evolution. In particular, the history of stress and temperature conditions experienced by a piece of polar ice is generally much longer, simpler and more steady than it would be in a glacier. This facilitates considerably the interpretation of deformation and recrys- 
tallization microstructures. Therefore, polar ice cores have become instrumental in microstructure investigations of natural ice.

In this work we reviewed our current knowledge of the mechanics and microstructure of natural ice. The main conclusions can be summarized as follows:

- Almost a half-century ago the tripartite paradigm of polar ice microstructure started to take form (also known as the "three-stage model"; Sect. 3.3 of Part I and Sect. 3.3). It would soon turn into the main cornerstone of our understanding of natural ice microstructures, establishing a concrete and sought-after research program on structural glaciology that is still pursued today. Notwithstanding, in spite of being as welcome and needed as it was, a large body of evidence has accumulated over the last decade, which reveals fundamental flaws in that paradigm.

- One fundamental premise of the tripartite paradigm that has to be critically reconsidered is the belief that only normal grain growth (NGG) can lead to grain coarsening. As discussed here and in Part I, a typical feature of polar ice cores is indeed the tendency towards an increase of the mean grain size with depth and age of the ice (modulated by climate changes). However, as we learn that microstructures characteristic of dynamic recrystallization abound in polar ice, we have to face the fact that dynamic recrystallization can also lead to grain coarsening, through a set of processes collectively named dynamic grain growth (cf. Appendix A).

- The growth rates and activation energy for grain growth extracted directly from ice-core data agree well with the rates and energy obtained in grain growth experiments with bubbly ice, but are in clear disagreement with the 
real values of these quantities, recently measured in controlled experiments of normal grain growth in pure, unstrained, bubble-free ice. These conclusions, together with independent results of recent numerical simulations of normal grain growth in ice, corroborate the dynamic nature of grain growth in ice sheets, in the sense that it occurs during deformation and is seriously affected by the stored strain energy, as well as by air inclusions and other impurities.

- The strong plastic anisotropy of the ice lattice gives rise to high internal stresses and concentrated strain heterogeneities in the polycrystal, which demand large amounts of strain accommodation. From the microstructural analyses of ice cores, we conclude that the formation of many and diverse subgrain boundaries and the splitting of grains by rotation recrystallization are the most fundamental mechanisms of dynamic recovery and strain accommodation in polar ice. Subgrain boundaries are endemic and very frequent at almost all depths in polar ice sheets.

- In addition to subgrain formation (i.e. grain subdivision) and rotation recrystallization, microstructural analyses of polar ice cores suggest that strain in fine-grained, high-impurity ice layers (e.g. cloudy bands) can sometimes be accommodated by diffusional flow (at low temperatures and stresses) or microscopic grain boundary sliding via microshear (in anisotropic ice sheared at high temperatures).

- Evidence of recrystallization with nucleation of new grains is observed at various depths in the ice sheet, provided that the concentration of strain energy is high enough (which is not seldom the case). Nucleation seems par- 
ticularly frequent in the lower firn layers, where the pore space is still large enough to weaken the ice matrix, but already small enough to allow considerable interaction between incompatible grains. As in other polycrystalline materials, nucleation does not happen in the classical sense of spontaneous embryo formation, but rather through a combination of recovery and recrystallization processes (grain boundary migration, subgrain rotation and growth, etc.) within very localized regions with large misorientation gradients. For this reason, we call this process nucleated migration recrystallization (SIBM-N; cf. Appendix A).

- As a substitute for the tripartite paradigm, we propose a novel dynamic recrystallization diagram in the three-dimensional state space of strain rate, temperature, and mean grain size (Figs. C.13 and C.14). This diagram summarizes the various competing recrystallization processes that contribute to the evolution of the polar ice microstructure.

Afterword. We dedicate this work to the 60th birthday of Sepp Kipfstuhl, whose views have inspired many ideas introduced here. Sepp has been a key personality of European glaciology in the last 30 years, having participated in more than 25 polar expeditions to date (authors' conservative estimate), including the First West-German Antarctic Research Overwintering (Georg von Neumeyer Station, Ekström Ice Shelf, 1981-83) and all European deep-drilling projects in Greenland and Antarctica since GRIP (cf. Table B.1 of Part I). In the early 1990s he played a decisive role in the partnership between European GRIP and U.S. GISP2 scientists (Sect. 4.2 of Part I) and since then he has investigated the physical properties of ice cores, often as the scientist in charge. Through his ingenious approach to 
observation and legendary devotion to ice, Sepp continues to inspire generations of scientists and to make ground-breaking findings about the microstructure of polar ice and firn.

\section{Appendix A. Glossary}

Below we summarize the main concepts and definitions used in this work for discussing ice mechanics and microstructure. They are based on the definitions put forward by Faria et al. (2009) and are partially inspired by the terms used in geology and materials science by Poirier (1985), Drury and Urai (1990), Bunge and Schwarzer (2001), Humphreys and Hatherly (2004), and Passchier and Trouw (2005).

Clathrate hydrate: Crystalline compound containing guest molecules enclosed in cagelike structures made up of hydrogen-bonded water molecules. When the guest molecules form gas under standard conditions, such compounds are also named gas hydrates. In particular, air hydrates are formed by atmospheric gases (viz. mainly $\mathrm{O}_{2}$ and $\mathrm{N}_{2}$ ). In natural ice, air hydrates are formed below a critical depth, which is fundamentally a function of the overburden pressure and temperature.

Cloudy band: Ice stratum with turbid appearance due to a high concentration of microinclusions. Experience shows a strong correlation between high impurity concentration and small grain sizes in cloudy-band ice.

Crystallite: See grain.

Deformation-related structures: Structural features produced and/or affected by deformation, e.g. dislocations, subgrain boundaries, slip bands, stratigraphic folds, etc.

Diffusion creep: See diffusional flow.

Diffusional flow: Strain caused by diffusional flux of matter through the material. In 
polycrystals, diffusional flow may involve mass transport through or around the grains. The former is named lattice diffusion creep (or Nabarro-Herring creep), while the latter is called grain-boundary diffusion creep (or Coble creep).

Dislocation wall: Deformation-related structure consisting of dislocations arranged in a two dimensional framework; the precursor of a subgrain boundary (cf. id.).

DML: Dronning Maud Land, Antarctica.

Dynamic grain growth (DGG): Class of phenomenological processes of grain coarsening in polycrystals during deformation. Several recovery and recrystallization processes may be simultaneously active during DGG, all competing for the minimization of both, the stored strain energy and the grain-boundary energy. The essential feature of DGG (in comparison to other recrystallization processes) is the monotonic increase of the mean grain size with time. Owing to its dynamic nature, however, the diversified kinetics of DGG can generally not be compared with the simple kinetics predicted for normal grain growth (NGG, cf. id.).

Dynamic recrystallization: See recrystallization.

EDC: EPICA Dome C (a deep-drilling site in Antarctica).

EDML: EPICA DML (a deep-drilling site in Antarctica).

Elementary structural process: The fundamental operation of structural change via recovery or recrystallization, e.g. grain boundary migration or subgrain rotation. Several elementary processes may combine in a number of ways to produce a variety of phenomenological structural processes (cf. id.).

Note A.1: Recovery and recrystallization are complex physical phenomena that are better understood if decomposed in a hierarchy of structural processes or mechanisms, here qualified as "elementary" and "phenomenological." A somewhat similar hierarchical scheme for recrystallization has formerly been proposed by Drury 
and Urai (1990), but with the expressions "elementary/phenomenological process" replaced respectively by "basic process" and "mechanism". We favor here the qualifiers "elementary/phenomenological" (against the "process/mechanism" scheme) because these qualifiers facilitate the visualization of the hierarchy and leave us free to use the terms "process" and "mechanism" as synonyms.

EPF: Expéditions Polaires Françaises.

EPICA: European Project for Ice Coring in Antarctica.

Fabric: See Lattice Preferred Orientation (LPO).

Firn: Sintered snow that has outlasted at least one summer.

GBS: See grain boundary sliding.

GISP2: Greenland Ice Sheet Project 2 (a deep-drilling site in Greenland).

Grain: Connected region in a polycrystalline solid composed of an uninterrupted (although possibly imperfect) crystalline lattice and bounded to other grains by grain boundaries. Also loosely called crystallite. It should be noticed the difference between grains of polycrystalline solids (e.g. ice) and the lose particles of crystalline granular media (e.g. snow).

Grain Boundary Sliding (GBS): Relative slide of a pair of grains by a shear movement at their common interface. The shear may be completely confined to the boundary, or occur within a zone immediately adjacent to it.

Grain stereology: Spatial arrangement of grains in a polycrystal, including their sizes and shapes (cf. orientation stereology and lattice preferred orientation).

Grain subdivision: Phenomenological recovery process of formation of new subgrain boundaries. It involves the progressive rotation of certain portions of the grain, called subgrains (cf. id.), as well as the strengthening of dislocation walls through dislocation rearrangement and migration in regions with strong lattice curvature. If the 
misorientation across the new subgrain boundary increases with time, grain subdivision may give rise to rotation recrystallization (cf. id.).

GRIP: Greenland Ice-core Project (a deep-drilling site in Greenland).

Inclusion: Locallized deposit of undissolved chemical impurities observed in polar ice, like air bubbles, clathrate hydrates, or brine pockets. Inclusions not larger than a few micrometers are often called microinclusions (e.g. dust particles, microbubbles, etc.).

Isotropic ice: In full isotropic polycrystalline ice. Ice with isotropic and homogeneous orientation stereology (cf. id.). In other words, homogeneous polycrystalline ice with no $L P O$ (cf. id.).

JIRP: Juneau Ice Field Research Project.

Lattice Preferred Orientation (LPO): Statistically preferred orientation of the crystalline lattices of a population of grains. In plural (LPOs): the directional pattern of lattice orientations in a polycrystalline region (cf. orientation stereology). In the glaciological literature, LPOs are often called fabric (Paterson, 1994), while in materials science they are frequently termed texture (Humphreys and Hatherly, 2004). In particular, a polycrystalline region with a random distribution of lattice orientations is said to have no LPO (viz. texture-free, random fabric).

LPO: See lattice preferred orientation.

Microbubble: Air bubble not larger than a critical diameter of ca. $100 \mu \mathrm{m}$ in shallow ice. The critical diameter is usually defined by the typically bimodal size distribution of air bubbles in natural ice. For deeper ice, the critical diameter reduces with the increasing overburden pressure. See also inclusion.

Microinclusion: See inclusion.

Microshear: Strong, localized shear across a grain that experiences a highly inhomogeneous shear deformation. It culminates with the formation of a new, flat subgrain 
boundary parallel to the shear plane, called microshear boundary (cf. slip bands). Microshear is often triggered by grain boundary sliding (cf. id.).

Microstructure: Collection of all microscopic deformation-related structures, inclusions, and the orientation stereology of a polycrystal.

Migration recrystallization: In full strain-induced migration recrystallization. Class of phenomenological recrystallization processes based on the elementary SIBM mechanism (cf. id.). If nucleation (cf. id.) is involved in the process, we may call it nucleated migration recrystallization (SIBM-N), where the suffix “-N" stands for "new grain". Otherwise, i.e. if the migration of boundaries occurs without formation of new grains, we may call it ordinary migration recrystallization (SIBM-O), where the suffix "-O" stands for "old grain".

Note A.2: The definition adopted here is based on the concept of "grain-boundary migration recrystallization" originally described in the pioneering work by Beck and Sperry (1950). Notice that this definition is not identical to that used by Poirier (1985) or Humphreys and Hatherly (2004), and it is also quite distinct from some loose connotations invoked in the glaciological literature. The terms SIBM-N and SIBM-O are not standard in the literature, but they are nevertheless adopted here because they describe quite precisely the kind of information obtained from microscopic analyses of ice core sections. There is unfortunately no one-to-one relation between SIBM-N/SIBM-O and the expressions "multiple/single subgrain SIBM" used e.g. by Humphreys and Hatherly (2004).

NBSAE: Norwegian-British-Swedish Antarctic Expedition.

NGRIP: North-Greenland Ice-Core Project, also abbreviated as NorthGRIP (a deepdrilling site in Greenland).

Normal grain growth (NGG): Phenomenological recrystallization process of grain coarsening in polycrystals, resulting from "the interaction between the topological require- 
ments of space-filling and the geometrical needs of (grain-boundary) surface-tension equilibrium" (Smith, 1952). By definition, grain coarsening during NGG is statistically uniform and self-similar, grain-boundary migration is exclusively driven by minimization of the grain-boundary area (and associated free energy), and the grain stereology is close to a configuration of "surface-tension equilibrium" (so-called "foamlike structure"). Owing to these essential features, NGG is generally regarded as a static recrystallization process (cf. recrystallization) taking place before/after deformation (cf. dynamic grain growth). Mathematical and physical arguments strongly suggest that the kinetics of NGG is parabolic with respect to the mean grain radius. Note A.3: As discussed by Smith (1952), the interest in NGG comes from the fact that its kinetics depends solely on the properties of the migrating boundaries and is otherwise independent of the medium or its deformation history. This means that the theory underlying the NGG kinetics is not restricted to polycrystals: similar coarsening phenomena are also observed in foams, some tissues, and many other cellular media.

Nucleation: Class of phenomenological recrystallization processes involving the formation of new nuclei (viz. tiny strain-free new grains). Two types of nucleation mechanisms can be identified, here called "pseudo-" and "classical nucleation". During classical nucleation a cluster of atoms/molecules spontaneously form a new embryo (the precursor of a nucleus) under the action of high internal stresses and thermallyactivated fluctuations. Despite persistent consideration of this mechanism in the glaciological literature, it is currently acknowledged that it is certainly not relevant for polar ice (see Note A.4 below). During pseudo-nucleation a special combination of elementary recrystallization processes (e.g. SIBM, subgrain rotation and growth) takes place within a small crystalline region with high stored strain energy, giving rise to a little strain-free new grain called pseudo-nucleus (see Note A.5 below). If pseudonucleation occurs naturally in polar ice, it most likely happens at grain boundaries and 
other zones of high stored strain energy, e.g. at air bubbles and solid inclusions. Note A.4: Calculations show (Cahn, 1970; Humphreys and Hatherly, 2004) that classical nucleation recrystallization is extremely unlikely to occur in single-phase polycrystals, owing to the high energies required for the creation and growth of classical nuclei, except if strong chemical driving forces are present, which is clearly not the case for polar ice.

Note A.5: The prefix "pseudo-" is used here to emphasize that this nucleus is usually much larger than the nucleus formed by classical nucleation, but still small enough to be strain-free. It should be noticed that the distinction between pseudo-nucleation and a combination of SIBM-O with rotation recrystallization is basically a matter of scale: in the latter case the new crystallite is large enough to inherit a considerable amount of internal structures from the parent grain.

Orientation stereology: Spatial arrangement of lattice orientations in a polycrystal, i.e. the combination of grain stereology and LPO.

Phenomenological structural process: Any combination of elementary structural processes that gives rise to general changes in the structure of the polycrystal (cf. elementary structural process). Examples of phenomenological processes are nucleation and grain subdivision.

Polygonization: Special type of recovery mechanism for the formation of tilt boundaries. It is a particular case of grain subdivision (cf. id.), by restricting it to tilting (bending) of crystallographic planes. In ice, polygonization is often used in reference to the bending of basal planes.

Pseudo-nucleus: See nucleation.

Recovery: Release of the stored strain energy by any thermomechanical process of microstructural change other than recrystallization. The qualifiers dynamic and static denote recovery phenomena occurring during and prior/after deformation, respectively. 
Frequently (especially under dynamic conditions), recovery and recrystallization coexist and may even be complementary (e.g. during rotation recrystallization), so that the distinction between them is sometimes very difficult.

Recrystallization: Any re-orientation of the lattice caused by grain boundary migration and/or formation of new grain boundaries, therefore including SIBM, RRX, DGG and NGG (cf. recovery and Note A.6 below). The qualifiers dynamic and static denote recrystallization phenomena occurring during and prior/after deformation, respectively. Further classification schemes often invoked in the literature include the qualifiers continuous/discontinuous and continual/discontinual, used to specify, respectively, the spatial homogeneity and temporal continuity of the recrystallization process. These classifications are, however, not always unique and are therefore of limited use.

Note A.6: In contrast to the definition adopted here, some authors reserve the term "recrystallization" solely for those processes driven by the stored strain energy, therefore excluding e.g. normal grain growth (NGG, cf. id.) from its definition. Other authors (especially in the older literature) loosely use "recrystallization" as a synonym for SIBM-N (cf. migration recrystallization).

Rotation recrystallization (RRX): Phenomenological recrystallization process responsible for the formation of new grain boundaries. It proceeds from the mechanism of grain subdivision, and as such it involves the progressive rotation of subgrains as well as the migration of subgrain boundaries through regions with lattice curvature. Notice that this recrystallization process does not require significant migration of pre-existing grain boundaries, in contrast to migration recrystallization.

SIBM: See strain-induced boundary migration.

SIBM-N/SIBM-O: See migration recrystallization.

Slip bands: Series of parallel layers of intense slip activity and high amount of intracrys- 
talline lattice defects (especially dislocations). Slip bands in ice appear always in groups parallel to the basal planes and are indicative of a nearly homogeneous shear deformation of the respective grain (cf. microshear).

\section{Static recrystallization: See recrystallization.}

Stored strain energy: Fraction of the mechanical energy expended during deformation that is stored in the material in diverse types of intracrystalline lattice defects, e.g. dislocations, stacking faults, subgrain boundaries, etc.

Strain-induced boundary migration (SIBM): Elementary recrystallization process of grain boundary motion driven by minimization of the stored strain energy. It involves the migration of a grain boundary towards a region of high stored strain energy. The migrating boundary heals the highly energetic lattice defects in that region, therefore promoting a net reduction in the total stored strain energy of the polycrystal. See also migration recrystallization.

Subglacial structure: Any structural feature underneath the ice, ranging from till and rocks to channels and lakes.

Subgrain: Sub-domain of a grain, delimited by a subgrain boundary and characterized by a lattice orientation that is similar, but not identical, to that of the rest of the grain. In ice, the lattice misorientation across a subgrain boundary is limited to a few degrees (ca. $<5^{\circ}$ for ice; (Suzuki, 1970; Weikusat et al., 2011)).

Texture: See Lattice Preferred Orientation (LPO).

Tilt boundary: Special type of subgrain boundary in which the misorientation axis is tangential to the boundary interface.

Twist boundary: Special type of subgrain boundary in which the misorientation axis is orthogonal to the boundary interface. 


\section{Appendix B. Deformation of EDML firn}

It is a common misconception that the firn zone is one of the least stressed parts of an ice sheet. In fact, rather the contrary is true. Although the overburden pressure on firn is much less than on deep ice, it is still large enough to promote the slow but relentless compaction of the delicate porous structure. Besides, the firn layer is continually stretched by the flowing ice underneath. These two processes combine to generate strain rates in firn that are much larger than in bulky ice.

In the snow and shallow firn zones, the dominant metamorphic process is the rearrangement and packing of old snow particles via boundary sliding (Alley, 1987). As the firn approaches a mass density of ca. $550 \mathrm{~kg} / \mathrm{m}^{3}$ (which corresponds to a packing fraction of $\phi=0.6$, very close to that of the maximally random jammed state, $\phi_{\mathrm{MRJ}} \approx 0.63$; Kansal et al., 2002), the dominant sintering mechanism changes to plastic deformation of the consolidated porous material via intracrystalline creep (Anderson and Benson, 1963; Maeno and Ebinuma, 1983). At the EDML site, this critical mass density is reached at around $20 \mathrm{~m}$ depth (Kipfstuhl et al., 2009), although recent computer tomographic analyses suggest that this transition could start already at $10 \mathrm{~m}$ depth, where the firn has an average mass density of only $475 \mathrm{~kg} / \mathrm{m}^{3}$ (Freitag et al., 2008). The creep of firn proceeds this way for hundreds of years, so that, in the lower half of the firn zone, typical values of the total vertical strain lie in the range of several tens percent.

From the supplementary material accompanying the work by Ruth et al. (2007), we estimate that the total vertical strain of the lower firn in the EDML site ranges between $-20 \%$ and $-50 \%$. It is evident that most of this thinning is actually caused by the compression of the pore space. This compression, however, cannot occur without plastic deformation of the ice matrix. It is very difficult to determine 
with precision the contribution to total vertical strain due to plastic deformation of the ice matrix alone. In the case of EDML, one possibility is to combine the true annual layer thickness with the ice-equivalent layer thickness and the estimated age of the layer (all data provided by Ruth et al., 2007) as follows

$$
\varepsilon=\ln \left(1+\varepsilon_{\mathrm{e}}\right), \quad \varepsilon_{\mathrm{e}}=\frac{y_{0}-y}{y},
$$

where $\varepsilon$ and $\varepsilon_{\mathrm{e}}$ are respectively the natural vertical strain and the engineering vertical strain of the layer, while $y$ and $y_{0}$ denote the number of years enclosed in the strained layer and in the reference layer, respectively. Using these formulas we conclude that the polycrystalline ice skeleton of the lower firn at EDML is already in the tertiary creep regime (cf. Sect. 3.1), and consequently it could be undergoing dynamic recrystallization. Indeed, even if we make a very conservative choice for the reference depth, by assuming that the ice matrix starts to creep only below $20 \mathrm{~m}$ depth, we still get $\varepsilon_{\text {i.eq. }} \approx-7 \%$ for the ice-equivalent vertical strain at only $50 \mathrm{~m}$ depth. For comparison, the total vertical strain of firn at this depth (i.e., including pore-space compression) is around $\varepsilon_{\text {total }} \approx-30 \%$. Recalling that it takes about 300 years for the EDML ice to traverse the depth interval 20-50 m, we conclude that the average ice-equivalent vertical strain rate should be about $\dot{\varepsilon}_{\text {i.eq. }} \approx 7.4 \times 10^{-12} \mathrm{~s}^{-1}$. Likewise, the average total strain rate of the firn layer, including pore-space compaction, should be around $\dot{\varepsilon}_{\text {total }} \approx 3.2 \times 10^{-11} \mathrm{~s}^{-1}$.

Admittedly, these are very crude estimates. However, it should be noticed that almost all the above inaccuracies can be blamed for being too conservative, that is, for introducing bias against dynamic recrystallization in polar firn. For instance:

- The reference depth is likely to be shallower than the one selected here. More realistic estimates point to $10-12 \mathrm{~m}$. 
- In practice, the shallow firn above the reference depth may also experience a certain amount of intracrystalline deformation, even though boundary sliding is the dominant deformation mechanism in that zone.

- The ice-equivalent estimates do not take into account the contribution of the pore space to strain accommodation.

- The deformation of firn is know to be extremely inhomogeneous. It is characterized by large strain variability with depth and intense stress concentrations, both influenced by the intricate geometry of the pore space. Therefore, the stored strain energy is likely to be very high in particular regions of the ice skeleton, where rotation and migration recrystallization may start very early.

Thus, we conclude that the real strain rate $\dot{\varepsilon}_{\text {real }}$ experienced by the ice grains in firn should be $\dot{\varepsilon}_{\text {total }} \geq \dot{\varepsilon}_{\text {real }} \geq \dot{\varepsilon}_{\text {i.eq. }}$.

The last item above explains also why the $c$-axis distributions in lower firn are generally random, with no evident preferred orientations: the stress field within the ice skeleton is rather complex, with a high spatial variability controlled by the geometry of the pore space. Therefore, the stresses perceived by the ice on the grain scale are generally very distinct from the applied macroscopic stress. Even if preferred orientations are formed on the scale of several grains, the spatial variability of stress and strain are sufficient to mask any preferred orientations on the macroscale. Evidently, dynamic recrystallization with nucleation of new grains can also contribute to suppress the formation of preferred orientations in firn.

Thus, the fact that the above estimates do support the occurrence of dynamic 
recrystallization in firn, in spite of all the bias against such a conclusion, just makes the arguments presented here stronger. Finally, we remark that these conclusions are coherent with the experimental observations of dynamic recrystallization in firn by Kipfstuhl et al. (2009).

\section{Acknowledgements}

The authors thank Daniel Koehn (Special Issue Editor), Jens Roessiger and an anonymous reviewer for insightful revisions, as well as Tim Horscroft (Review Papers Coordinator) and Joao Hipertt (Editor) for managing the submission and publication process. Thanks go also to Daniela Jansen and Christian Weikusat for discussions and assistance in the preparation of some figures. Special thanks to Atsushi Miyamoto for discussions and for kindly providing the micrographs of Dome F deep ice core. Support from ESF Research Networking Programme Micro-Dynamics of Ice (Micro-DICE) is gratefully acknowledged. IW acknowledges also financial support by the German Research Foundation (HA 5675/1-1, WE 4695/1-2) via SPP 1158 and by the Helmholtz Association (VH-NG-802).

\section{References}

Ahmad, S., Whitworth, R. W., 1988. Dislocation motion in ice: a study by synchrotron X-ray topography. Philos. Mag. A 57 (5), 749-766.

Alley, R. B., 1987. Firn densification by grain boundary sliding: a first model. J. Phys. (Paris) 48 (C1), 249-256.

Alley, R. B., 1988. Fabrics in polar ice sheets: development and prediction. Science $240,493-495$. 
Alley, R. B., 1992. Flow-law hypothesis for ice-sheet modelling. J. Glaciol. 38, $245-256$.

Alley, R. B., Gow, A. J., Meese, D. A., 1995. Mapping c-axis fabrics to study physical processes in ice. J. Glaciol. 41 (137), 197-203.

Alley, R. B., Perepezko, J. H., Bentley, C. R., 1986a. Grain growth in polar ice: I. Theory. J. Glaciol. 32 (112), 415-424.

Alley, R. B., Perepezko, J. H., Bentley, C. R., 1986b. Grain growth in polar ice: II. Application. J. Glaciol. 32 (112), 425-433.

Alterthum, H., 1922a. Zur Theorie der Rekristallisation. Z. Metallk. 14 (11), 417424.

Alterthum, H., 1922b. Zur Theorie der Rekristallisation. Z. Elektrochem. Angew. Phys. Chem. 28 (15-16), 347-356.

Anderson, D. L., Benson, C. S., 1963. The densification and diagenesis of snow. In: Kingery, W. D. (Ed.), Ice and Snow. MIT Press, Cambridge, MA, pp. 391411.

Andrade, E. N. d. C., 1910. On the viscous flow in metals, and allied phenomena. Proc. Roy. Soc. London A 84, 1-12.

Ashby, M. F., 1966. Work hardening of dispersion-hardened crystals. Philos. Mag. 14 (132), 1157-1178.

Azuma, N., 1994. A flow law for anisotropic ice and its application to ice sheets. Earth Planet. Sci. Lett. 128, 601-614. 
Azuma, N., 1995. A flow law for anisotropic polycrystalline ice under uniaxial compressive deformation. Cold Reg. Sci. Technol. 23 (2), 137-147.

Azuma, N., Goto-Azuma, K., 1996. An anisotropic flow law for ice-sheet ice and its implications. Ann. Glaciol. 23, 202-208.

Azuma, N., Higashi, A., 1985. Formation processes of ice fabric patterns in ice sheets. Ann. Glaciol. 6, 130-134.

Azuma, N., Miyakoshi, T., Yokoyama, S., Takata, M., 2012. Impeding effect of air bubbles on normal grain growth of ice. J. Struct. Geol. 42, 184-193.

Azuma, N., Wang, Y., Mori, K., Narita, H., Hondoh, T., Shoji, H., Watanabe, O., 1999. Textures and fabrics in the Dome F (Antarctica) ice core. Ann. Glaciol. 29, 163-168.

Azuma, N., Wang, Y., Yoshida, Y., Narita, H., Hondoh, T., Shoji, H., Watanabe, O., 2000. Crystallographic analysis of the Dome Fuji ice core. In: Hondoh, T. (Ed.), Physics of Ice Core Records. Hokkaido University Press, Sapporo, pp. $45-61$.

Bader, H., 1951. Introduction to ice petrofabrics. J. Geol. 59 (6), 519-536.

Barnes, P., Tabor, D., Walker, J. C. F., 1971. The friction and creep of polycrystalline ice. Proc. Roy. Soc. London A 324, 127-155.

Barrette, P. D., Sinha, N. K., 1994. Lattice misfit as revealed by dislocation etch pits in a deformed ice crystal. J. Mater. Sci. Letters 13, 1478-1481.

Bartels-Rausch, T., Bergeron, V., Cartwright, J. H. E., Escribano, R., Finney, J. L., Grothe, H., Gutierrez, P. J., Haapala, J., Kuhs, W. F., Pettersson, J. B. C., Price, 
S. D., Sainz-Diaz, C. I., Stokes, D., Strazzulla, G., Thomson, E. S., Trinks, H., , Uras-Aytemiz, N., 2012. Ice structures, patterns, and processes: A view across the icefields. Reviews of Modern Physics.

URL http://link.aps.org/doi/10.1103/RevModPhys.84.885

Beck, P. A., Sperry, P. R., 1950. Strain induced grain boundary migration in high purity aluminum. J. Appl. Phys. 21, 150-152.

Bernal, J. D., Fowler, R. H., 1933. A theory of water and ionic solution, with particular reference to hydrogen and hydroxyl ions. J. Chem. Phys., 515-548.

Bons, P. D., Jessell, M. W., 1999. Micro-shear zones in experimentally deformed octachloropropane. J. Struct. Geol. 21, 323-334.

Bryant, G. W., Mason, B. J., 1960. Etch pits and dislocations in ice crystals. Phil. Mag., Structure and Properties of Condensed Matter 5 (8), 1221-1227.

Budd, W. F., 1972. The development of crystal orientation fabrics in moving ice. Z. Gletscherkunde Glazialgeol. 8 (1-2), 65-105.

Budd, W. F., Jacka, T. H., 1989. A review of ice rheology for ice sheet modelling. Cold Reg. Sci. Technol. 16, 107-144.

Bunge, H. J., Schwarzer, R. A., 2001. Orientation stereology-a new branch in texture research. Adv. Eng. Mater. 13 (1-2), 25-39.

Burg, J. P., Wilson, C. J. L., Mitchell, J. C., 1986. Dynamic recrystallization and fabric development during the simple shear deformation of ice. J, Struct. Geol. $8(8), 857-870$. 
Burrows, S., Humphreys, J., White, S., 1979. Dynamic recrystallization. a comparison between magnesium and quartz. Bull. Minéral. 102, 75-79.

Cahn, J. W., Taylor, J. E., 2004. A unified approach to motion of grain boundaries, relative tangential translation along grain boundaries, and grain rotation. Acta Mater. 52, 4887-4898.

Cahn, R. W., 1970. Recovery and recrystallization. In: Cahn, R. W. (Ed.), Physical Metallurgy. North-Holland, Amsterdam, pp. 1129-1197.

Clifford, J., 1967. Proton magnetic resonance data on ice. Chem. Commun. (London) $17,880-881$.

Colbeck, S. C., Evans, R. J., 1973. A flow law for temperate glacier ice. J. Glaciol. 12 (64), 71-86.

Cole, D. M., 2004. A dislocation-based model for creep recovery in ice. Philos. Mag. 84 (30), 3217-3234.

Cole, D. M., Durell, G. D., 2001. A dislocation-based analysis of strain history effects in ice. Philos. Mag. 81 (7), 1849-1872.

Cuffey, K. M., Conway, H., Gades, A., Hallet, B., Raymond, C. F., Whitlow, S., 2000a. Deformation properties of subfreezing glacier ice: role of crystal size, chemical impurities and rock particles inferred from in situ measurements. J. Geophys. Res. 105 (B12), 27895-27915.

Cuffey, K. M., Thorsteinsson, T., Waddington, E. D., 2000b. A renewed argument for crystal size control of ice sheet strain rates. J. Geophys. Res. 105 (B12), 27889-27894. 
Dahl-Jensen, D., 1985. Determination of the flow properties at Dye 3, south Greenland, by bore-hole-tilting measurements and perturbation modelling. J. Glaciol. 31 (108), 92-98.

Dahl-Jensen, D., Gundestrup, N. S., 1987. Constitutive properties of ice at Dye 3, Greenland. In: IAHS Red Book 170, The Physical Basis of Ice Sheet Modelling. International Association of Hydrological Sciences, pp. 31-43.

De la Chapelle, S., Castelnau, O., Lipenkov, V., Duval, P., 1998. Dynamic recrystallization and texture development in ice as revealed by the study of deep ice cores in antarctica and greenland. J. Geophys. Res. 103, 5091-5105.

den Brok, B., Zahid, M., Passchier, C., 1998. Cataclastic solution creep of very soluble brittle salt as a rock analogue. Earth Planet. Sci. Lett. 163 (1-4), 83-95.

Doake, C. S. M., Wolff, E. W., 1985. Flow law for ice in polar ice sheets. Nature 314 (6008), 255-257.

Doherty, R. D., Hughes, D. A., Humphreys, F., Jonas, J. J., Juul Jensen, D., Kassner, M. E., King, W. E., McNelley, T. R., McQueen, H. J., Rollet, A. D., 1997. Current issues in recrystallization: a review. Mater. Sci. Engineer. 238, 219274.

Drury, M. R., Humphreys, F. J., 1988. Microstructural shear criteria associated with grain-boundary sliding during ductile deformation. J. Struct. Geol. 10, 8389.

Drury, M. R., Urai, J. L., 1990. Deformation-related recrystallization processes. Tectonophys. 172, 235-253. 
Duesbery, M. S., 1998. Dislocation motion, constriction and cross-slip in fcc metals. Modelling Simul. Mater. Sci. Eng. 6, 35-49.

Durand, G., Persson, A., Samyn, D., Svensson, A., 2008. Relation between neighbouring grains in the upper part of the NorthGRIP ice core: implications for rotation recrystallization. Earth Planet. Sci. Lett. 265 (3), 666-671.

Durand, G., Weiss, J., Lipenkov, V., Barnola, J. M., Krinner, G., Parrenin, F., Delmonte, B., Ritz, C., Duval, P., Rothlisberger, R., Bigler, M., 2006. Effect of impurities on grain growth in cold ice sheets. J. Geophys. Res. 111, F01015.

Durham, W. B., Stern, L. A., Kirby, S. H., 2001. Rheology of ice I at low stress and elevated confining pressure. J. Geophys. Res. 106 (6), 11031-11042.

Duval, P., 1978. Anelastic behaviour of polycrystalline ice. J. Glaciol. 21 (85), $621-627$.

Duval, P., 1985. Grain growth and mechanical behaviour of polar ice. Ann. Glaciol. 6, 79-82.

Duval, P., Ashby, M. F., Anderman, I., 1983. Rate-controlling processes in the creep of polycrystalline ice. J. Phys. Chem. 87, 4066-4074.

Duval, P., Castelnau, O., 1995. Dynamic recrystallization of ice in polar ice sheets. J. Phys. IV (Paris), colloq. C3 5, 197-205.

Duval, P., Montagnat, M., 2002. Comment on "Superplastic deformation of ice: Experimental observations" by D. L. Goldsby and D. L. Kohlstedt. J. Geophys. Res. 107 (B4), 2082. 
Etheridge, D. M., 1989. Dynamics of the Law Dome ice cap, Antarctica, as found from bore-hole measurements. Ann. Glaciol. 12, 46-50.

Evans, R. C., 1976. An Introduction to Crystal Chemistry, 2nd Edition. Cambridge University Press, Cambridge.

Faria, S. H., 2001. Mixtures with continuous diversity: general theory and application to polymer solutions. Continuum Mech. Thermodyn. 13 (2), 91-120.

Faria, S. H., 2003. Mechanics and thermodynamics of mixtures with continuous diversity: From complex media to ice sheets. Ph.D. thesis, Darmstadt University of Technology, Darmstadt.

Faria, S. H., 2006a. Creep and recrystallization of large polycrystalline masses. Part I: general continuum theory. Proc. Roy. Soc. London A 462 (2069), 14931514.

Faria, S. H., 2006b. Creep and recrystallization of large polycrystalline masses. Part III: continuum theory of ice sheets. Proc. Roy. Soc. London A 462 (2073), 2797-2816.

Faria, S. H., Freitag, J., Kipfstuhl, S., 2010. Polar ice structure and the integrity of ice-core paleoclimate records. Quat. Sci. Rev. 29 (1), 338-351.

Faria, S. H., Hamann, I., Kipfstuhl, S., Miller, H., 2006a. Is Antarctica like a birthday cake? Preprint 33/2006, Max Planck Institute for Mathematics in the Sciences, Leipzig.

Faria, S. H., Hutter, K., 2001. The challenge of polycrystalline ice dynamics. In: Kim, S., Jung, D. (Eds.), Advances in Thermal Engineering and Sciences 
for Cold Regions. Society of Air-Conditioning and Refrigerating Engineers of Korea (SAREK), Seoul, pp. 3-31.

Faria, S. H., Kipfstuhl, S., 2004. Preferred slip band orientations and bending observed in the Dome Concordia (East Antarctica) ice core. Ann. Glaciol. 39, 386-390.

Faria, S. H., Kipfstuhl, S., 2005. Comment on "Deformation of grain boundaries in polar ice" by G. Durand et al. Europhys. Lett. 71 (5), 873-874.

Faria, S. H., Kipfstuhl, S., Azuma, N., Freitag, J., Hamann, I., Murshed, M. M., Kuhs, W. F., 2009. The multiscale structure of Antarctica. Part I: inland ice. Low Temp. Sci. 68, 39-59.

Faria, S. H., Kipfstuhl, S., Lambrecht, A., in preparation. The EPICA-DML deep ice core. Springer, Heidelberg.

Faria, S. H., Kremer, G. M., Hutter, K., 2003. On the inclusion of recrystallization processes in the modeling of induced anisotropy in ice sheets: a thermodynamicist's point of view. Ann. Glaciol. 37, 29-34.

Faria, S. H., Kremer, G. M., Hutter, K., 2006b. Creep and recrystallization of large polycrystalline masses. Part II: constitutive theory for crystalline media with transversely isotropic grains. Proc. Roy. Soc. London A 462 (2070), 16991720.

Faria, S. H., Ktitarev, D., Hutter, K., 2002. Modelling evolution of anisotropy in fabric and texture of polar ice. Ann. Glaciol. 35, 545-551. 
Faria, S. H., Weikusat, I., Azuma, N., this issue. The microstructure of polar ice. Part I: highlights from ice core research. J. Struct. Geol.

Fischer, D. A., Koerner, R. M., 1986. On the special rheological properties of ancient microparticle-laden Northern Hemisphere ice as derived from bore-hole and core measurements. J. Glaciol. 32 (112), 501-510.

Fowler, A., 2001. Modelling the flow of glaciers and ice sheets. In: Straughan, B., Greve, R., Ehrentraut, H., Wang, Y. (Eds.), Continuum Mechanics and Applications in Geophysics and the Environment. Springer, Heidelberg, pp. 201-221.

Freitag, J., Kipfstuhl, S., Faria, S. H., 2008. The connectivity of crystallite agglomerates in low density firn at Kohnen station, Dronning Maud Land, Antarctica. Ann. Glaciol. 49, 114-120.

Frost, H. J., Ashby, M. F., 1982. Deformation-mechanism Maps. Pergamon, Oxford.

Frujita, S., Nakawo, M., Mae, S., 1987. Orientation of the 700m Mizuho core and its strain story. Proc. NIPR Symp. Polar Meteo. Glaciol. 1, 122-131.

Fukuda, A., Hondoh, T., Higashi, A., 1987. Dislocation mechanisms of plastic deformation of ice. J. Phys. (Paris) 48, 163-173.

Gammon, P. H., Kiefte, H., Clouter, M. J., Denner, W. W., 1983. elastic constants of artificial and natural ice samples by Brillouin spectroscopy. J. Glaciol. 29 (103), 433-460.

Gifkins, R. C., 1976. Grain-boundary sliding and its accommodation during creep and superplasticity. Metall. Trans. A 7, 1225-1232. 
Gillet-Chaulet, F., Gagliardini, O., Meyssonnier, J., Montagnat, M., Castelnau, O., 2005. A user-friendly anisotropic flow law for ice-sheet modeling. J. Glaciol. 51 (172), 3-14.

Gilra, N. K., 1974. Non-basal glide in ice. physica status solidi (a) 21 (1), 323327.

Glen, J. W., 1952. Experiments on the deformation of ice. J. Glaciol. 2 (12), 111114.

Glen, J. W., 1955. The creep of polycrystalline ice. Proc. Roy. Soc. London A 228, 519-538.

Glen, J. W., 1968. The effect of hydrogen disorder on dislocation movement and plastic deformation of ice. Phys. Kondens. Mater 7, 43-51.

Glen, J. W., 1974. The physics of ice. Cold regions science and engineering monograph II C2a, U. S. Army CRREL, Hanover, NH.

Glen, J. W., 1975. The mechanics of ice. Cold regions science and engineering monograph II C2b, U. S. Army CRREL, Hanover, NH.

Glen, J. W., Perutz, M. F., 1954. The growth and deformation of ice crystals. J. Glaciol. 2, 397-403.

Gödert, G., Hutter, K., 1998. Induced anisotropy in large ice sheets: theory and its homogenization. Continuum Mech. Thermodyn. 13, 91-120.

Goldsby, D. L., Kohlstedt, D. L., 1997. Grain boundary sliding in fine-grained ice. Scripta Mater. 37, 1399-1406. 
Goldsby, D. L., Kohlstedt, D. L., 2001. Superplastic deformation of ice: experimental observations. J. Geophys. Res. 106, 11017-11030.

Goldsby, D. L., Kohlstedt, D. L., 2002. Reply to comment by P. Duval and M. Montagnat on "Superplastic deformation of ice: experimental observations". J. Geophys. Res. 107 (B11), 2313.

Goodman, D. J., Frost, H. J., Ashby, M. F., 1981. The plasticity of polycrystalline ice. Philos. Mag. 43, 665-695.

Gow, A. J., 1963. Results of measurements in the 309 meter bore hole at Byrd Station, Antarctica. J. Glaciol. 4 (36), 771-784.

Gow, A. J., 1969. On the rates of growth of grains and crystals in south polar firn. J. Glaciol. 8 (53), 241-252.

Gundestrup, N. S., Hansen, B. L., 1984. Bore-hole survey at Dye 3, south Greenland. J. Galciol. 30, 282-288.

Hamann, I., Weikusat, C., Azuma, N., Kipfstuhl, S., May 2007. Evolution of ice crystal microstructures during creep experiments. J. Glaciol. 53 (182), 479-489.

Higashi, A., 1978. Structure and behaviour of grain boundaries in polycrystalline ice. J. Glaciol. 21 (85), 589-605.

Higashi, A., Fukuda, A., Shoji, H., Oguro, M., Hondoh, T., Goto-Azuma, K., 1988. Lattice defects in ice crystals. Hokkaido University Press, Sapporo, Japan.

Higashi, A., Sakai, N., 1961. Movement of small angle boundary of ice crystal. J. Fac. Sci. Hokkaido Univ. Ser. 2 Phys. 5 (5), 221-237. 
Hirth, J. P., Lothe, J., 1992. Theory of Dislocations, 2nd Edition. Krieger Publishing Company, Malabar, FL.

Hobbs, P. V., 1974. Ice Physics. Clarendon, Oxford.

Hondoh, T., 2000. Nature and behavior of dislocations in ice. In: Hondoh, T. (Ed.), Physics of Ice Core Records. Hokkaido University Press, Sapporo, pp. $3-24$.

Hondoh, T., 2009. An overview of microphysical processes in ice sheets: toward nanoglaciology. Low Temp. Sci. 68, 1-23.

Hondoh, T., Higashi, A., 1978. X-ray diffraction topographic observations of the large-angle grain boundary in ice under deformation. J. Glaciol. 21 (85), 629638.

Hondoh, T., Higashi, A., 1983. Generation and absorption of dislocations at largeangle grain boundaries in deformed ice crystals. J. Phys. Chem. 87 (21), 40444050 .

Hondoh, T., Iwamatsu, H., Mae, S., 1990. Dislocation mobility for nonbasal glide in ice measured by in situ x-ray topography. Phylos. Mag. 62, 89-102.

Hooke, R. L., 1973. Structure and flow in the margin of the Barnes Ice Cap, Baffin Island, N.W.T., Canada. J. Glaciol. 66, 423-438.

Hooke, R. L., 1981. Flow law for polycrystalline ice in glaciers: comparison of theoretical predictions, laboratory data, and field measurements. Rev. Geophys. Space Phys. 19 (4), 664-672. 
Hooke, R. L., 2005. Principles of Glacier Mechanics, 2nd Edition. Cambridge University Press, Cambridge.

Hudleston, P. J., 1977. Similar folds, recumbent folds, and gravity tectonics in ice and rocks. J. Geol. 85, 113-122.

Humphreys, F. J., Hatherly, M., 2004. Recrystallization and Related Annealing Phenomena, 2nd Edition. Pergamon, Oxford.

Hutchinson, W. B., 1976. Bonds and self consistent estimates for creep of polycrystal materials. Proc. Roy. Soc. London A 348 (1652), 101-127.

Hutter, K., 1980. Time-dependent surface elevation of an ice slope. J. Glaciol. 25 (92), 247-266.

Hutter, K., 1981. The effect of longitudinal strain on the shear stress of an ice sheet: in defence of using stretched coordinates. J. Glaciol. 27 (95), 39-56.

Hutter, K., 1982. Dynamics of glaciers and large ice masses. Ann. Rev. Fluid Mech. 14, 87-130.

Hutter, K., 1983. Theoretical Glaciology. Reidel, Dordrecht.

Hutter, K., Legerer, F., Spring, U., 1981. First-order stresses and deformations in glaciers and ice sheets. J. Glaciol. 27 (96), 227-270.

Iliescu, D., Baker, I., Chang, H., 2004. Determining the orientations of ice crystals using electron backscatter patterns. Microsc. Res. Tech. 63, 183-187.

Jacka, T. H., 1984. The time and strain required for development of minimum strain rates in ice. Cold Reg. Sci. Technol. 8 (3), 261-268. 
Jacka, T. H., Li, J., 1994. The steady-state crystal size of deforming ice. Ann. Glaciol. 20, 13-18.

Jacka, T. H., Li, J., 2000. Flow rates and crystal orientation fabrics in compression of polycrystalline ice at low temperatures and stresses. In: Hondoh, T. (Ed.), Physics of Ice Core Records. Hokkaido University Press, Sapporo, pp. 83-102.

Jessell, M. W., 1986. Grain boundary migration and fabric development in experimentally deformed octachloropropane. J. Struct. Geol. 8 (5), 527-542.

Jones, S. J., Chew, H. A. M., 1983. Creep of ice as a function of hydrostatic pressure. J. Phys. Chem. 87 (21), 4064-4066.

Kamb, B., 1972. Experimental recrystallization of ice under stress. In: Heard, H. C., Borg, I. Y., Carter, N. L., Raleigh, C. B. (Eds.), Flow and Fracture of Rocks. No. 16 in Geophysical Monograph. American Geophysical Union, Washington, DC, pp. 211-241.

Kamb, W. B., 1959. Ice petrofabric observations from Blue Glacier, Washington, in relation to theory and experiment. J. Geophys. Res. 64 (11), 1891-1909.

Kamb, W. B., 1964. Glacier geophysics. Science 146 (3642), 353-365.

Kansal, A. R., Torquato, S., Stillinger, F. H., 2002. Diversity of order and densities in jammed hard-particle packings. Phys. Rev. E 66 (4), 041109-1-041109-8.

Kipfstuhl, S., Faria, S. H., Azuma, N., Freitag, J., Hamann, I., Kaufmann, P., Miller, H., Weiler, K., Wilhelms, F., 2009. Evidence of dynamic recrystallization in polar firn. J. Geophys. Res. 114, B05204. 
Kipfstuhl, S., Hamann, I., Lambrecht, A., Freitag, J., Faria, S. H., Grigoriev, D., Azuma, N., 2006. Microstructure mapping: A new method for imaging deformation-induced microstructural features of ice on the grain scale. J. Glaciol. 52 (178), 398-406.

Kirby, S. H., Durham, W. B., Stern, L. A., 1991. Mantle phase changes and deepearthquake faulting in subducting lithosphere. Science 252 (1991), 216-225.

Kizaki, K., 1969. Ice-fabric study of the Mawson region, East Antarctica. J. Glaciol. 8 (53), 253-276.

Kocks, U. F., 1970. The relation between polycrystal deformation and singlecrystal deformation. Metall. Trans. 1, 1121-1143.

Kondo, T., Kato, H. S., Kawai, M., Bonn, M., 2007. The distinct vibrational signature of grain-boundary water in nano-crystalline ice films. Chem. Phys. Lett. 448 (1-3), 121-126.

Ktitarev, D., Gödert, G., Hutter, K., 2002. Cellular automaton model for recrystallization, fabric and texture development in polar ice. J. Geophys. Res. 107 (B8), EPM 5-1-EPM 5-9.

Legrand, M., Mayewski, P. A., 1997. Glaciochemistry of polar ice cores: a review. Rev. Geophys. 35, 219-143.

Lemke, P., Ren, J., Alley, R. B., Allison, I., Carrasco, J., Flato, G., Fujii, Y., Kaser, G., Mote, P., Thomas, R. H., Zhang, T., 2007. Observations: changes in snow, ice and frozen ground. In: Solomon, S., Qin, D., Manning, M., Chen, Z., Marquis, M., Averyt, K. B., Tignor, M., Miller, H. L. (Eds.), Climate Change 
2007: The Physical Science Basis. Contribution of Working Group I to the Fourth Assessment Report of the Intergovernmental Panel on Climate Change (IPCC). Cambridge University Press, Cambridge.

Lile, R. C., 1978. The effect of anisotropy on the creep of polycrystalline ice. J. Glaciol. 21 (85), 475-483.

Lipenkov, V. Y., Barkov, N. I., Duval, P., Pimienta, P., 1989. Crystalline texture of the $2083 \mathrm{~m}$ ice core at vostok station, antarctica. J. Glaciol. 35 (121), 392-398.

Liu, F., Baker, I., Dudley, M., 1993. Dynamic observations of dislocation generation at grain boundaries in ice. Philos. Mag. A 67, 1261-1276.

Liu, F., Baker, I., Dudley, M., 1995. Dislocation-grain boundary interactions in ice crystals. Philos. Mag. A 71, 15-42.

Lliboutry, L., 1969. The dynamics of temperate glaciers from the detailed viewpoint. J. Glaciol. 8 (53), 185-205.

Lliboutry, L., 1976. Physical processes in temperate glaciers. J. Glaciol. 16 (74), $151-158$.

Louchet, F., 2004. Dislocations and plasticity in ice. C. R. Physique 5, 687-698.

Mader, H. M., 1992. The thermal behaviour of the water-vein system in polycrystalline ice. J. Glaciol. 38 (130), 359-374.

Maeno, N., Ebinuma, T., 1983. Pressure sintering of ice and its implication to the densification of snow at polar glaciers and ice sheets. J. Phys. Chem. 87 (21), 4103-4110. 
Marshall, H. P., Harper, J. T., Pfeffer, W. T., Humphrey, N., 2002. Depth-varying constitutive properties observed in an isothermal glacier. Geophys. Res. Letters $29(23), 61-1-61-4$.

Mathiesen, J., Ferkinghoff-Borg, J., Jensen, M. H., Levinsen, M., Olesen, P., DahlJensen, D., Svensson, A., 2004. Dynamics of crystal formation in the Greenland NorthGRIPice core. J. Glaciol. 50 (170), 325-328.

Matsuda, M., 1979. Determination of axis orientations of polycrystalline ice. J. Glaciol. 22 (86), 165-169.

Matsuda, M., Wakahama, G., 1978. Crystallographic structure of polycrystalline ice. J. Glaciol. 21 (85), 607-620.

Matsuyama, M., 1920. On some physical properties of ice. J. Geol. 28 (7), 607631.

McConnel, J. C., 1890. On the plasticity of an ice crystal. Proc. Roy. Soc. London 49 (296-301), 323-343.

McConnel, J. C., Kidd, D. A., 1888. On the plasticity of glacier and other ice. Proc. Roy. Soc. London 44 (266-272), 331-367.

Means, W. D., 1989. Synkinematic microscopy of transparent polycrystals. J. Struct. Geol. 11 (1-2), 163-174.

Means, W. D., Jessell, M. W., 1986. Accommodation migration of grain boundaries. Tecronophys. 127, 67-86. 
Meier, M. F., 1958. Vertical profiles of velocity and the flow law of glacier ice. In: IAHS Red Book 47, Physics of the Movement of Ice. International Association of Hydrological Sciences, pp. 169-170.

Meier, M. F., 1960. Mode of flow of Saskatchewan Glacier, Alberta, Canada. Professional Paper 351, U.S. Geological Survey, Washington, DC.

Mellor, M., Testa, R., 1969a. Creep of ice under low stress. J. Glaciol. 8 (52), $147-152$.

Mellor, M., Testa, R., 1969b. Effect of temperature on the creep of ice. J. Glaciol. 8 (52), 1131-145.

Merkle, K. L., Thompson, L. J., 1973. Atomic-scale observation of grain boundary motion. Mater. Lett. 48 (3-4), 188-193.

Miyamoto, A., Weikusat, I., Hondoh, T., 2011. Complete determination of ice crystal orientation and microstructure investigation on ice core samples enabled by a new x-ray laue diffraction method. J. Glaciol. 57 (201), 67-74, awin18929.

Montagnat, M., Castelnau, O., Bons, P. D., Faria, S. H., Gagliardini, O., GilletChaulet, F., Griera, A., Lebensohn, R., Roessiger, J., 2013. Multiscale modeling of ice deformation behavior. J. Struct. Geol. this issue.

Montagnat, M., Duval, P., 2000. Rate controlling processes in the creep of polar ice, influence of grain boundary migration associated with recrystallization. Earth Planet. Sci. Lett. 183, 179-186. 
Morland, L. W., Staroszczyk, R., 1998. Viscous response of polar ice with evolving fabric. Continuum Mech. Thermodyn. 10, 135-152.

Mott, N. F., 1948. Slip at grain boundaries and grain growth in metals. Proc. Phys. Soc. 60 (4), 391-394.

Nakaya, U., 1958. The deformation of single crystals of ice. In: IAHS Red Book 47, Physics of the Movement of Ice. International Association of Hydrological Sciences, pp. 229-240.

Norton, F. H., 1929. The Creep of Steel at High Temperatures. McGraw-Hill, New York.

Nye, J. F., 1953. The flow law of ice from measurements in glacier tunnels laboratory experiments and the Jungfraufirn experiment. Proc. Roy. Soc. London A 219, 477-489.

Nye, J. F., 1957. The distribution of stress and velocities in glaciers and ice-sheets. Proc. Roy. Soc. London A 239, 113-133.

Nye, J. F., Frank, F. C., 1973. Hydrology of the intergranular veins in a temperate glacier. In: IAHS Red Book 95, Symposium on the Hydrology of Glaciers. International Association of Hydrological Sciences, pp. 157-161.

Okada, Y., Hondoh, T., Mae, S., 1999. Basal glide of dislocations in ice observed by synchrotron radiation topography. Philos. Mag. A 79 (11), 2853-2868.

Ostwald, W., 1929. Ueber die rechnerische darstellung des strukturgebietes der viskosität. Kolloid-Z. 47 (2), 176-187. 
Parameswaran, V. R., 1982. Fracture criterion for ice using a dislocation model. J. Glaciol. 28 (98), 161-169.

Passchier, C. W., Trouw, R. A. J., 2005. Microtectonics, 2nd Edition. Springer, Berlin.

Paterson, W. S. B., 1977. Secondary and tertiary creep of glacier ice as measured by borehole closure rates. Rev. Geophys. Space Phys. 15 (1), 47-55.

Paterson, W. S. B., 1991. Why ice-age ice is sometimes "soft". Cold Reg. Sci. Technol. 20 (1), 75-98.

Paterson, W. S. B., 1994. The Physics of Glaciers, 3rd Edition. Pergamon, Oxford.

Pauling, L., 1935. The structure and entropy of ice and of other crystals with some randomness of atomic arrangement. J. Amer. Chem. Soc. 57, 2680-2684.

Peltier, W. R., Goldsby, D. L., Tarasov, L., 2000. Ice-age ice-sheet rheology: constraints from the Last Glacial Maximum form of the Laurentide ice sheet. Ann. Glaciol. 30, 163-176.

Perutz, M. F., 1949. The flow of ice and other solids. in: Joint meeting of the british glaciological society, the british rheologists' club and the institute of metals. J. Glaciol. 1 (5), 231-240.

Perutz, M. F., 1950. In: Glaciology-the flow of glaciers. The Observatory $70(855), 64-65$.

Perutz, M. F., Seligman, G., 1939. A crystallographic investigation of glacier structure and the mechanism of glacier flow. Proc. Roy. Soc. London A 172, $335-360$. 
Petrenko, V. F., Whitworth, R. W., 1999. Physics of Ice. Oxford University Press, Oxford.

Pettit, E. C., Waddington, E. D., 2003. Ice flow at low deviatoric stress. J. Glaciol. 49 (166), 359-369.

Piazolo, S., Montagnat, M., Blackford, J. R., 2008. Sub-structure characterization of experimentally and naturally deformed ice using cryo-EBSD. J. Microsc. $230(3), 509-519$.

Pimienta, P., Duval, P., 1987. Rate controlling processes in the creep of polar glacier ice. J. Phys., Colloq. C1, Suppl. 3 48, 243-248.

Placidi, L., Faria, S. H., Hutter, K., 2004. On the role of grain growth, recrystallization, and polygonization in a continuum theory for anisotropic ice sheets. Ann. Glaciol. 39, 49-52.

Placidi, L., Greve, R., Seddik, H., Faria, S. H., 2010. Continuum-mechanical, anisotropic flow model, based on an anisotropic flow enhancement factor (CAFFE). Continuum Mech. Thermodyn. 22 (3), 221-237.

Placidi, L., Hutter, K., 2006. Thermodynamics of polycrystalline materials treated by the theory of mixtures with continuous diversity. Cont. Mech. Thermodyn. $17(6), 409-451$.

Poirier, J.-P., 1985. Creep of Crystals. Cambridge University Press, Cambridge.

Prior, D. J., Boyle, A. P., Brenker, F., Cheadle, M. C., Day, A., Lopez, G., Peruzzo, L., Potts, G. J., Reddy, S., Spiess, R., Timms, N. E., Trimby, P., Wheeler, J., Zetterström, L., 1999. The application of electron backscatter diffraction and 
orientation contrast imaging in the sem to textural problems in rocks. American Mineralogist 1741-1759, 84.

Prior, D. J., Diebold, S., Obbard, R., Daghlian, C., Goldsby, D. L., Durham, W. B., Baker, I., 2012. Insight into the phase transformations between ice Ih and ice II from electron backscatter diffraction data. Scripta Mater. 66 (2), 69 - 72.

Prior, D. J., Wheeler, J., Peruzzo, L., Spiess, R., Storey, C., 2002. Some garnet microstructures: an illustration of the potential of orientation maps and misorientation analysis in microstructural studies. Journal of Structural Geology 24 (6-7), 999 - 1011.

Ramseier, R. O., 1967. Self-diffusion of tritium in natural and synthetic ice monocrystals. J. Appl. Phys. 38 (6), 2553-2556.

Read, W. T., Shockley, W., 1950. Dislocation models of crystal grain boundaries. Phys. Rev. 78 (3), 275-289.

Rigsby, G. P., 1951. Crystal fabric studies on Emmons Glacier Mount Rainier, Washington. J. Geol. 59 (6), 590-598.

Rigsby, G. P., 1958a. Effect of hydrostatic pressure on velocity of shear deformation on single ice crystals. J. Glaciol. 3 (24), 271-278.

Rigsby, G. P., 1958b. Fabrics of glacier and laboratory deformed ice. In: IAHS Red Book 47, Physics of the Movement of Ice. International Association of Hydrological Sciences, pp. 351-358.

Rigsby, G. P., 1960. Crystal orientation in glacier and in experimentally deformed ice. J. Glaciol. 3 (27), 589-606. 
Rigsby, G. P., 1968. The complexities of the three-dimensional shape of individual crystals in glacier ice. J. Glaciol. 7 (50), 233-251.

Roessiger, J., Bons, P. D., Faria, S. H., 2013. Influence of bubbles on grain growth in ice. J. Struct. Geol. this issue.

Roessiger, J., Bons, P. D., Griera, A., Jessell, M. W., Evans, L., Montagnat, M., Kipfstuhl, S., Faria, S. H., Weikusat, I., 2011. Competition between grain growth and grain-size reduction in polar ice. J. Glaciol. 57 (205), 942-948.

Rosen, J., 1995. Symmetry in Science. Springer, New York.

Rosen, J., 2005. The symmetry principle. Entropy 7 (4), 308-313.

Russell-Head, D. S., Budd, W. F., 1979. Ice-sheet flow properties derived from bore-hole shear measurements combined with ice-core studies. J. Glaciol. $24(90), 117-130$.

Ruth, U., Barnola, J. M., Beer, J., Bigler, M., Blunier, T., Castellano, E., Fischer, H., Fundel, F., Huybrechts, P., Kaufmann, P., Kipfstuhl, S., Lambrecht, A., Morganti, A., Oerter, H., Parrenin, F., Rybak, O., Severi, M., Udisti, R., Wilhelms, F., Wolff, E., 2007. "EDML1": a chronology for the EPICA deep ice core from Dronning Maud Land, Antarctica, over the last 150000 years. Clim. Past 3, 475-484.

Schulson, E. M., Duval, P., 2009. Creep and Fracture of Ice. Cambridge University Press, Cambridge.

Seligman, G., 1941. The structure of a temperate glacier. Geogr. J. 97 (5), 295315. 
Seligman, G., 1949. The growth of the glacier crystal. J. Glaciol. 1 (5), 254-268.

Sharp, R. P., 1954. Glacier flow: a review. Geol. Soc. Amer. Bull. 65, 821-838.

Shearwood, C., Whitworth, R. W., 1991. The velocity of dislocations in ice. Philosophical Magazine A 64 (2), 289-302.

Shoji, H., Langway, Jr., C. C., 1984. Flow behavior of basal ice as related to modeling considerations. Ann. Glaciol. 5, 141-148.

Shoumsky, P. A., 1958. The mechanism of ice straining and its recrystallization. In: IAHS Red Book 47, Physics of the Movement of Ice. International Association of Hydrological Sciences, pp. 244-248.

Smith, C. S., 1952. Grain shapes and other metallurgical applications of topology. In: Metal Interfaces. American Society for Metals (ASM), Cleveland, OH, pp. 65-108.

Smith, G. D., Morland, L., 1981. Viscous relations for the steady creep of polycrystalline ice. Cold Reg. Sci.Technol. 5 (2), 141-150.

Song, M., 2008. An evaluation of the rate-controlling flow process in newtonian creep of polycrystalline ice. Mater. Sci. Eng. A 486, 27-31.

Staroszczyk, R., Morland, L. W., 2001. Strengthening and weakening of induced anisotropy in polar ice. Proc. Roy. Soc. London A 451 (2014), 2419-2440.

Steinemann, S., 1954. Results of preliminary experiments on the plasticity of ice crystals. J. Glaciol. 2, 404-412. 
Steinemann, S., 1958. Experimentelle Untersuchungen zur Plastizität von Eis. Beitr. Geol. Schweiz, Hydrol. 10, 1-72, also as Ph.D. Thesis, Swiss Federal Institute of Technology (ETH) Zurich.

Stephenson, P. J., 1967. Some considerations of snow metamorphism in the antarctic ice sheet in the light of ice crystal studies. In: Oura, H. (Ed.), Physics of Snow and Ice. Vol. 1. Hokkaido University Press, Sapporo, pp. 725-740, proceedings of the International Conference on Low Temperature Science, 1966, Sapporo, Japan.

Stern, L. A., Durham, W. B., Kirby, S. H., 1997. Grain-size-induced weakening of $\mathrm{H}_{2} \mathrm{O}$ ices I and II and associated anisotropic recrystallization. J. Geophys. Res. 102 (B3), 5313-5325.

Sutton, A. P., Balluffi, R. W., 1995. Interfaces in Crystalline Materials. Clarendon, Oxford.

Suzuki, S., 1970. Grain Coarsening of Microcrystals of Ice. (III). Low Temperature Science Ser. A 28, 47-61.

Suzuki, S., Kuroiwa, D., 1972. Grain-boundary energy and grain-boundary groove angles in ice. J. Glaciol. 11 (62), 265-277.

Talalay, P. G., Hooke, R. L., 2007. Closure of deep boreholes in ice sheets: a discussion. Ann. Glaciol. 47, 125-133.

Tammann, G., Dreyer, K. L., 1929. Die Rekristallisation leicht schmelzender Stoffe und die des Eises. Z. Anorg. Allg. Chem. 182 (1), 289-313. 
Tarr, R. S., Rich, J. L., 1912. The properties of ice-experimental studies. Z. Gletscherkunde 6 (4), 225-249.

Taylor, G. I., 1938. Plastic strain in metals. J. Inst. Metals 62, 307-324.

Thompson, D. E., 1979. Stability of glaciers and ice sheets against flow perturbations. J. Glaciol. 24 (90), 427-441.

Thorsteinsson, T., 2002. Fabric development with nearest-neighbor interaction and dynamic recrystallization. J. Geophys. Res. 107 (B1), ECV3-1-ECV3-13.

Thorsteinsson, T., Kipfstuhl, J., Miller, H., 1997. Textures and fabrics in the GRIP ice core. J. Geophys. Res. 102, 26583-26599.

Trepied, L., Doukhan, J. C., Paquet, J., January 1980. Subgrain boundaries in quartz theoretical analysis and microscopic observations. Phys. Chem. Miner. 5 (3), 201-218.

Treverrow, A., Budd, W. F., H., J. T., Warner, R. C., 2012. The tertiary creep of polycrystalline ice: experimental evidence for stress-dependent levels of strainrate enhancement. J. Glaciol. 58 (208), 301-314.

Urai, J. L., Humphreys, F. J., Burrows, S. E., 1980. In-situ studies of the deformation and dynamic recrystallization of rhombohedral camphor. J. Mater. Sci. 15, $1231-1240$.

Urai, J. L., Means, W. D., Lister, G. S., 1986. Dynamic recrystallization of minerals. In: Hobbs, B. E., Heard, H. C. (Eds.), Mineral and Rock Deformation: Laboratory Studies. Geophysical Monograph 36. American Geophysical Union, Washington, pp. 161-199. 
Van der Veen, C. J., Whillans, I. M., 1994. Development of fabric in ice. Cold Reg. Sci. Technol. 22, 171-195.

Waddington, E. D., 2010. Life, death and afterlife of the extrusion flow theory. J. Glaciol. 56 (200), 973-996.

Wakahama, G., 1964. On the plastic deformation of ice. V. Plastic deformation of polycrystalline ice. Low Temp. Sci. A 22, 1-24, in Japanese with English summary.

Wang, Y., Kipfstuhl, S., Azuma, N., Thorsteinsson, T., Miller, H., 2003. Icefabrics study in the upper $1500 \mathrm{~m}$ of the Dome $\mathrm{C}$ (East Antarctica) deep ice core. Ann. Glaciol. 37, 97-104.

Wang, Y., Thorsteinsson, T., Kipfstuhl, J., Miller, H., Dahl-Jensen, D., Shoji, H., 2002. A vertical girdle fabric in the NorthGRIP deep ice core, North Greenland. Ann. Glaciol. 35, 515-520.

Weertman, J., 1983. Creep deformation of ice. Ann. Rev. Earth Planet Sci. 11, $215-240$.

Weertman, J., Weertman, J. R., 1992. Elementary Dislocation Theory. Oxford University Press, New York.

Weikusat, I., de Winter, D. A. M., Pennock, G. M., Hayles, M., Schneijdenberg, C. T. W. M., Drury, M. R., June 2010. Cryogenic EBSD on ice: preserving a stable surface in a low pressure SEM. J. Microsc. 242 (3), 295-310.

Weikusat, I., Kipfstuhl, S., Azuma, N., Faria, S. H., Miyamoto, A., 2009a. Defor- 
mation microstructures in an Antarctic ice core (EDML) and in experimentally deformed artificial ice. Low Temp. Sci. 68, 115-123.

Weikusat, I., Kipfstuhl, S., Faria, S. H., Azuma, N., Miyamoto, A., 2009b. Subgrain boundaries and related microstructural features in EDML(Antarctica) deep ice core. J. Glaciol. 55 (191), 461-472.

Weikusat, I., Miyamoto, A., Faria, S. H., Kipfstuhl, S., Azuma, N., Hondoh, T., 2011. Subgrain boundaries in Antarctic ice quantified by X-ray Laue diffraction. J. Glaciol. 57 (201), 85-94.

Wilen, L. A., DiPrinzio, C. L., Alley, R. B., Azuma, N., 2003. Development, principles, and applications of automated ice fabric analyzers. Microsc. Res. Technique 62, 2-18.

Wilson, C. J. L., 1979. Boundary structures and grain shape in deformed multilayered polycrystalline ice. Tectonophys. 57 (2-4), T19-T25.

Wilson, C. J. L., 1982. Texture and grain growth during the annealing of ice. Textur. Microstr. 5, 19-31.

Wilson, C. J. L., 1986. Deformation induced recrystallization of ice: the application of in situ experiments. In: Hobbs, B. E., Heard, H. C. (Eds.), Mineral and Rock Deformation: Laboratory Studies. Geophysical Monograph 36. American Geophysical Union, Washington, pp. 213-232.

Wilson, C. J. L., Burg, Mitchell, 1986. The origin of kinks in polycrystalline ice. Tectonophysics 127, 27-48. 
Wilson, C. J. L., Peternell, M., Piazolo, S., Luzin, V., this issue. Microstructure and fabric development in ice: lessons learned from in situ experiments and implications for understanding rock evolution. J. Struct. Geol.

Wilson, C. J. L., Russell-Head, D. S., Kunze, K., Viola, G., March 2007. The analysis of quartz c-axis fabrics using a modified optical microscope. J. Microsc. 227 (1), 30-41.

Wilson, C. J. L., Russell-Head, D. S., Sim, H. M., 2003. The application of an automated fabric analyzer system to the textural evolution of folded ice layers in shear zones. Ann. Glaciol. 37, 7-17.

Wilson, C. J. L., Zhang, Y., 1996. Development of microstructure in the hightemperature deformation of ice. Ann. Glaciol. 23, 293-302.

Zhang, Y., Wilson, C. J. L., 1997. Lattice rotation in polycrystalline aggregates and single crystals with one slip system: a numerical and experimental approach. J. Struct. Geol. 19 (6), 875-885. 


\section{Appendix C. FIGURE CAPTIONS}

Figure C.1: The crystalline lattice of ice Ih. Red and white spheres represent oxygen and hydrogen atoms, respectively, while grey rods symbolize hydrogen bonds. Top: view along the $c$-axis. Bottom: view along an $a$-axis. The hexagonal symmetry of the lattice is highlighted by the yellow dashed line (after Faria and Hutter, 2001).

Figure C.2: Schematic representation of possible slip systems in ice (after Hondoh, 2000; Faria, 2003). Cf. Table D.1. 
Figure C.3: Mosaic image showing examples of several microstructural features in a sublimated sample of Antarctic ice (EDML, $1656 \mathrm{~m}$ depth). Recognizable are slip bands (SB), grain boundaries (GB), subgrain boundaries (sGB), and [decomposed] air hydrates ([d]AH). Sublimation polishes the ice sample surface through thermal etching, forming as by-product observable etch grooves at points where grain or subgrain boundaries meet the surface (Kipfstuhl et al., 2006). In contrast, slip bands are volume features, which appear as series of parallel fringes that are only observable in sections with a certain thickness (several hundreds of micrometers), when the $c$-axis of the sheared grain lies nearly parallel to the sample surface plane (within a few degrees of misorientation). Air hydrates inside the sample appear as bright inclusions. If they lie on the surface, however, they decompose and appear dark, because they are not stable at atmospheric pressure and high temperatures. Completely unfocused structures are sublimation-etched features at the bottom side of the sample, visible through the transparent ice matrix. The dark circular object on the top right is a deposit or imperfection on the surface, while the curved shadow at the right border is part of a bubble in the silicone oil that preserves the ice surface.

Figure C.4: Schematic representation of extended basal dislocations combined with non-basal dislocation segments in ice. (a) A dislocation with an initially arbitrary shape soon evolves into the more stable "terraced" configuration illustrated here, which combines long basal and short non-basal segments. (b) Glissile screw dislocation dipole with Burgers vector $\boldsymbol{a}=(1 / 3)<11 \overline{2} 0>$ led by a glissile non-basal edge segment. (c) Sessile edge dislocation dipole with Burgers vector $\boldsymbol{c}=<0001>$ or $\boldsymbol{a}+\boldsymbol{c}=(1 / 3)<11 \overline{2} 3>$ led by a glissile non-basal screw segment. After Hondoh (2000). 
Figure C.5: Typical manifestations of internal stresses and heterogeneous strains in an Antarctic EDML sample from $556 \mathrm{~m}$ depth (bubbly ice). Air bubbles appear black. Width of each micrograph: $2.5 \mathrm{~mm}$. Top left: Classical example of migration recrystallization (SIBM-O; cf. Appendix A). Many subgrain boundaries and dislocation walls irradiating from a bulged grain boundary, which is migrating to the left towards the region with high stored strain energy. The illumination is especially favourable in this image for revealing the 3D-shape of the bulging grain boundary: one can identify the bulged shadow produced by the grain boundary groove at the bottom surface of the sample, as well as a grain boundary edge emanating from the triple junction on the left towards the bottom of the sample. Top right: Another classical example of SIBM-O (centre), as well as of grain subdivision (top left). Notice the elongated (sub-)grain island (centre top) nucleated in the region of high stored strain energy. Centre left: Well-developed subgrain island (left) in a region of highly heterogeneous strain, characterised by many entangled dislocation walls and subgrain boundaries. Centre right: Bending of a large grain and simultaneous consumption of the irregular tilt boundary by a smaller grain (bottom right). Again, the 3D-shape of the smaller grain can be visualized by the defocused curve/shadow produced by the groove at the bottom surface of the sample (notice the cusp pointing in the direction of the "tilt boundary"). From the visible slip bands, the misorientation across the irregular tilt boundary is $\gtrsim 7^{\circ}$. Bottom left: Large, welldeveloped subgrain island (bottom) near a jagged subgrain boundary. Notice also the tiny subgrain island at the centre top. Bottom right: Classical examples of nucleated migration recrystallization (SIBM-N; cf. Appendix A). A newly nucleated grain (top right) grows into the highly strained region in the centre, characterized by numerous subgrain boundaries and dislocation walls. At the same time, the bulge on the top left seems to be in the process of becoming a new grain by rotating itself with respect to its parent grain, as indicated by the roughly vertical subgrain boundaries at the top left. The unfocused shadows on the left are grain boundary grooves on the bottom surface of the sample. 
Figure C.6: Typical creep curves obtained in laboratory tests for initially isotropic (black) and optimal anisotropic (blue) ice. The evolution of the LPOs in the case of unconfined vertical compression is also outlined. Capital letters delimit the various deformation stages. AB: "instantaneous" elastic strain. BC: transient primary creep $(\ddot{\varepsilon}<0)$. CD: minimum secondary creep $(\ddot{\varepsilon}=0)$. DE: accelerating tertiary creep $(\ddot{\varepsilon}>0)$. EF: steady tertiary creep $(\ddot{\varepsilon}=0)$. For initially isotropic ice (black), the strain rate first decelerates to a minimum value $\left(\dot{\varepsilon}_{\min }\right.$ at $\varepsilon_{\min } \approx 1 \%$ ) prior to accelerating to the stable tertiary creep rate $\left(\dot{\varepsilon}_{\max }\right.$ at $\left.\varepsilon_{\max } \approx 10 \%\right)$. In contrast, the optimal anisotropic ice (blue) decelerates much less and reaches the stable tertiary creep rate already at the end of secondary creep $\left(\varepsilon_{\min }=\varepsilon_{\max } \approx 1 \%\right.$ ), without passing through the phase of accelerating tertiary creep, because it already has fully developed LPOs compatible with the stress regime. (based on Budd and Jacka, 1989; Treverrow et al., 2012).

Figure C.7: Dynamic recrystallization of polar firn. Dark patches depict the pore space, while dark lines are grain boundary grooves on the sample surface. Some straight vertical lines are remaining scratches from microtoming (sublimation of firn samples must be performed with moderation, in order to preserve the original geometry of the pore space). Scale bars: $1 \mathrm{~mm}$. Left: EDML firn sample from $40 \mathrm{~m}$ depth. Grain boundaries seem straight and smooth, although some subgrain boundaries (faint lines) are visible, indicating some points of internal stress concentration. Notice also how much pore space exists for accommodating strain incompatibilities. Right: EDML firn sample from $70 \mathrm{~m}$ depth. Grain interaction is much stronger at this depth, causing heterogeneous strains and high internal stresses that manifest themselves in the forms of grain subdivision (subgrain boundaries), rotation recrystallization (RRX), migration recrystallization (SIBM-O) and nucleation (SIBM-N); cf. Appendix A. 
Figure C.8: Dynamic recrystallization in the bubbly-ice zone of various ice cores. In these examples we can identify bulged and cuspidate grain boundaries (SIBM-O; cf. Appendix A), subgrain boundaries, nucleated grains (SIBM-N) at triple junctions or at grain boundaries as two-sided grains. Grain boundary pinning by air bubbles or subgrain boundaries is also evident. Scale bars: $1 \mathrm{~mm}$. Top: Two examples from Dome F core, $175 \mathrm{~m}$ depth. Centre: Two examples from EDML core, $304 \mathrm{~m}$ depth. Bottom: Two examples from EDC core, $685 \mathrm{~m}$ depth.

Figure C.9: Evolution of techniques for displaying the microstructure of natural ice. From left to right: Seligman's pencil rubbing on paper (Seligman, 1949, scale bar: $5 \mathrm{~cm}$ ); thin section between crossed polarizers (scale bar: $1 \mathrm{~cm}$ ); digital mosaic trend representation of the azimuth (color) and colatitude (brightness) of $c$-axes in a thin section, produced by a modern Automatic Fabric Analyzer (AFA; see e.g. Wilen et al., 2003; Wilson et al., 2003, scale bar: $1 \mathrm{~cm}$ ); digital mosaic image of a thick section consisting of ca. 1500 high-resolution micrographs, produced by the method of Microstructure Mapping ( $\mu$ SM; see e.g. Kipfstuhl et al., 2006, scale bar: $1 \mathrm{~cm}$ ). Notice that the first and last methods do not reveal $c$-axis orientations, but reproduce the precise shape of grain boundaries as they meet the ice surface. In contrast, the two intermediate methods do display $c$-axis orientations, but show only the depth-integrated shape of grain boundaries across the thickness of the sample.

Figure C.10: Mosaic image of an Antarctic ice sample (EDML, $2176 \mathrm{~m}$ depth) produced via Microstructure Mapping ( $\mu$ SM; Kipfstuhl et al., 2006). Abbreviation as in Fig. C.3. Grain and subgrain boundaries appear as dark and grey lines, respectively. Polygonal or dash-shaped objects are post-drilling relaxation voids called plate-like inclusions (PLI). Blue arrows show examples of different types of subgrain boundaries: $p=$ parallel to basal planes, $n=$ normal to basal planes (Nakaya type) and z=zigzag type. 
Figure C.11: Dynamic recrystallization in the bubble-free-ice zone of various ice cores. In these examples we can identify bulged and cuspidate grain boundaries (SIBM-O; cf. Appendix A), subgrain boundaries, nucleated grains (SIBM-N) at triple junctions or at grain boundaries as two-sided grains. Grain boundary pinning by air hydrates or subgrain boundaries is also evident. Top: Two examples from EDML core, $1885 \mathrm{~m}$ depth (scale bars: $1 \mathrm{~mm}$ ). Notice the pinning by air hydrates in both images. Whether the isolate pearl-shaped grain in the left image is a true grain island (cf. Fig. C.5) or just the cross section of a protruded grain is not clear. Centre: Two examples from EDC core, $2061 \mathrm{~m}$ depth (scale bars: left $1 \mathrm{~mm}$, right $2 \mathrm{~mm}$ ). A large two-sided grain can be seen in the left image. The fact that it does not show internal structures and is bulging towards a region rich in dislocation walls and subgrain boundaries suggests that it has nucleated via SIBM-N (cf. Appendix A). In the right image, complex subgrain boundary formations and severe bulging and pinning of grain boundaries are evident. Bottom: Grain subdivision, rotation recrystallization (RRX), migration recrystallization (SIBM-O) and nucleation (SIBM-N) in Antarctic ice samples from EDC core (left; $2061 \mathrm{~m}$ depth) and EDML core (right; $1885 \mathrm{~m}$ depth). Scale bars: $2 \mathrm{~mm}$. In particular, notice the small, two-sided, square-shaped grain at the top of the right image, which seems to have just nucleated via SIBM-N.

Figure C.12: Microinclusions (tiny black dots) accumulated at a grain boundary of deep Antarctic ice (EDML core, $2656 \mathrm{~m}$ depth; scale bar: $3 \mathrm{~mm}$ ). By moving the focal point into the sample, the focused microinclusions reveal the 3D shape of the grain boundary, which penetrates the sample in a slope towards the bottom of the image. 
Figure C.13: State space for the dynamic recrystallization diagram. The blue surface $D_{\mathrm{SS}}$ represents the steady-state region of constant grain size, for a given strain rate and temperature. Below this surface there is the zone of grain growth, while above the surface there is the zone of grain reduction. The small panel on the right illustrates the case of a hypothetical deep ice core: the green curve describes the increase of mean grain size with depth up to the steady state size $D_{\text {SS }}$. Further grain-size increase with depth is caused by the higher temperatures at the bottom of the ice sheet, and is represented by the red line that follows the $D_{\text {SS }}$ surface towards higher values of temperature. For more information, see the description in the main text.

Figure C.14: Cross sections of the dynamic recrystallization diagram shown in Fig. C.13, including the zones of major influence of different recrystallization mechanisms (cf. Appendix A): rotation recrystallization (RRX), migration recrystallization without nucleation (SIBM-O), migration recrystallization with nucleation (SIBM-N) and normal grain growth (NGG). The latter occurs only when $\dot{\varepsilon}=0$. 
Table D.1: Possible slip systems in ice. After Hondoh (2009).

\begin{tabular}{l||l}
\multicolumn{1}{l||}{ slip plane } & slip system \\
\hline \hline basal & $(0001)\langle 11 \overline{2} 0\rangle$ \\
\hline primary prismatic & $\{1 \overline{1} 00\}\langle 11 \overline{2} 0\rangle$ \\
& $\{1 \overline{1} 00\}\langle 0001\rangle$ \\
& $\{1 \overline{1} 00\}\langle 11 \overline{2} 3\rangle$ \\
\hline secondary prismatic & $\{\overline{1} 20\}\langle 0001\rangle$ \\
\hline primary pyramidal & $\{\overline{1} 011\}\langle 11 \overline{2} 0\rangle$ \\
& $\{\overline{1} 011\}\langle 11 \overline{2} 3\rangle$ \\
\hline secondary pyramidal & $\{\overline{11} 22\}\langle 11 \overline{2} 3\rangle$ \\
\hline
\end{tabular}


Table D.2: Subgrain boundaries in polar ice. The vectors $\boldsymbol{a}$ and $\boldsymbol{c}$ denote the translation vectors of the ice unit cell. Dislocation data from Hondoh (2000) and subgrain boundary statistics from Weikusat et al. (2011).

\begin{tabular}{|c|c|c|c|c|c|}
\hline \multicolumn{3}{|c|}{ subgrain boundary } & \multicolumn{3}{|c|}{ component dislocation } \\
\hline type & misorient. axis & frequency & type & Burgers vector $\boldsymbol{b}$ & length $b$ \\
\hline basal tilt & $a$ & $39 \%$ & edge & $\boldsymbol{a}=(1 / 3)<11 \overline{2} 0>$ & $4.52 \AA$ \\
\hline $\begin{array}{c}\text { non-basal } \\
\text { tilt }\end{array}$ & $a$ & $27 \%$ & edge & $\begin{array}{c}c=<0001> \\
a+c=(1 / 3)<11 \overline{2} 3>\end{array}$ & $\begin{array}{l}7.36 \AA \\
8.63 \AA\end{array}$ \\
\hline basal twist & $c$ & $7 \%$ & screw & $\boldsymbol{a}=(1 / 3)<11 \overline{2} 0>$ & $4.52 \AA$ \\
\hline other & arbitrary & $27 \%$ & & diverse and mixed & \\
\hline
\end{tabular}


Figure 1

Click here to download high resolution image
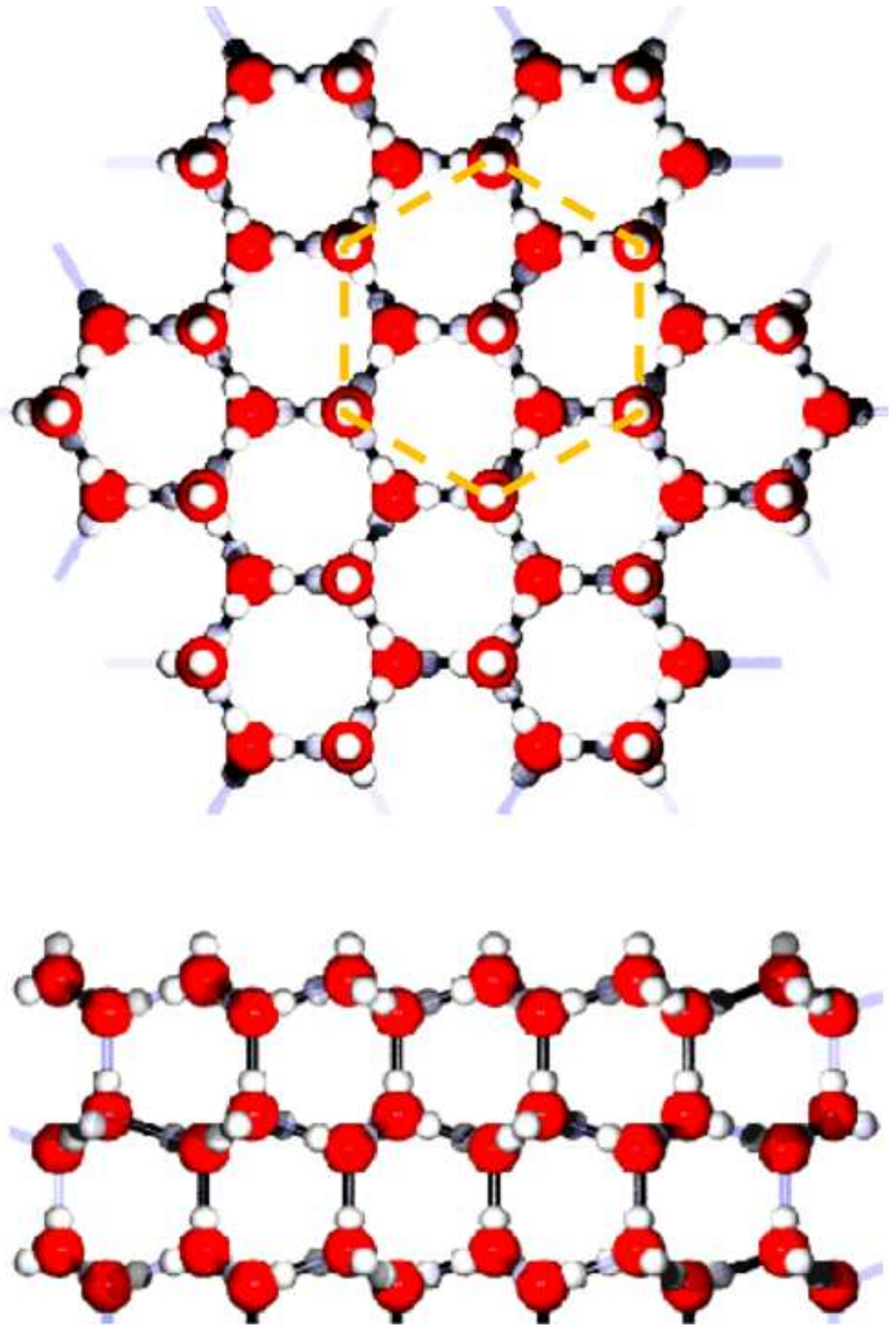

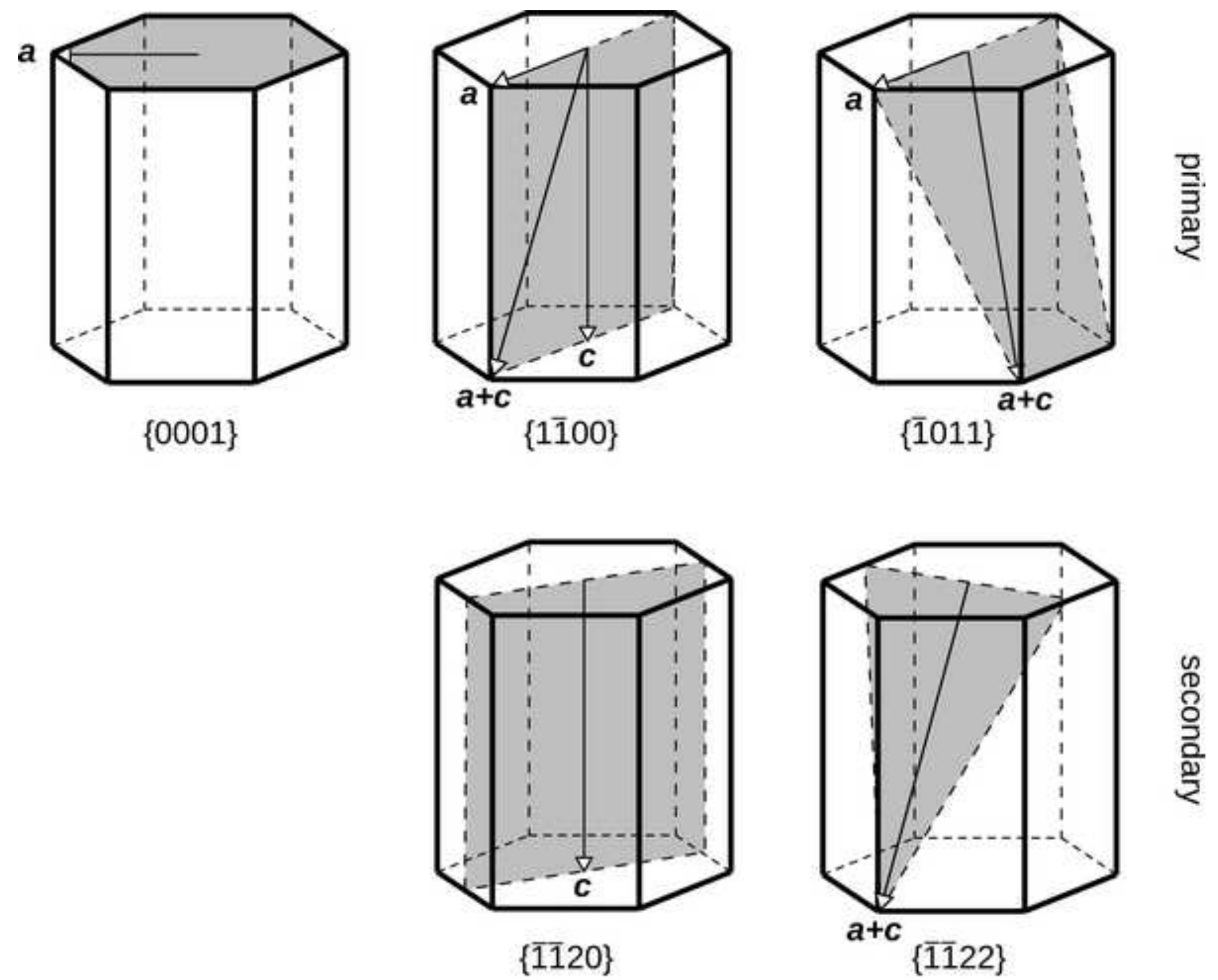

Basal
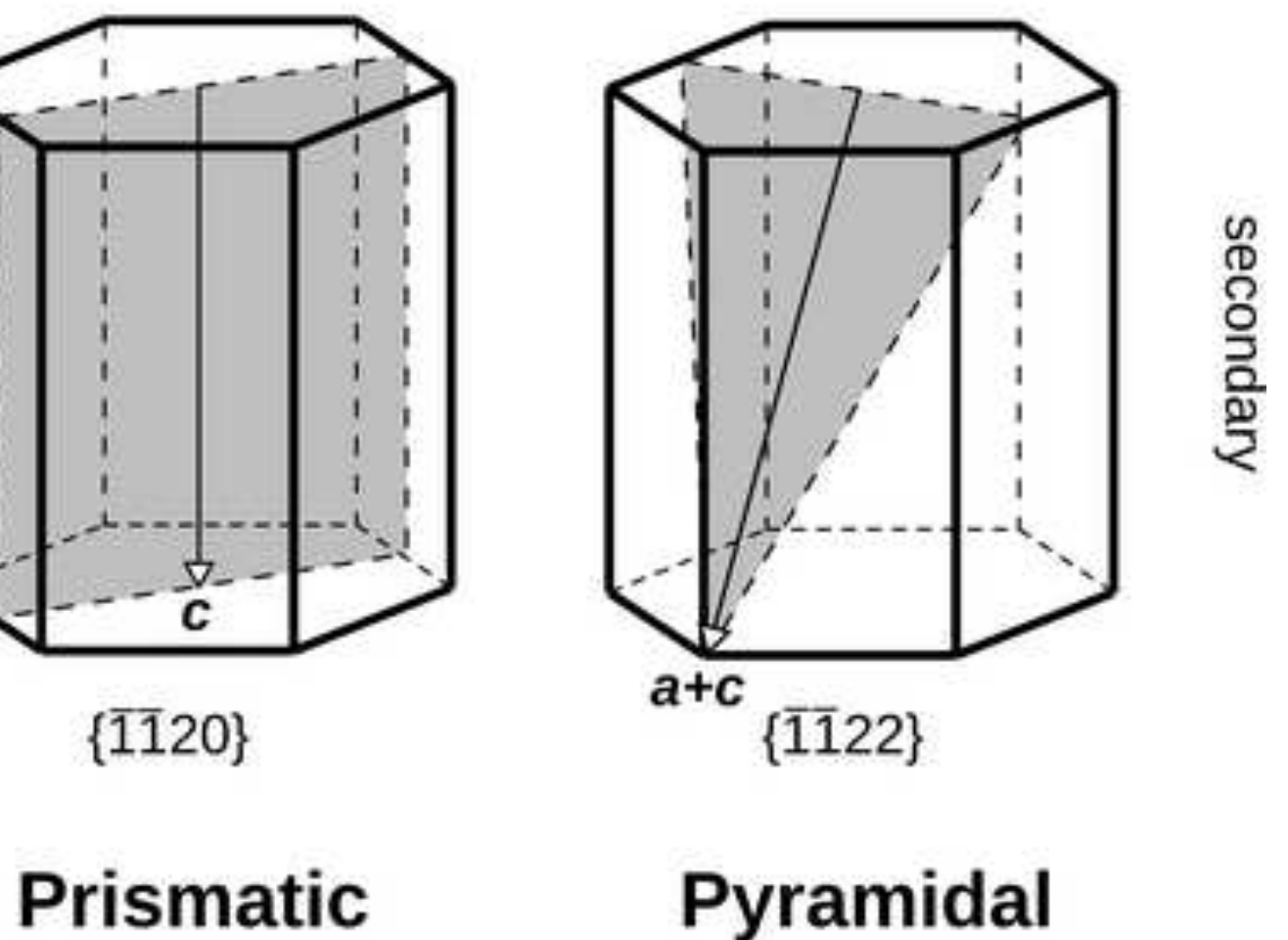

Pyramidal 
Click here to download high resolution image

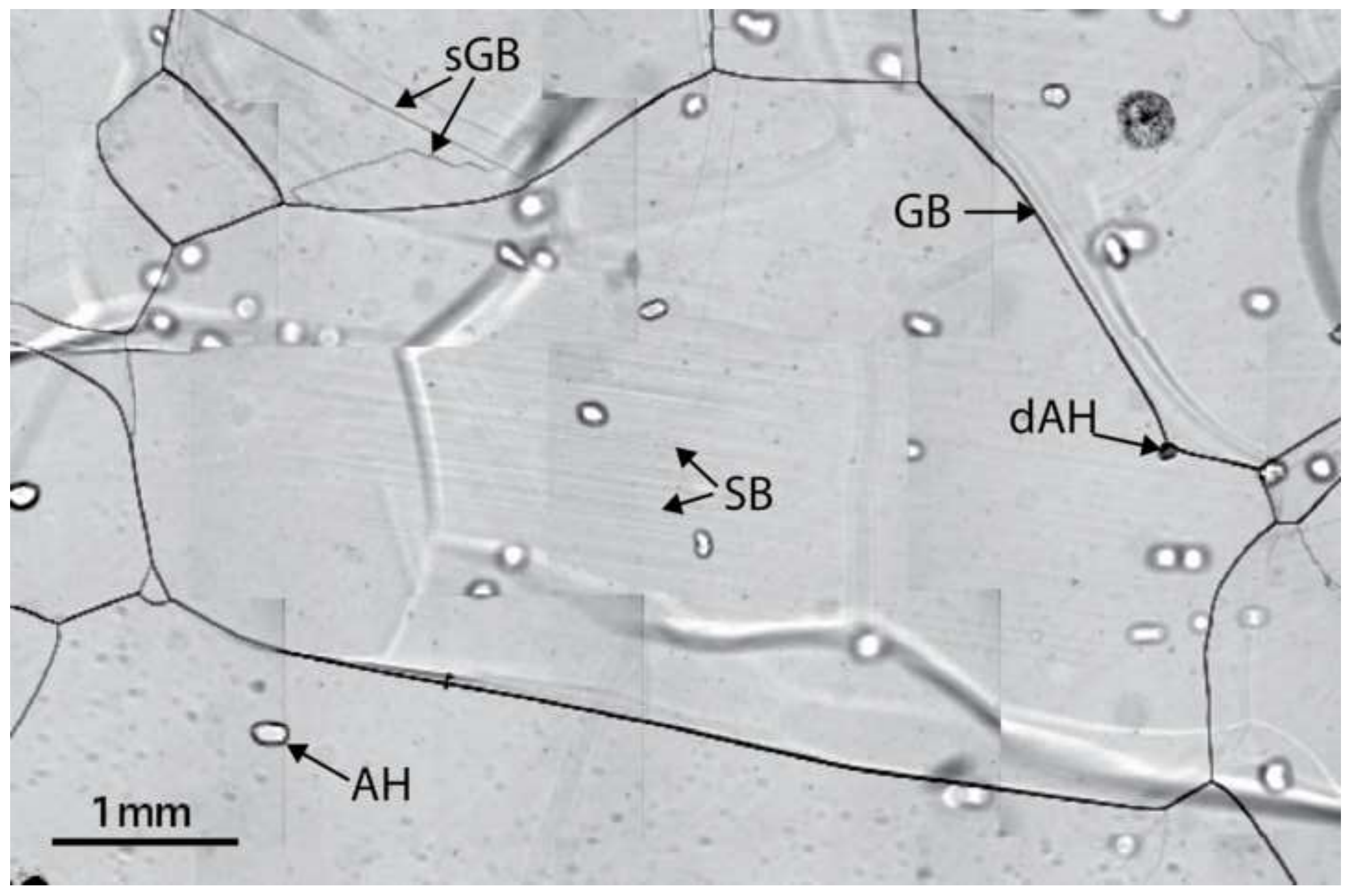


Figure
Click here to download high resolution image
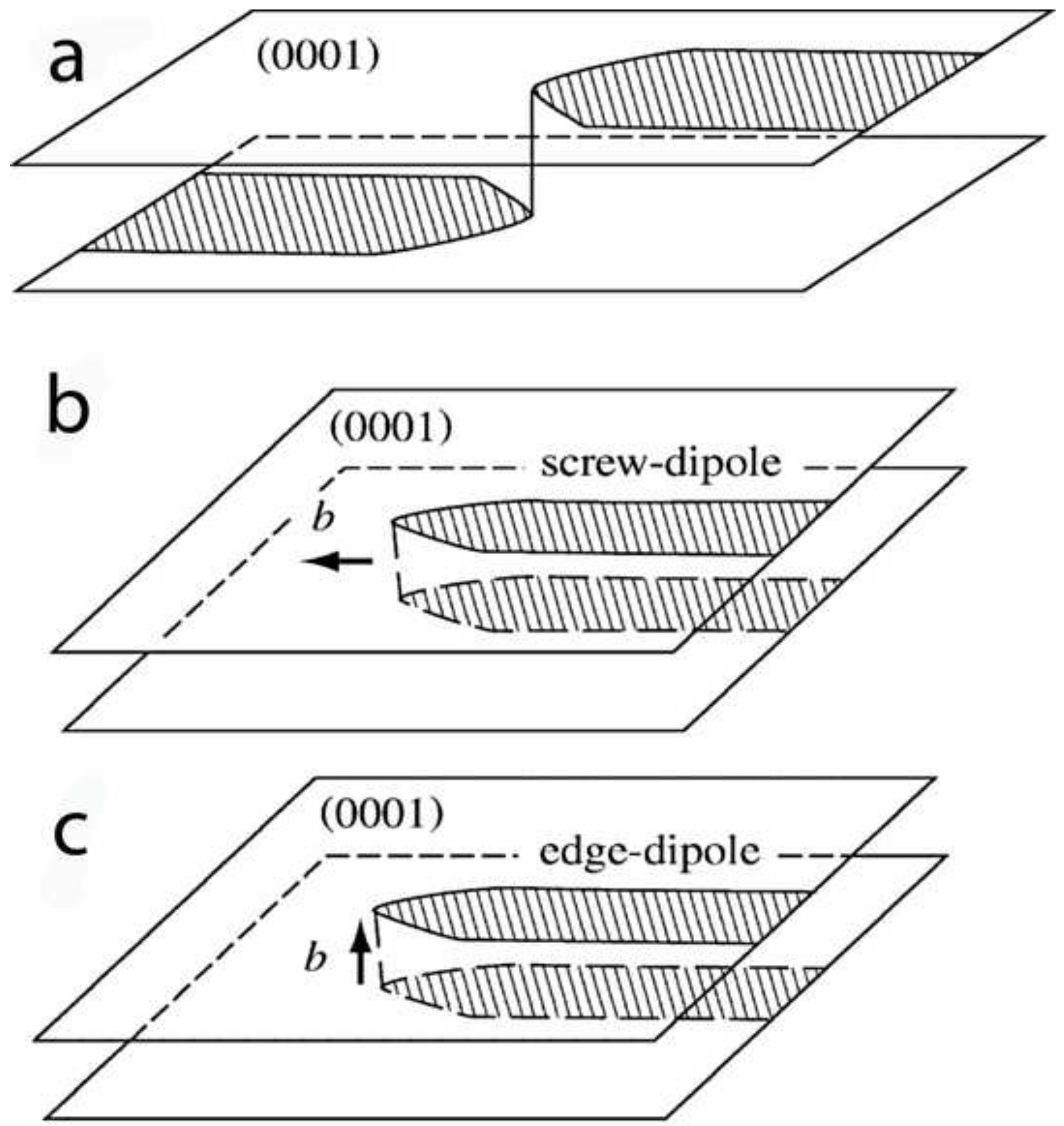
Click here to download high resolution image

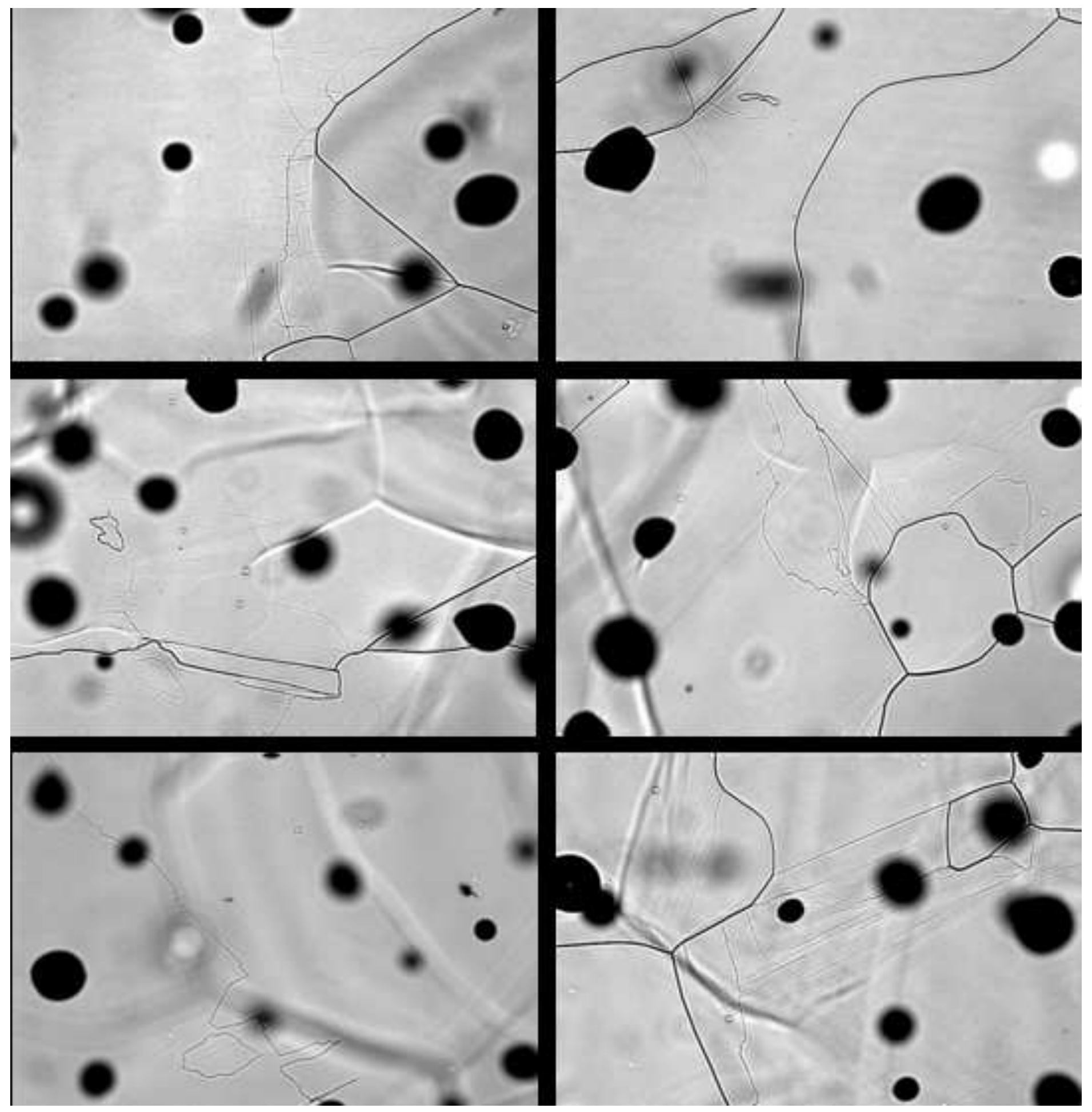


Click here to download high resolution image
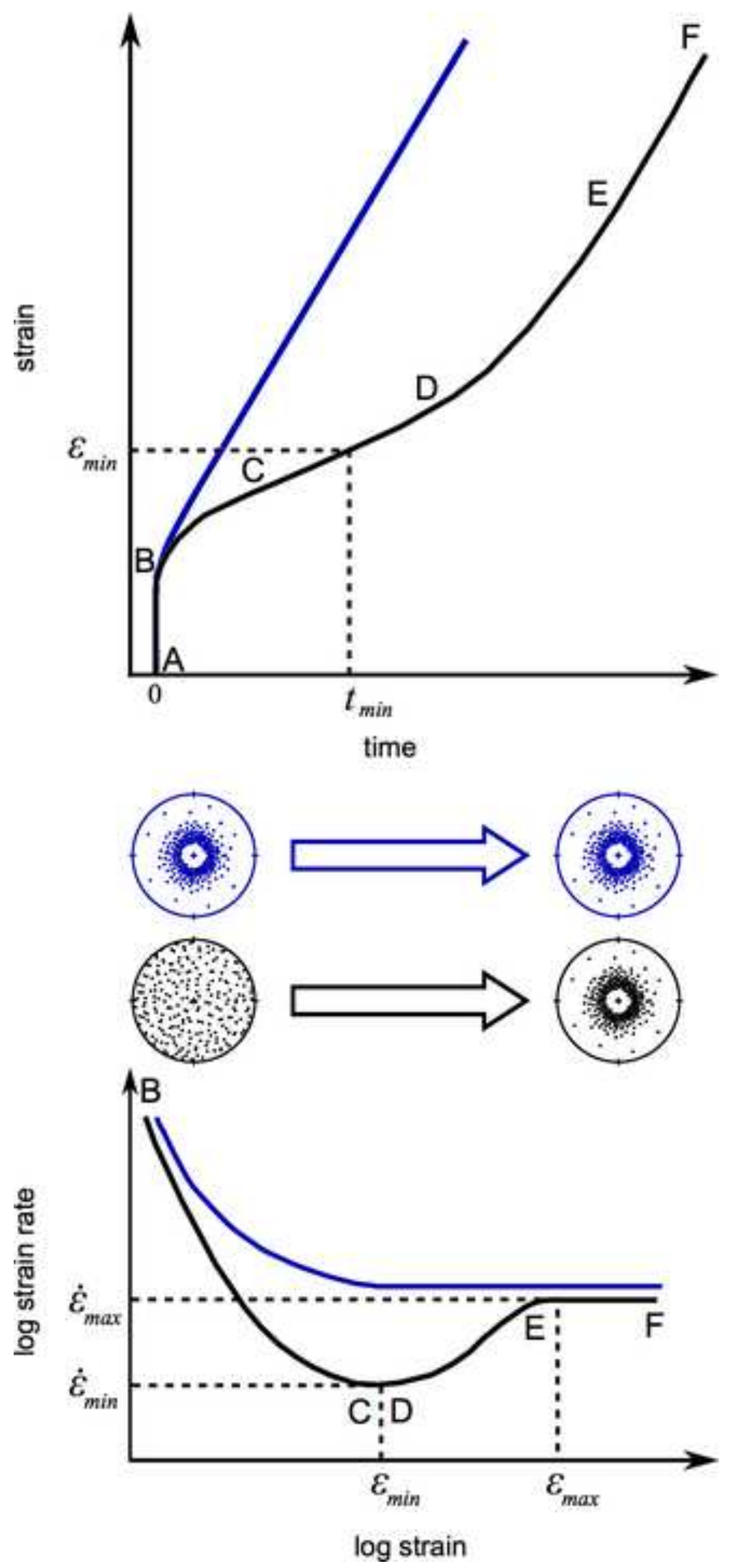

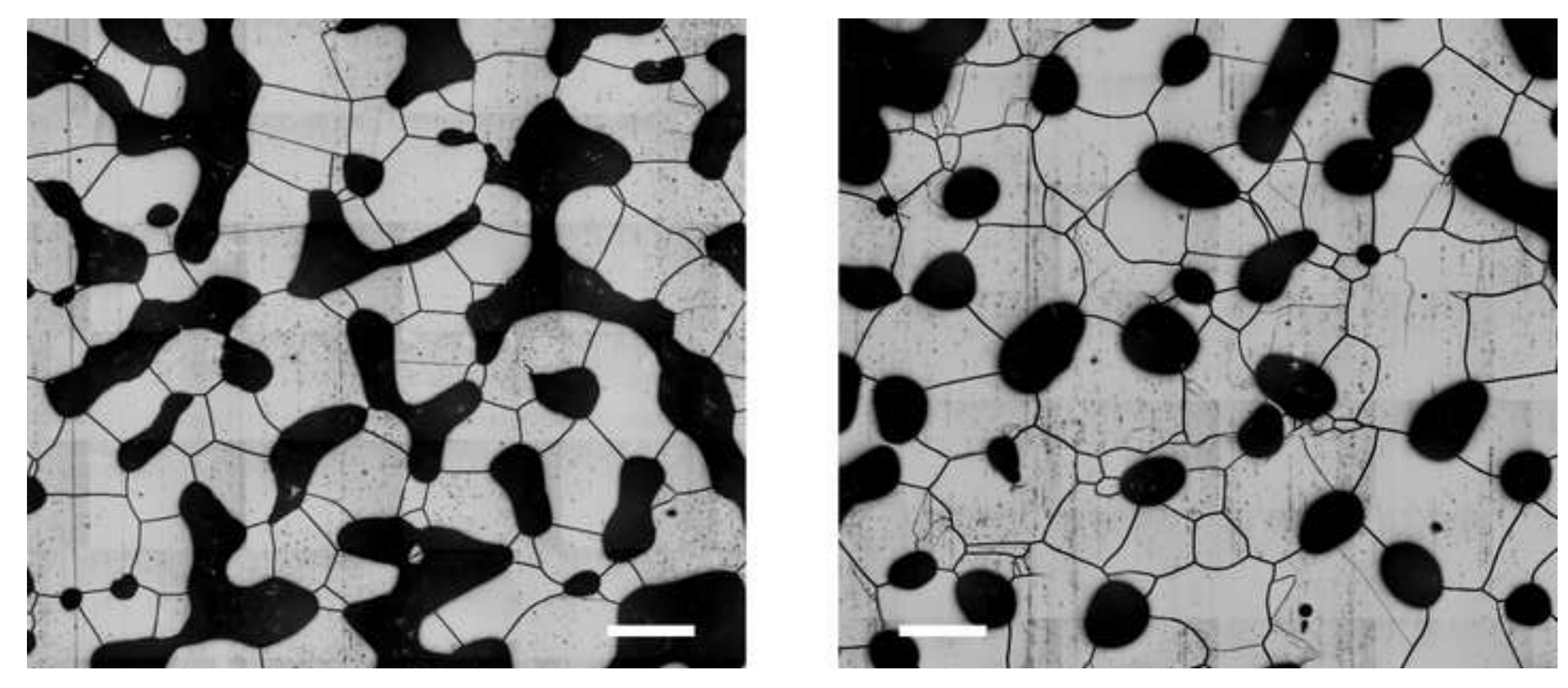


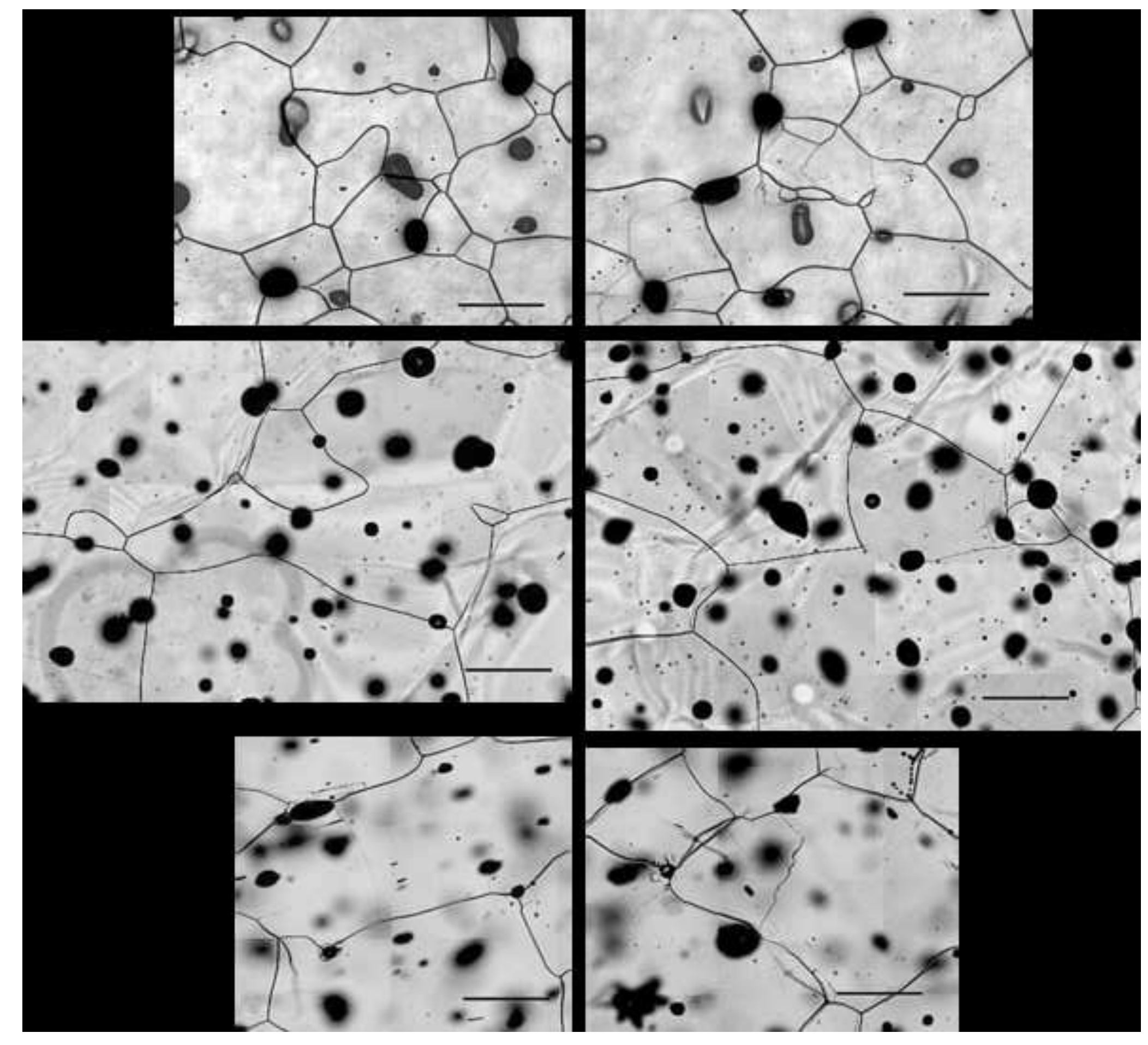


Click here to download high resolution image
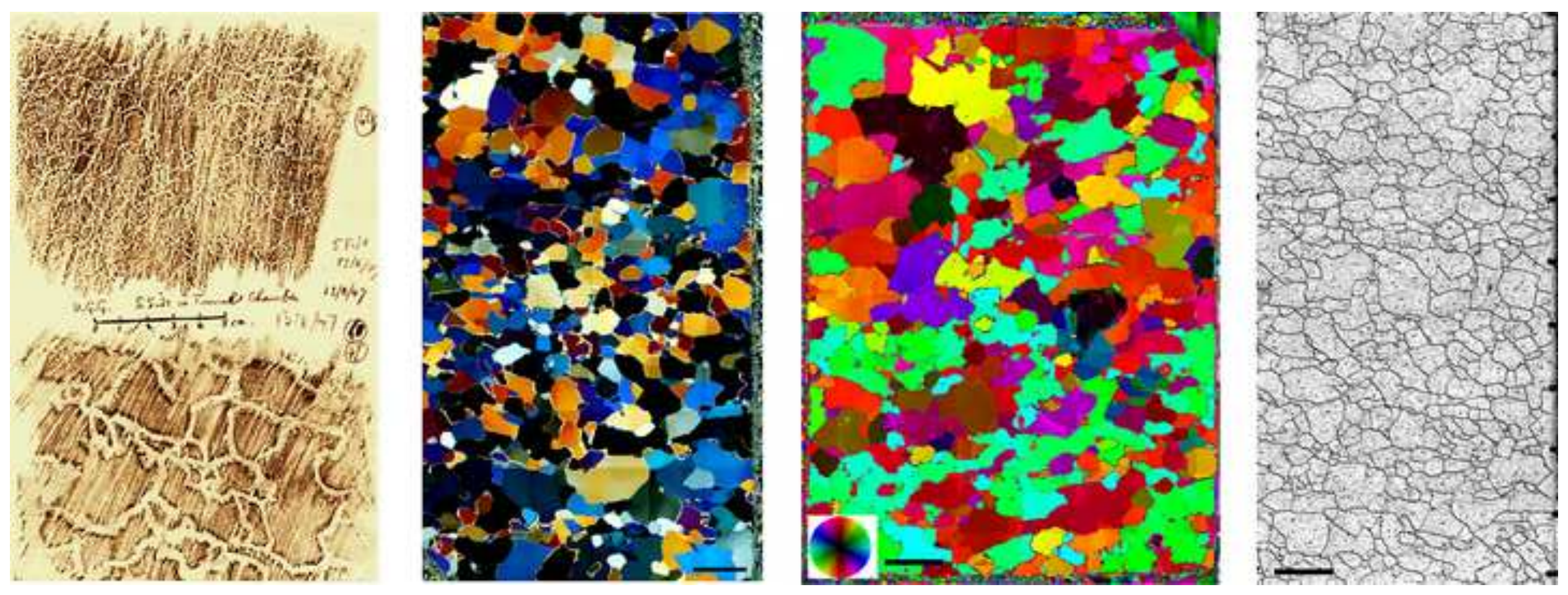


$$
5
$$


Click here to download high resolution image

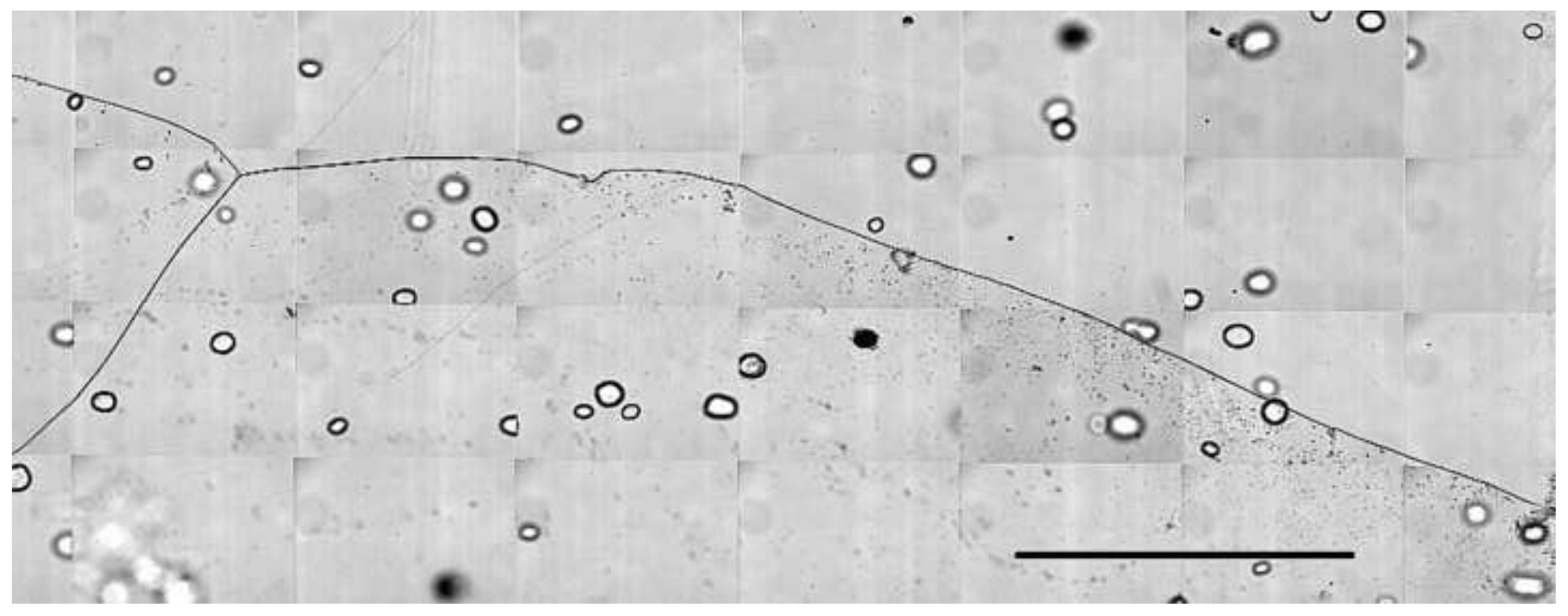




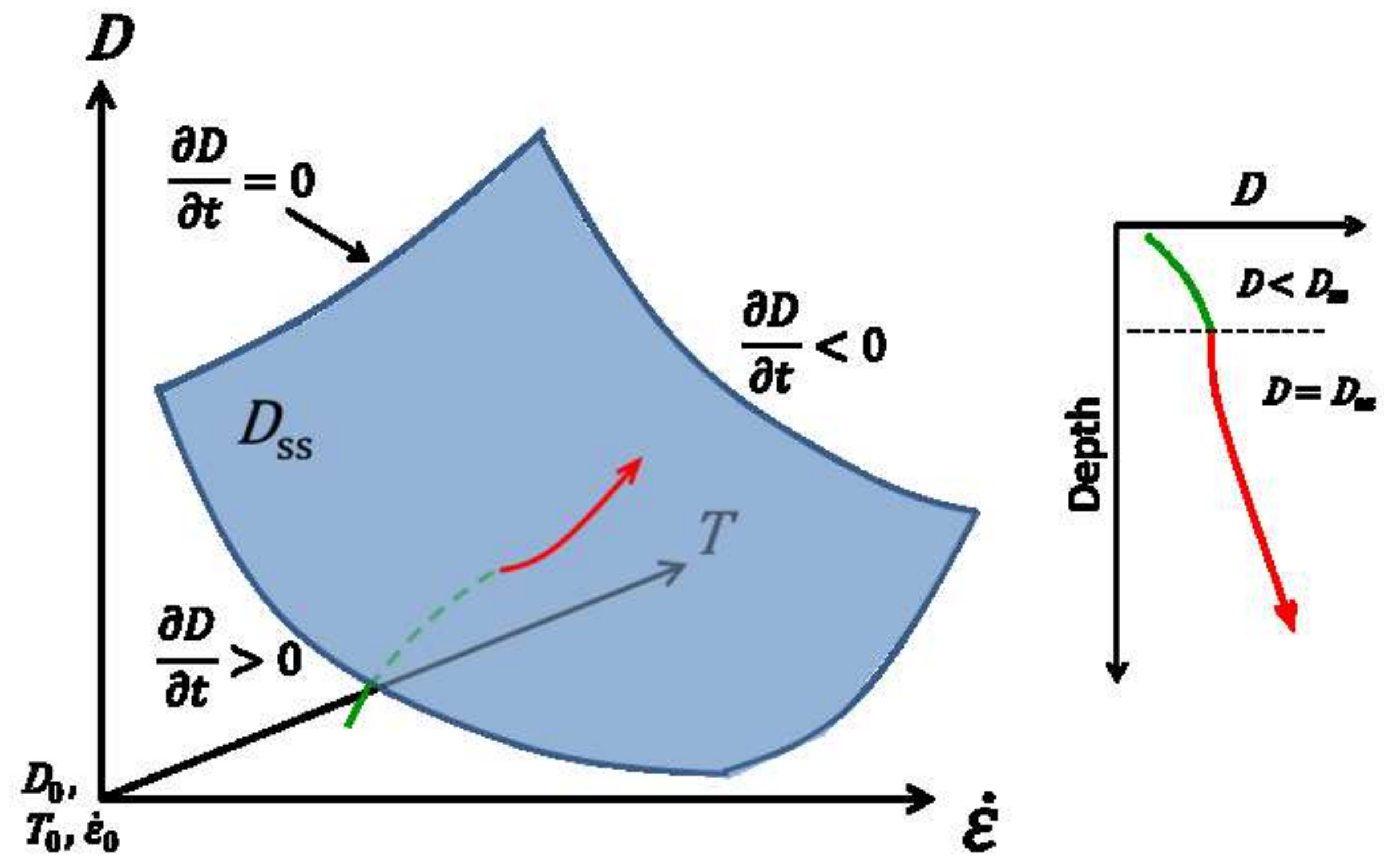


Click here to download high resolution image
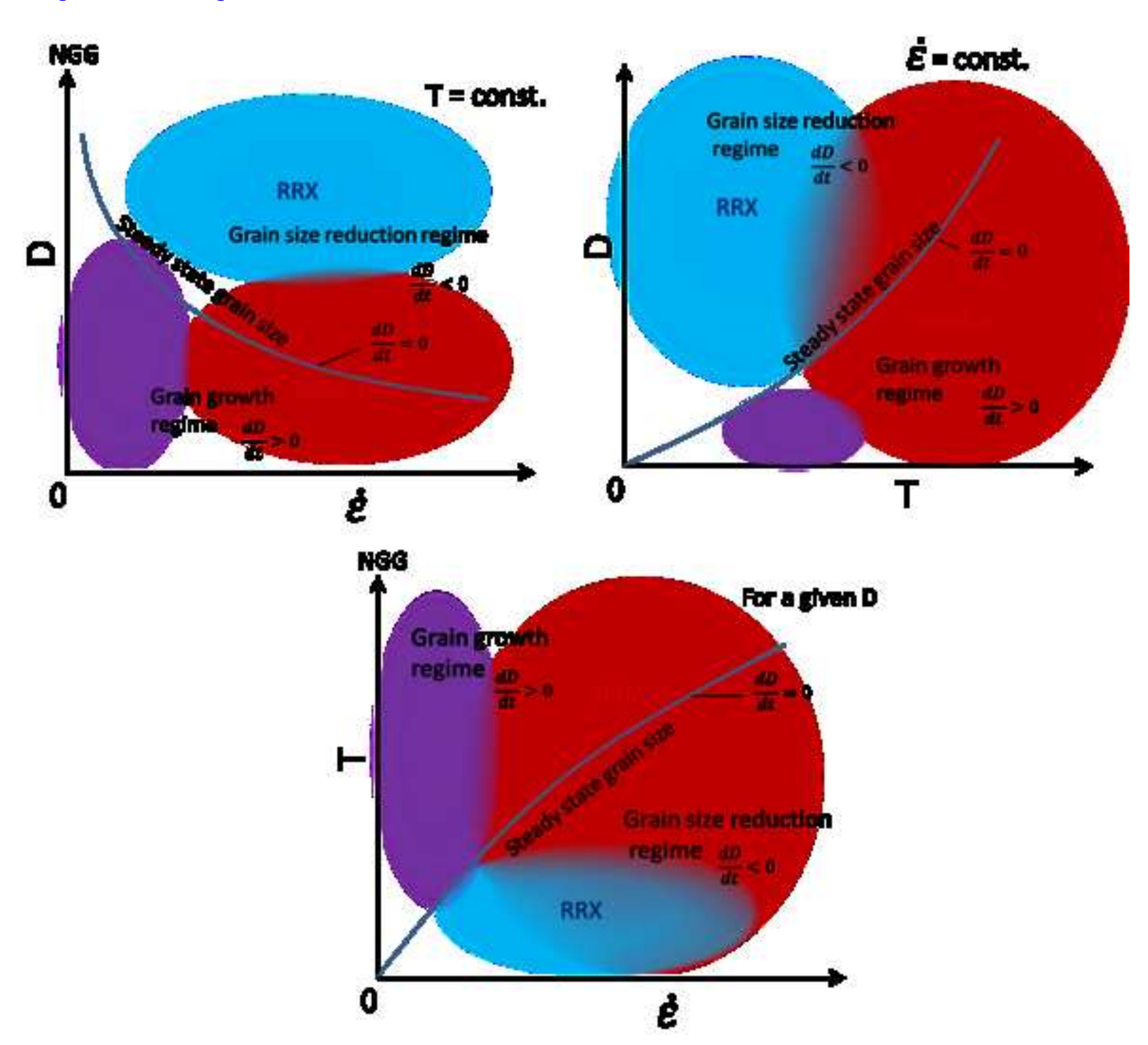

\section{Click here}

(

